Universidad de Lima

Facultad de Ingeniería y Arquitectura

Carrera de Ingeniería Industrial

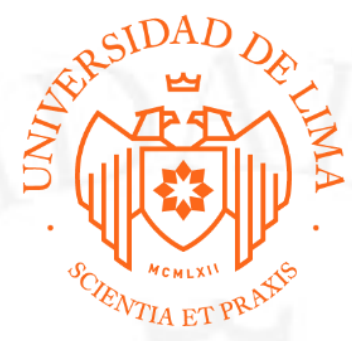

\title{
ESTUDIO DE PREFACTIBILIDAD PARA LA INSTALACIÓN DE UNA PLANTA PRODUCTORA DE ACEITE DE COCO
}

Trabajo de investigación para optar el Título Profesional de Ingeniero Industrial

Adela Devly Noli Alva

Código 20112095

Carmen Jesus Chamorro Chavez

Código 20110300

Asesor
Julio Francisco Ota Montalbán

Lima-Perú

Septiembre de 2019 


\section{COCONUT OIL PRODUCER PLANT INSTALLAMENT FEASIBILITY ANALYSIS}




\section{TABLA DE CONTENIDO}

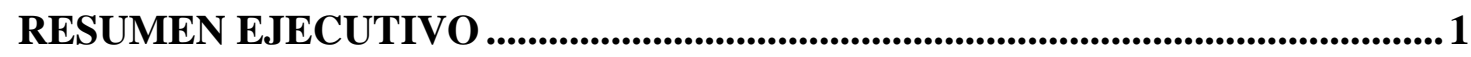

EXECUTIVE SUMMARY ............................................................................................... 3

CAPÍTULO I: ASPECTOS GENERALES................................................................5

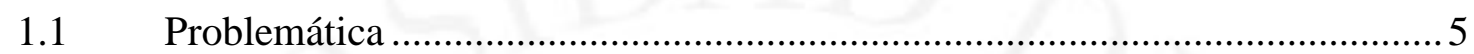

1.2 Objetivos de la investigación.................................................................... 5

1.3 Alcance y limitaciones de la investigación.................................................. 6

$1.4 \quad$ Justificación del tema .......................................................................... 7

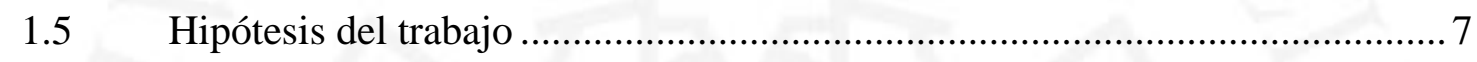

1.6 Marco referencial de la investigación........................................................... 7

1.7 Marco conceptual ................................................................................... 8

CAPÍTULO II: ESTUDIO DE MERCADO .......................................................... 10

2.1 Aspectos generales del estudio de mercado .............................................. 10

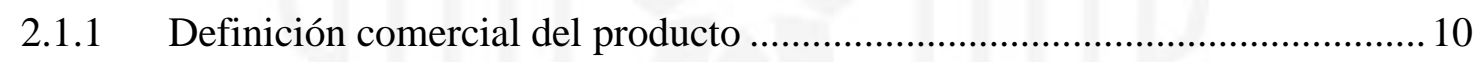

2.1.2 Principales características del producto ................................................ 11

2.1.2.1 Usos y características del producto ....................................................... 11

2.1.2.2 Bienes sustitutos y complementarios............................................... 13

2.1.3 Determinación del área geográfica que abarcará el estudio ......................... 13

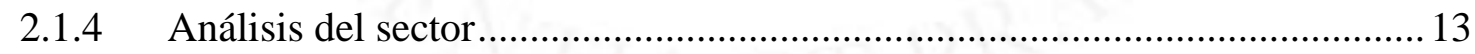

2.1.5 Determinación de la metodología que se empleará en la investigación de mercado 15

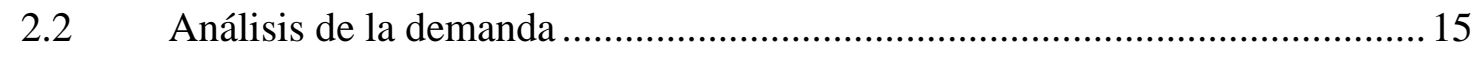

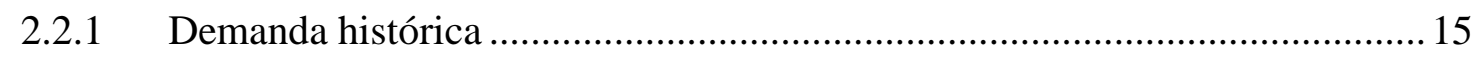

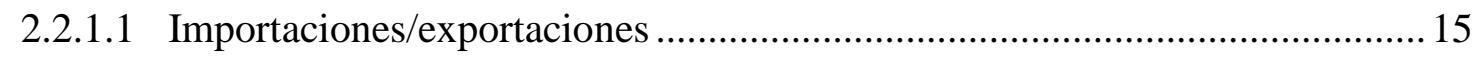

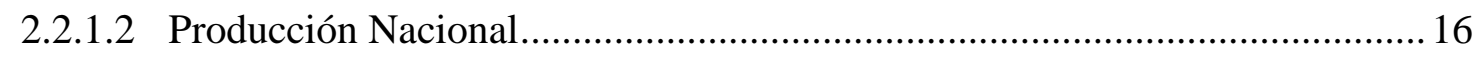


2.2.1.3 Demanda Interna Aparente (DIA) ………….............................................. 16

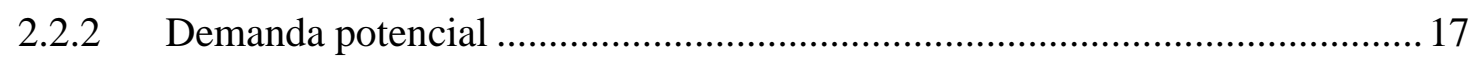

2.2.2.1 Patrones de consumo: incremento poblacional, consumo per cápita,

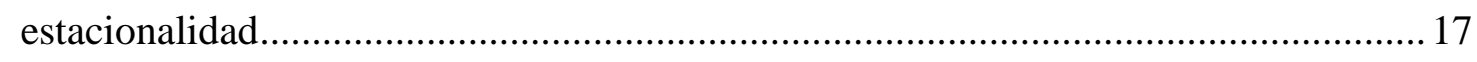

2.2.2.2 Determinación de la demanda potencial....................................................... 18

2.2.3 Demanda mediante fuentes primarias......................................................... 18

2.2.3.1 Diseño y Aplicación de Encuestas u otras técnicas ......................................... 18

2.2.3.2 Determinación de la demanda del proyecto ……………………………......2 20

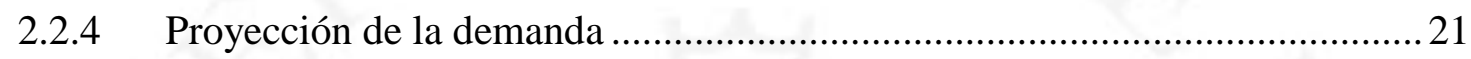

2.2.5 Consideraciones sobre la vida útil del proyecto .............................................2 21

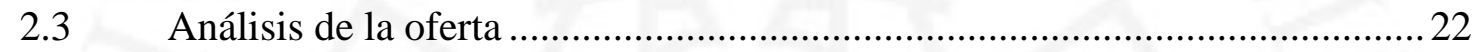

2.3.1 Empresas productoras, importadoras y comercializadoras.............................. 22

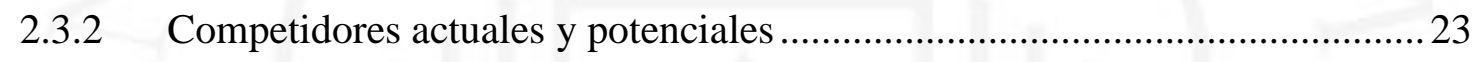

2.4 Determinación de la demanda para el proyecto...............................................23

2.4.1 Segmentación del mercado .........................................................................2 23

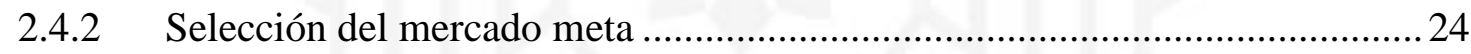

2.4.3 Demanda específica para el proyecto ………………....................................2 24

2.5 Definición de la Estrategia de Comercialización ............................................. 24

2.5.1 Políticas de comercialización y distribución ....................................................2 24

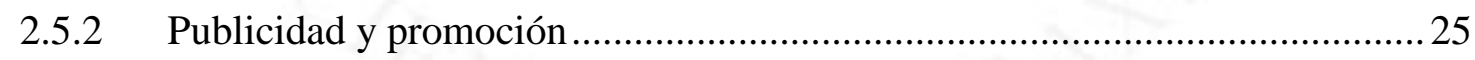

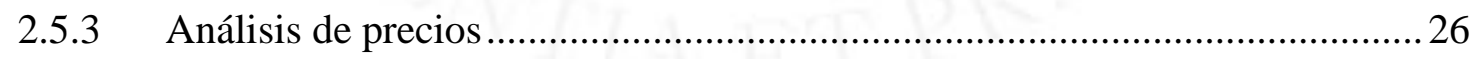

2.5.3.1 Tendencia histórica de los precios .................................................................2 26

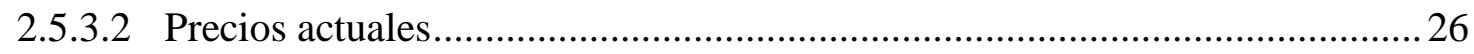

2.6 Análisis de Disponibilidad de los insumos principales ..................................26

2.6.1 Características principales de la materia prima ..............................................26

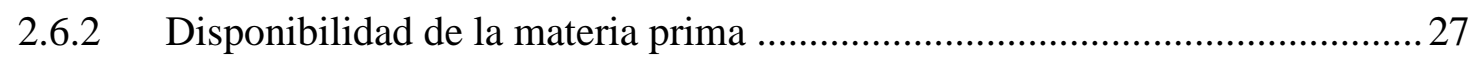




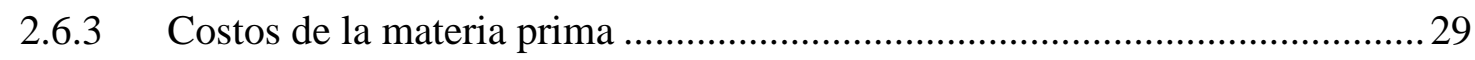

CAPÍTULO III. LOCALIZACIÓN DE PLANTA .....................................................30

3.1 Identificación y análisis detallado de los factores de localización ..................30

3.2 Identificación y descripción de las alternativas de localización ......................30

Evaluación y selección de localización ........................................................ 31

3.3.1 Evaluación y selección de la macro localización .......................................... 31

3.3.2 Evaluación y selección de la micro localización ........................................ 34

CAPÍTULO IV. TAMAÑ̃ DE PLANTA................................................................... 37

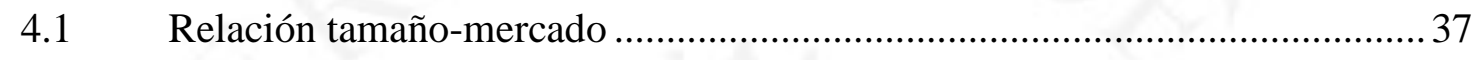

4.2 Relación tamaño-recursos productivos................................................. 37

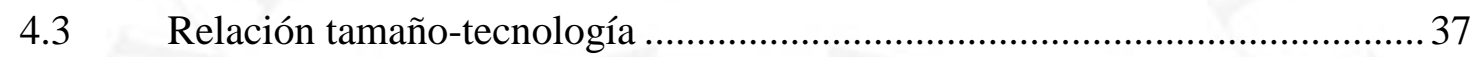

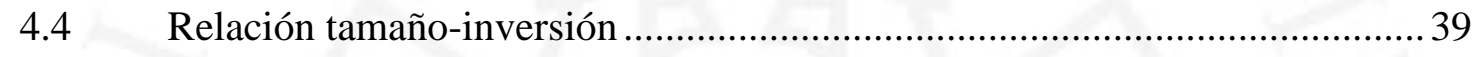

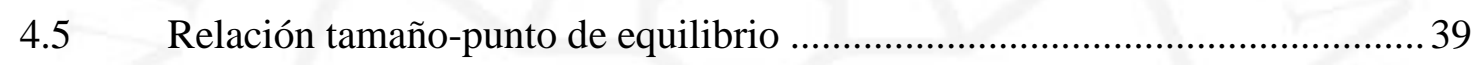

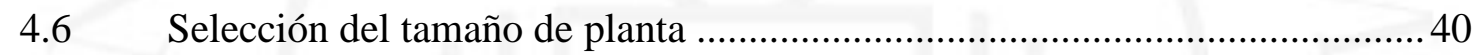

CAPÍTULO V. INGENIERÍA DEL PROYECTO ........................................41

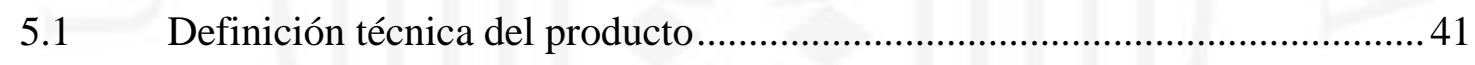

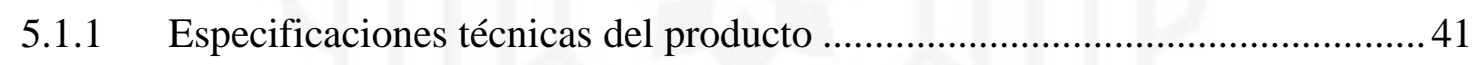

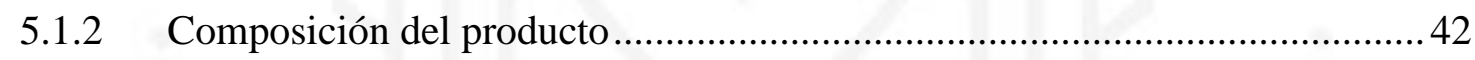

5.1.3 Diseño gráfico del producto ............................................................. 43

5.1.4 Regulaciones técnicas al producto............................................................ 44

5.2 Tecnologías existentes y procesos de producción ....................................... 45

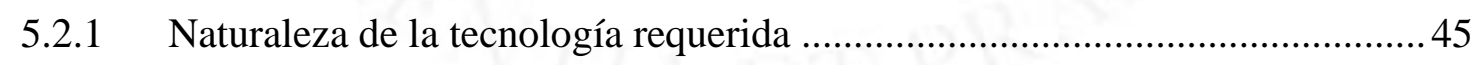

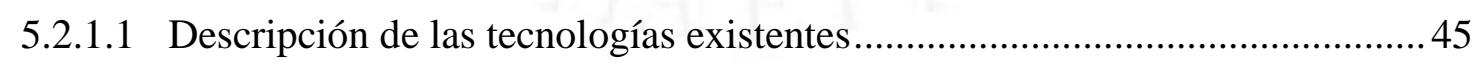

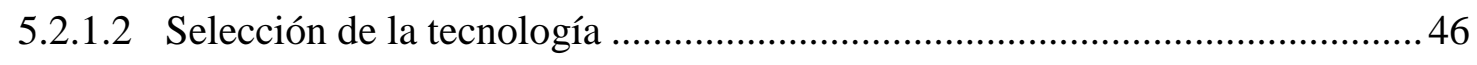

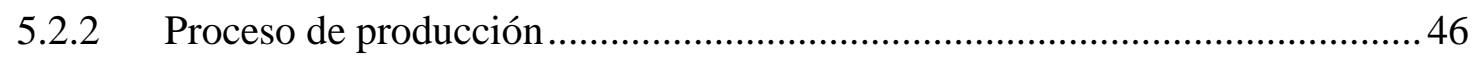

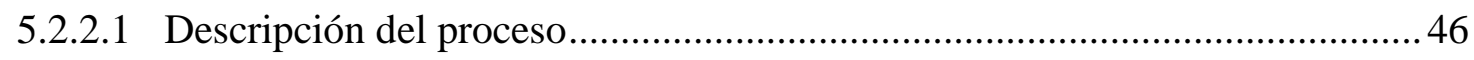

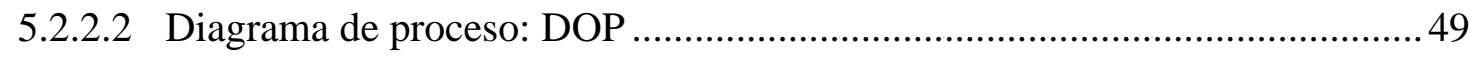




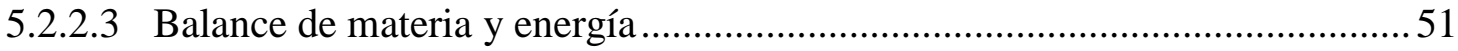

5.3 Características de las instalaciones y equipos ...........................................53

5.3.1 Selección de la maquinaria y equipos........................................................53

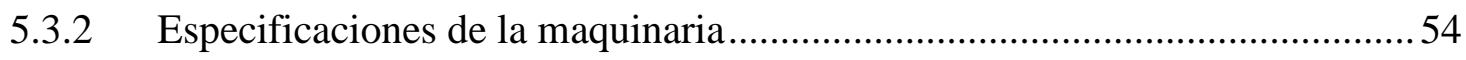

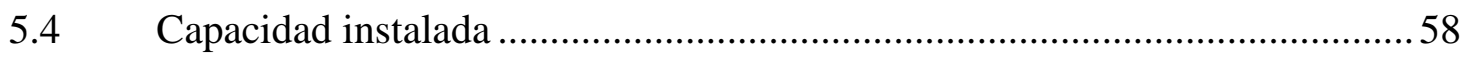

5.4.1 Cálculo de la capacidad instalada ..........................................................58

5.4.2 Cálculo detallado del número de máquinas requeridas ..............................59

5.5 Resguardo de la calidad y/o inocuidad del producto ..................................59

5.5.1 Calidad de la materia prima, de los insumos, del proceso y del producto......59

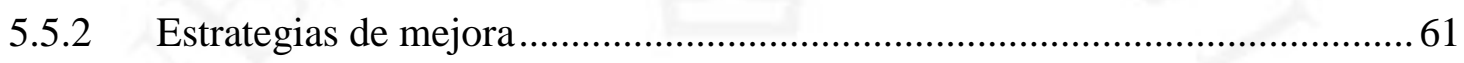

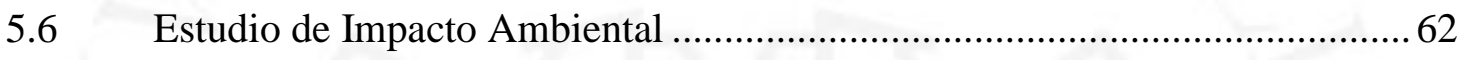

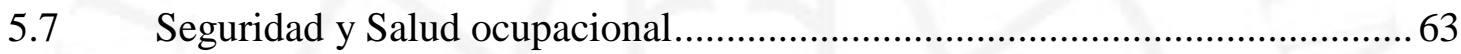

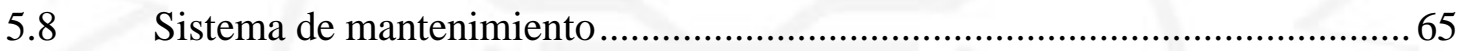

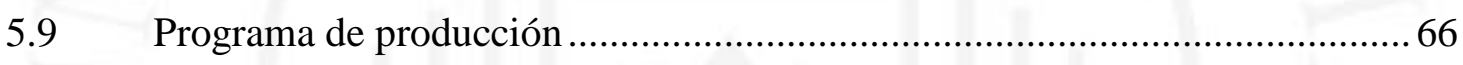

5.9.1 Factores para la programación de la producción ........................................ 66

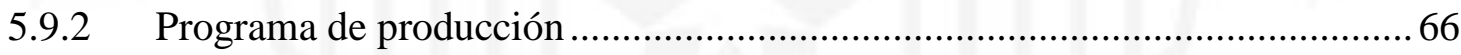

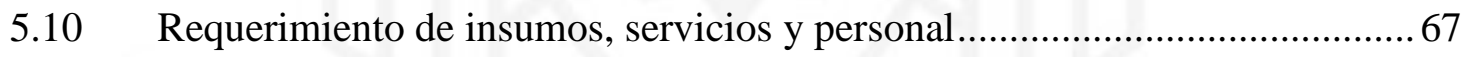

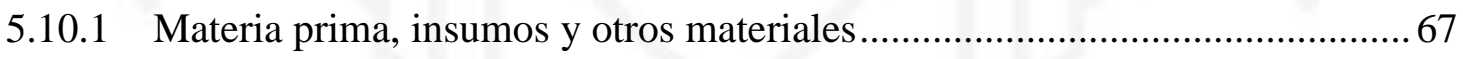

5.10.2 Servicios: energía eléctrica, agua, vapor, combustible, etc.......................... 68

5.10.3 Determinación del número de operarios y trabajadores indirectos ............... 74

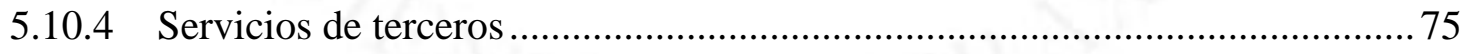

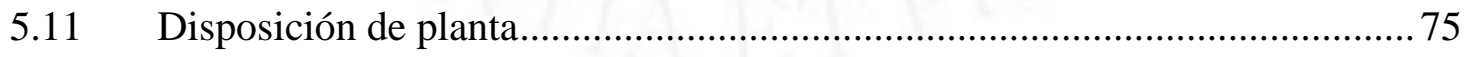

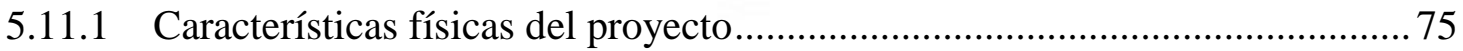

5.11.2 Determinación de las zonas físicas requeridas ...................................... 76

5.11.3 Cálculo de áreas para cada zona ........................................................... 81

5.11.4 Dispositivos de seguridad industrial y señalización ................................... 82

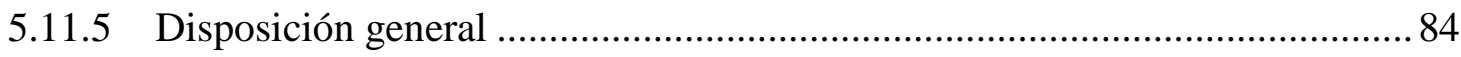




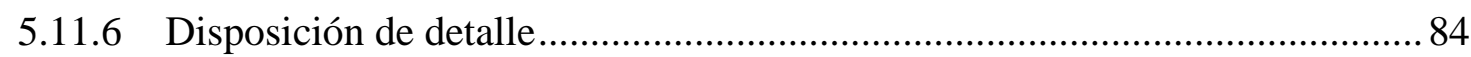

5.12 Cronograma de implementación del proyecto .................................................. 89

CAPÍTULO VI. ORGANIZACIÓN Y ADMINISTRACIÓN..................................90

6.1 Formación de la Organización empresarial …………………........................90

6.2 Requerimientos de personal directivo, administrativo y de servicios ............ 90

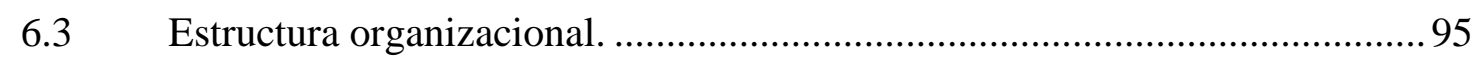

CAPÍTULO VII. ASPECTOS ECONÓMICOS Y FINANCIEROS .......................96

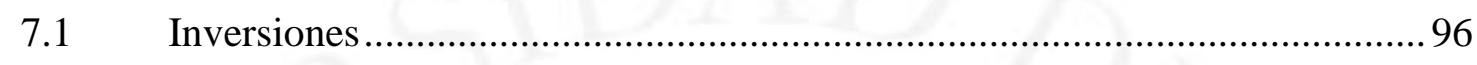

7.1.1 Estimación de las inversiones de largo plazo (tangibles e intangibles)..........96

7.1.2 Estimación de las inversiones de corto plazo (Capital de trabajo) .................. 99

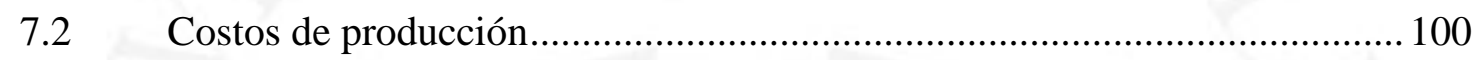

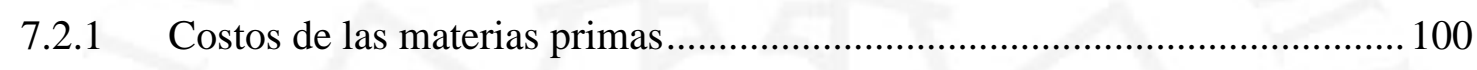

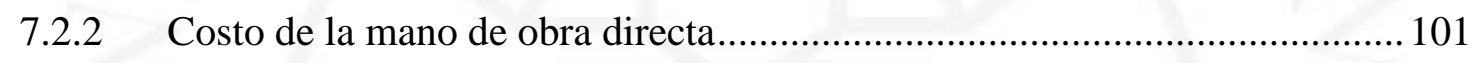

7.2.3 Costo Indirecto de Fabricación (materiales indirectos, mano de obra indirecta

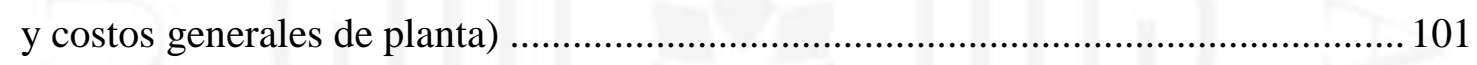

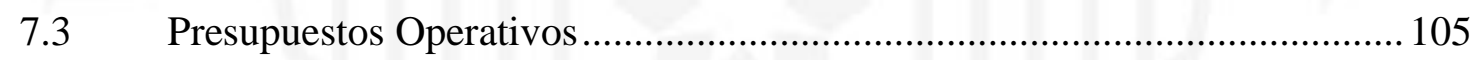

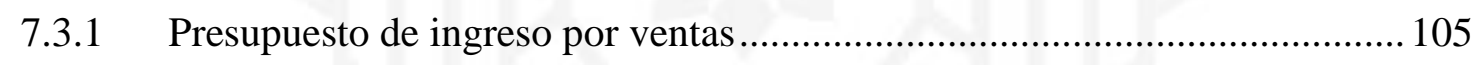

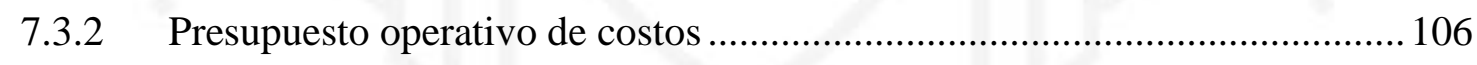

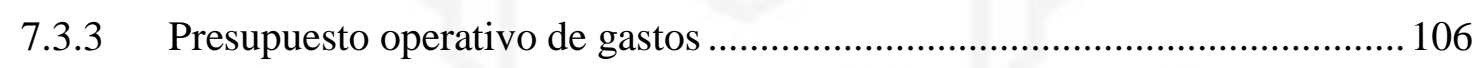

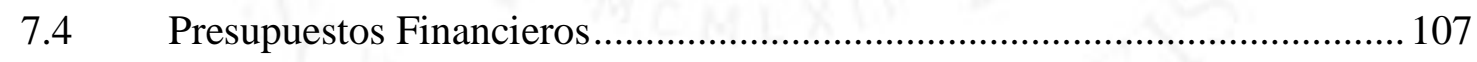

7.4.1 Presupuesto de Servicio de Deuda................................................................ 107

7.4.2 Presupuesto de Estado Resultados.............................................................. 108

7.4.3 Presupuesto de Estado de Situación Financiera …………………………..... 110

7.4.4 Flujo de caja de corto plazo …………………........................................ 110

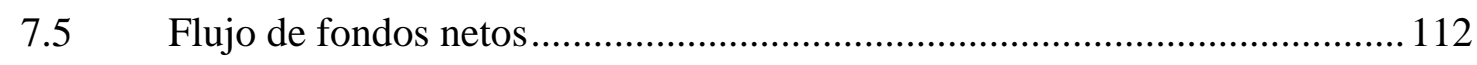

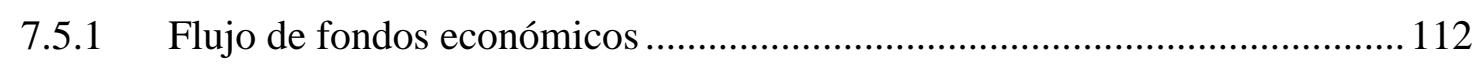

7.5.2 Flujo de fondos financieros …………………........................................ 112 


\section{CAPÍTULO VIII. EVALUACIÓN ECONÓMICA Y FINANCIERA DEL

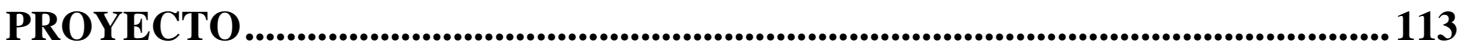

8.1 Evaluación económica: VAN, TIR, B/C, PR …………………………........ 113

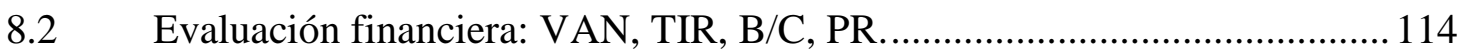

8.2.1 Análisis de ratios (liquidez, solvencia, rentabilidad) e indicadores económicos

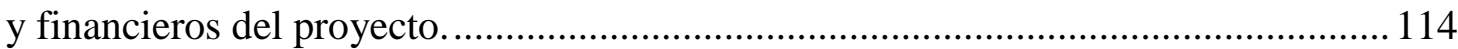

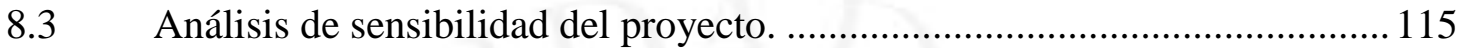

CAPÍTULO IX. EVALUACIÓN SOCIAL DEL PROYECTO ...............................117

9.1 Identificación de las zonas y comunidades de influencia del proyecto ......... 117

9.2 Análisis de indicadores sociales (valor agregado, densidad de capital,

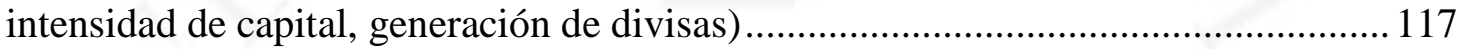

CONCLUSIONES ................................................................................................................ 120

RECOMENDACIONES …............................................................................................ 121

REFERENCIAS..................................................................................................................... 122

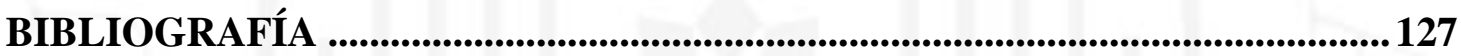

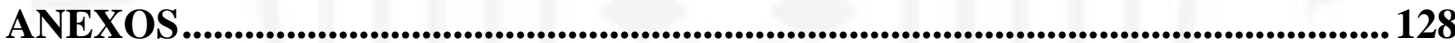




\section{ÍNDICE DE TABLAS}

Tabla 2. 1 Modelo de negocios Canvas .................................................................... 11

Tabla 2. 2 Partida arancelaria de aceite de coco ..................................................... 12

Tabla 2. 3 Códigos numéricos de rama de actividad económica según CIIU - 3 ....... 12

Tabla 2. 4 Producción de coco por departamentos (Toneladas) ................................ 14

Tabla 2. 5 Exportaciones e importaciones de aceite de oliva ................................... 16

Tabla 2. 6 Producción nacional de aceite de oliva.................................................. 16

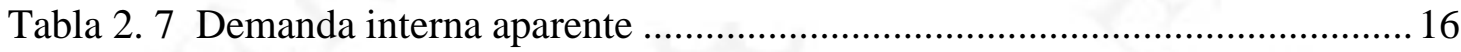

Tabla 2. 8 Cálculos para hallar la DIA del año 2018 ........................................... 17

Tabla 2. 9 Incremento poblacional nacional .................................................. 17

Tabla 2. 10 Consumo per cápita de aceite de oliva .............................................. 18

Tabla 2. 11 Demanda potencial de aceites de oliva 2015 .................................... 18

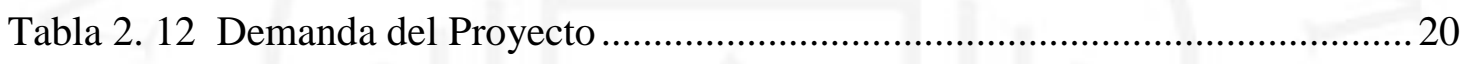

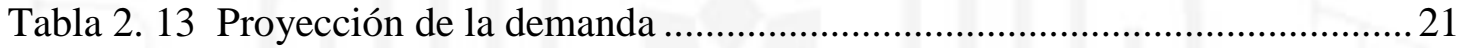

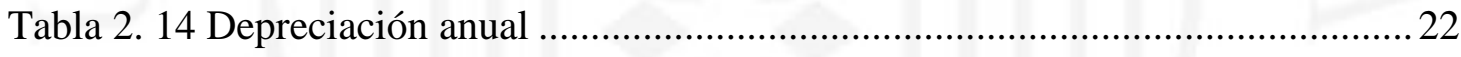

Tabla 2. 15 Empresas productoras, importadoras y comercializadoras ..................... 22

Tabla 2. 16 Variable para segmentar el mercado.................................................. 23

Tabla 2. 17 Demanda específica para el proyecto ............................................... 24

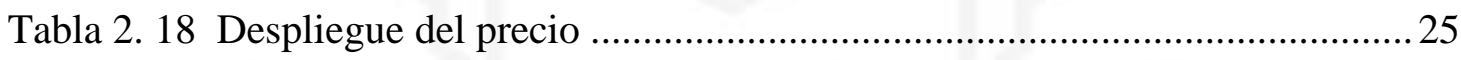

Tabla 2. 19 Tendencia histórica de los precios (Soles por $200 \mathrm{gr}$ ) ...........................26

Tabla 2. 20 Precios de aceite de coco al 2016 ....................................................... 26

Tabla 2. 21 Producción de coco a nivel nacional (Toneladas) .................................. 27

Tabla 2. 22 Proyección de producción de coco .....................................................29

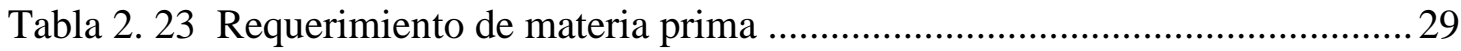

Tabla 3. 1 Factores de marco localización............................................................ 30

Tabla 3. 2 Factores de micro localización ................................................................30

Tabla 3. 3 Producción de coco por departamentos (Toneladas) ................................. 31

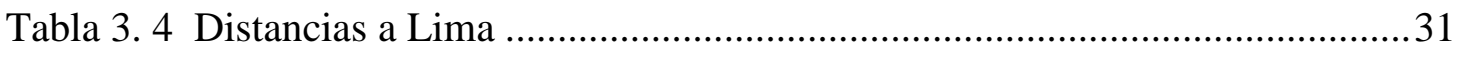

Tabla 3. 5 Kilómetros totales de carretera pavimentada por departamento.................32 


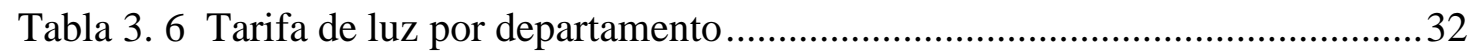

Tabla 3. 7 Tarifa de agua por departamento ......................................................... 32

Tabla 3. 8 Tabla de enfrentamiento para macro localización .....................................33

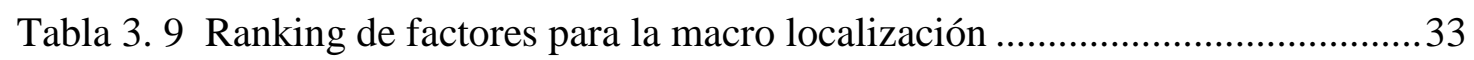

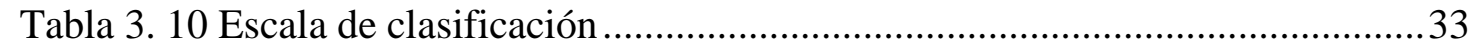

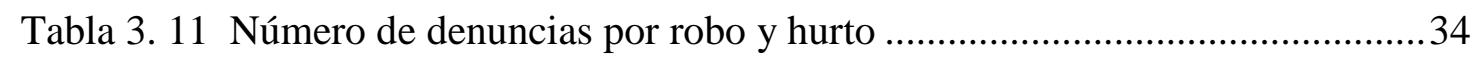

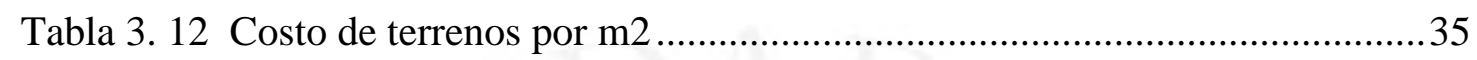

Tabla 3. 13 Puntaje y valoración para la micro localización ....................................35

Tabla 3. 14 Ranking de factores para la micro localización ..................................... 35

Tabla 4. 1 Capacidad de la planta (Kg/año).......................................................... 38

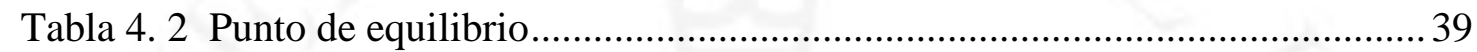

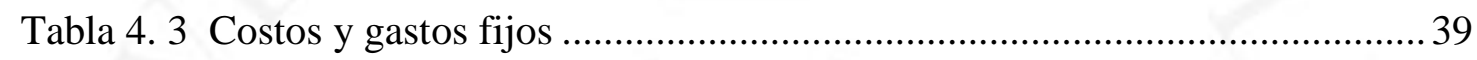

Tabla 4. 4 Relación comparativa de tamaños de planta........................................... 40

Tabla 5. 1 Definición técnica del producto .............................................................. 41

Tabla 5. 2 Composición del aceite de coco. ........................................................... 42

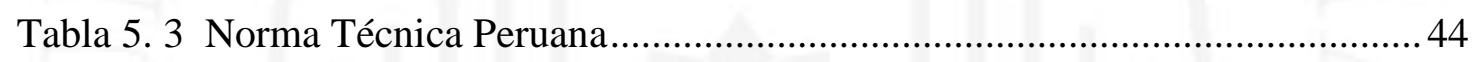

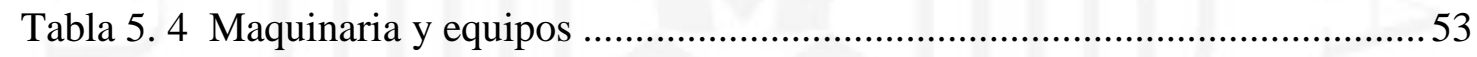

Tabla 5. 5 Especificaciones de las máquinas e instrumentos (Parte 1).......................54

Tabla 5. 6 Especificaciones de las máquinas e instrumentos (Parte 2).......................55

Tabla 5. 7 Especificaciones de las máquinas e instrumentos (Parte 3) ........................56

Tabla 5. 8 Especificaciones de las máquinas e instrumentos (Parte 4)......................57

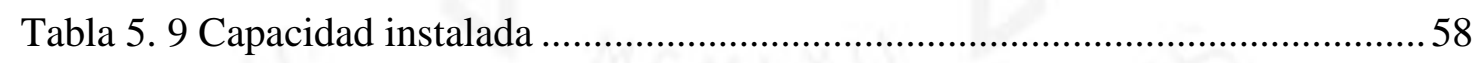

Tabla 5. 10 Cálculo del número de máquinas.......................................................59

Tabla 5. 11 Hoja de trabajo de análisis y riesgos................................................. 60

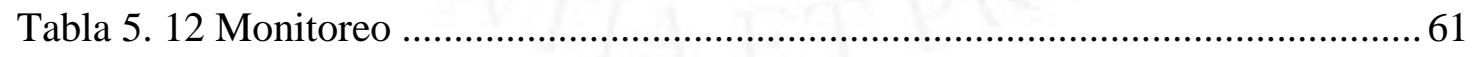

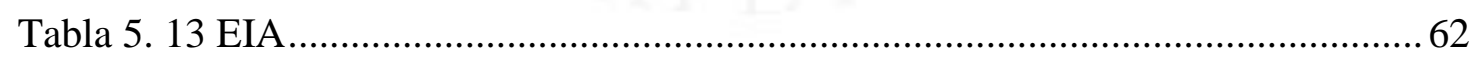

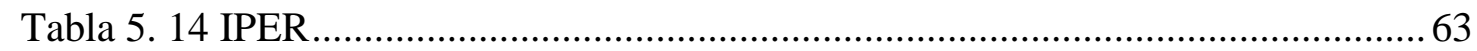

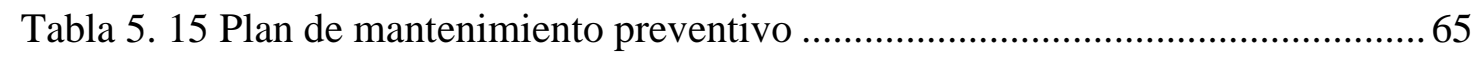

Tabla 5. 16 Programa de producción durante la vida útil del proyecto ....................... 66

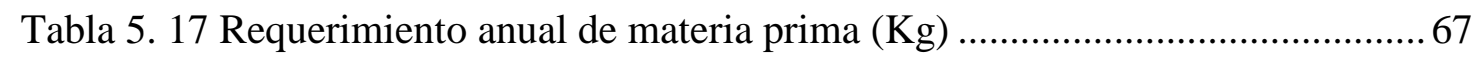

Tabla 5. 18 Requerimiento anual de envases (unidades) ....................................... 67 
Tabla 5. 19 Requerimiento anual de etiquetas (Unid.) 68

Tabla 5. 20 Requerimiento teórico anual de energía eléctrica por maquinaria. (kW -año) 68

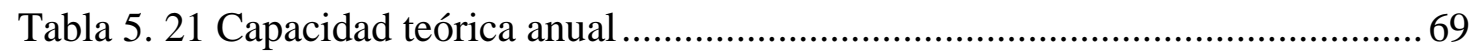

Tabla 5. 22 Porcentaje anual de utilización de la planta.........................................69

Tabla 5. 23 Requerimiento anual de energía eléctrica por maquinaria real. (KW-año)70

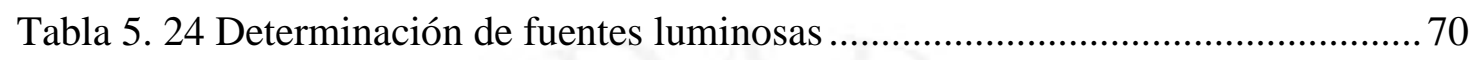

Tabla 5. 25 Requerimiento de energía no fabril ..................................................... 70

Tabla 5. 26 Requerimiento de energía fabril sin maquinaria................................... 71

Tabla 5. 27 Requerimiento de energía total .......................................................... 71

Tabla 5. 28 Consumo teórico anual de agua potable. (L / año) .................................. 71

Tabla 5. 29 Consumo real anual de agua potable por maquinaria (1/año) ................... 72

Tabla 5. 30 Determinación de la dotación del agua por persona ............................... 72

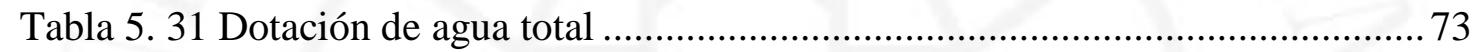

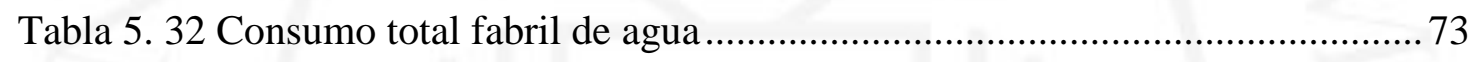

Tabla 5. 33 Consumo total no fabril de agua ........................................................ 73

Tabla 5. 34 Cálculo del número de operarios .................................................... 74

Tabla 5. 35 Número de trabajadores indirectos de producción ................................... 74

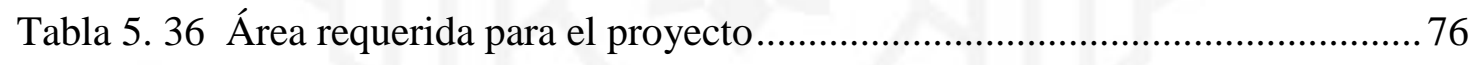

Tabla 5. 37 Requerimiento área para oficinas ................................................... 79

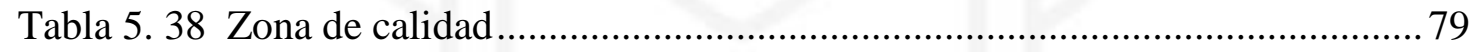

Tabla 5. 39 Guerchet de elementos estáticos ....................................................... 81

Tabla 5. 40 Guerchet de elementos móviles .......................................................... 81

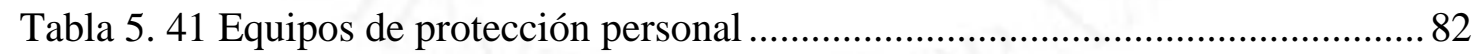

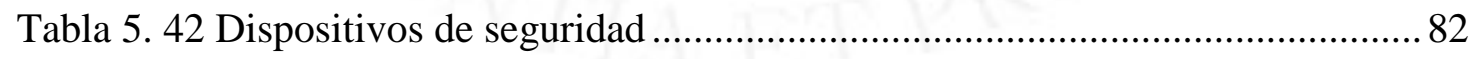

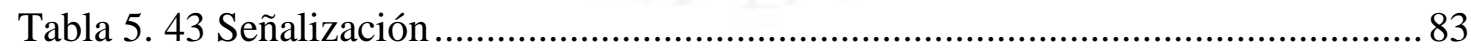

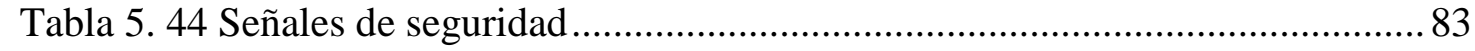

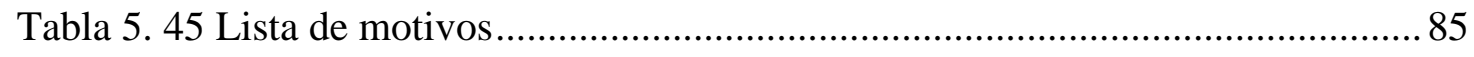

Tabla 5. 46 Escala de valores para la proximidad de las actividades ......................... 86

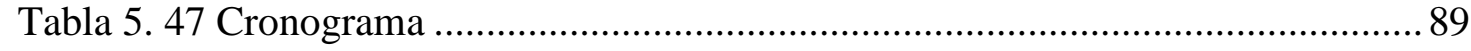

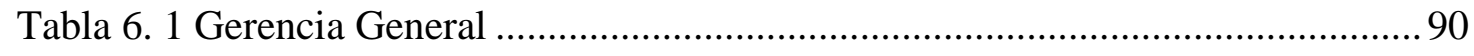


Tabla 6. 2 Distribución y logística............................................................................. 91

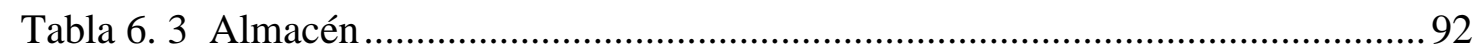

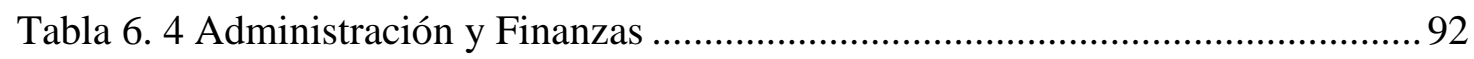

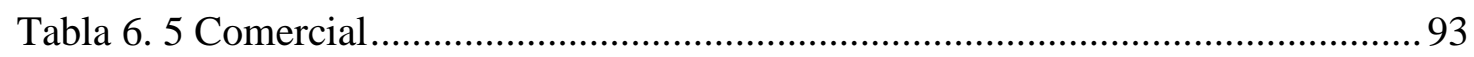

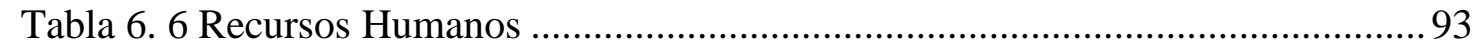

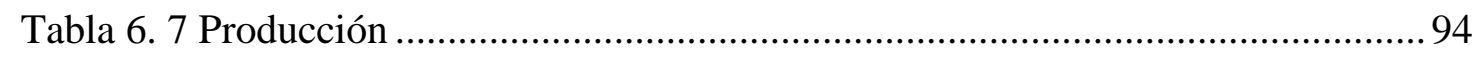

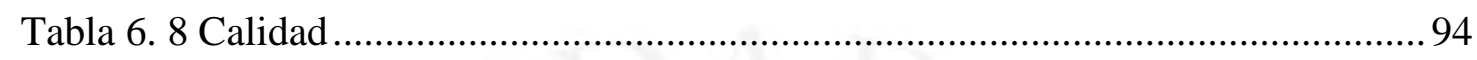

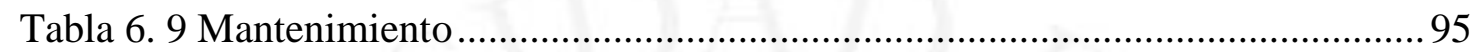

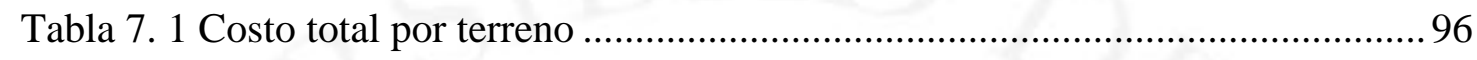

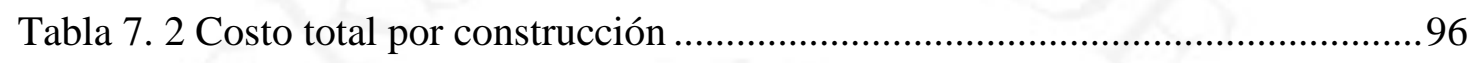

Tabla 7. 3 Costo total por maquinaria y equipos puestos en planta.................................97

Tabla 7. 4 Muebles y enseres fabriles...........................................................................97

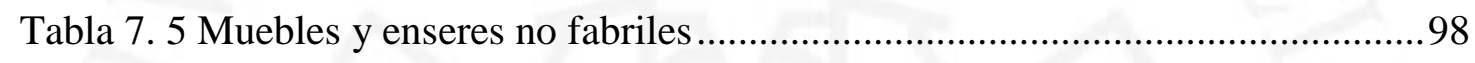

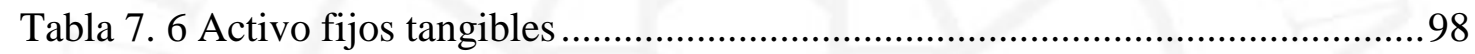

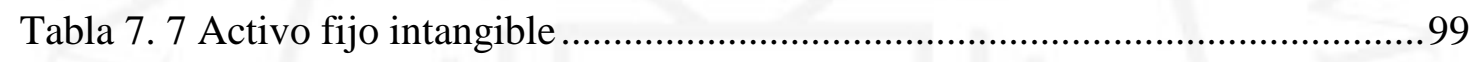

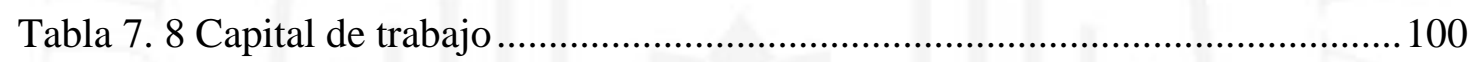

Tabla 7. 9 Precio unitario de materia prima e insumos sin IGV …………………......100

Tabla 7. 10 Costos anualizados de materia prima e insumos ........................................100

Tabla 7. 11 Pago anual de la mano de obra directa ……………………...................... 101

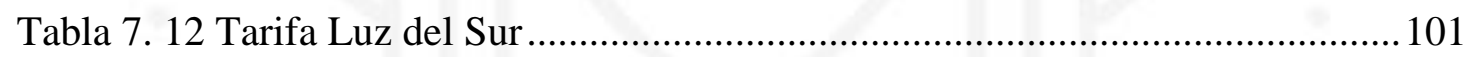

Tabla 7. 13 Costo anualizado de energía eléctrica fabril ............................................ 102

Tabla 7. 14 Costo anualizado de energía eléctrica no fabril .........................................102

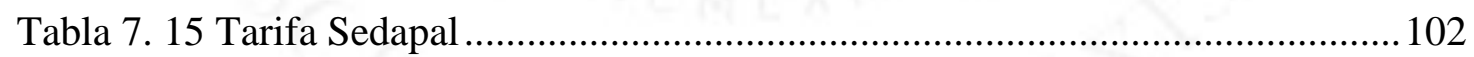

Tabla 7. 16 Costo fabril anualizado de agua............................................................... 102

Tabla 7. 17 Costo no fabril anualizado de agua....................................................... 103

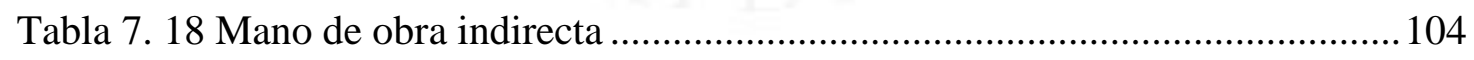

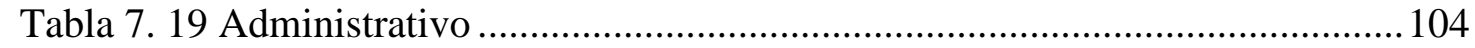

Tabla 7. 20 Costos indirectos de fabricación ............................................................ 105

Tabla 7. 21 Presupuesto de ingreso por ventas .......................................................... 105

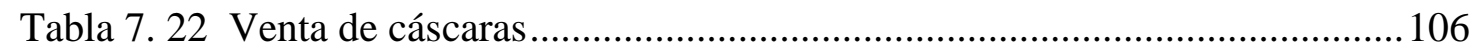

Tabla 7. 23 Presupuesto de costo de producción ...........................................................106 


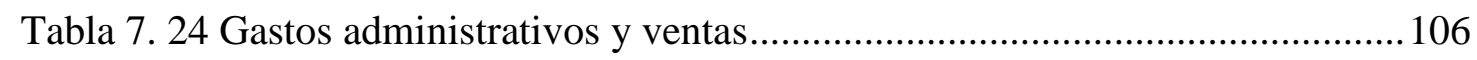

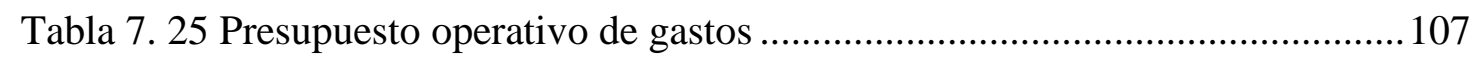

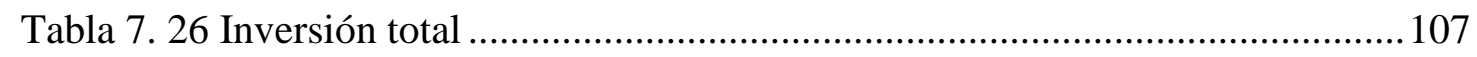

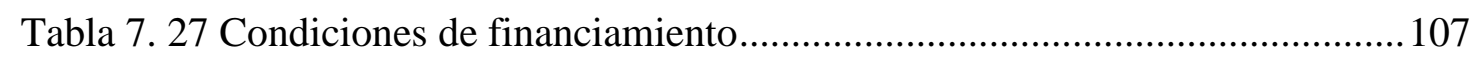

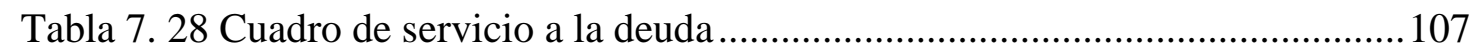

Tabla 7.29 Depreciación de activos tangibles ..................................................... 108

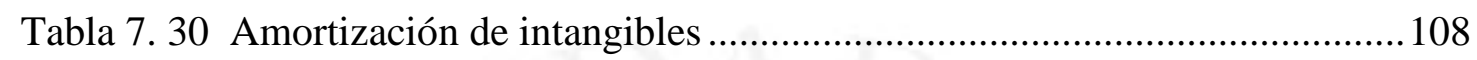

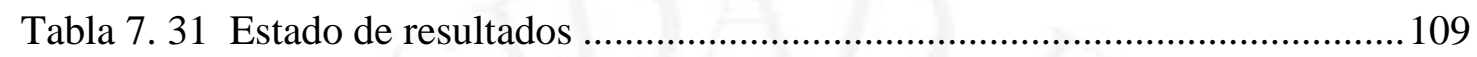

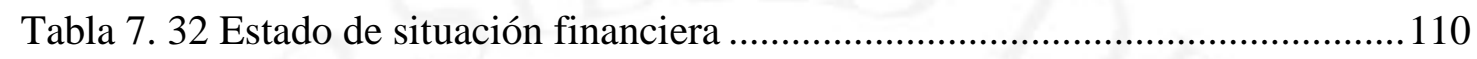

Tabla 7. 33 Cobranzas enero 2018 - Febrero 2019 ............................................... 111

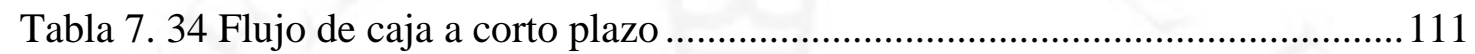

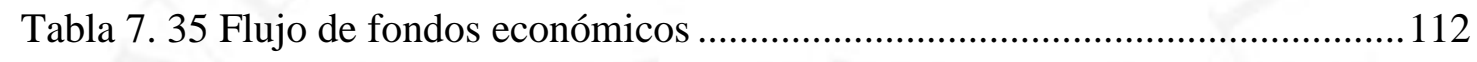

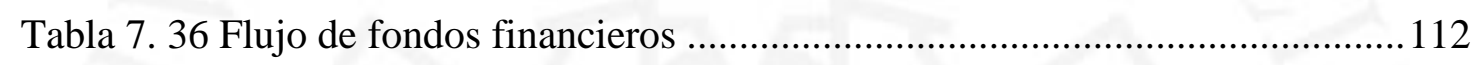

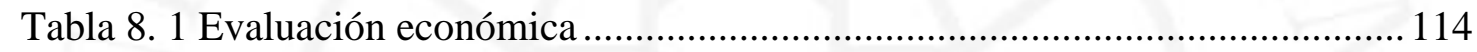

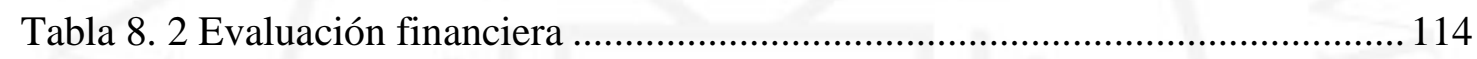

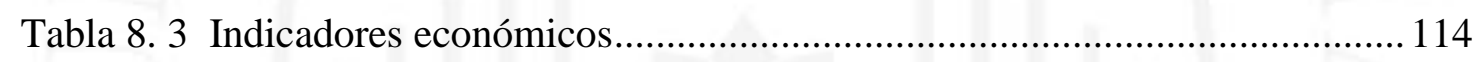

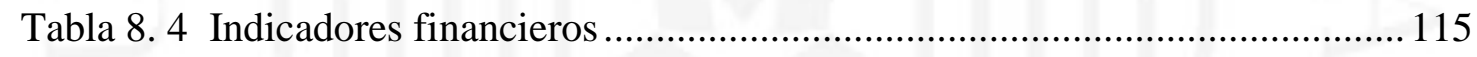

Tabla 8. 5 Ratios al 31 de diciembre del 2018................................................... 115

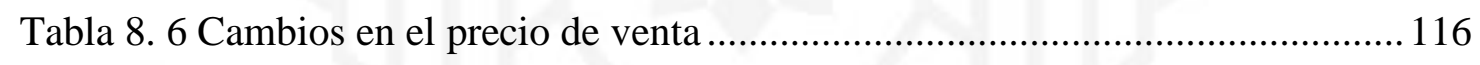

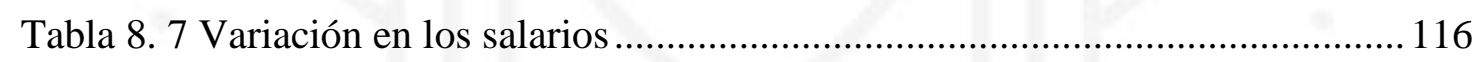

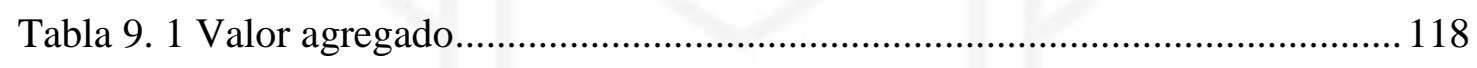

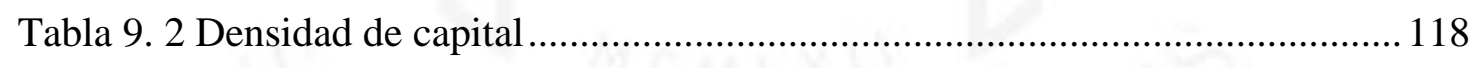

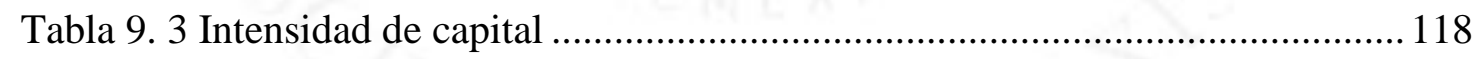




\section{ÍNDICE DE FIGURAS}

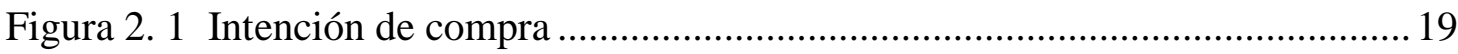

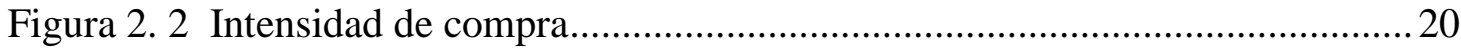

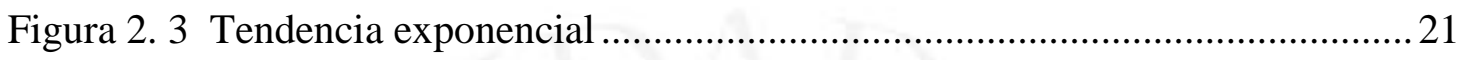

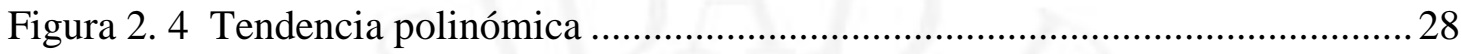

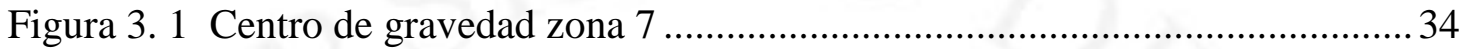

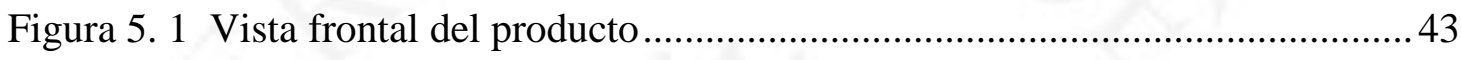

Figura 5. 2 Vista trasera del producto ........................................................... 43

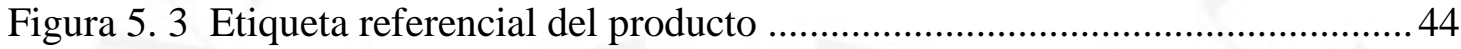

Figura 5. 4 DOP del aceite de coco (Parte 1) .................................................... 49

Figura 5. 5 DOP del aceite de coco (Parte 2) .....................................................50

Figura 5. 6 Balance de materia (Parte 1) ….......................................................... 51

Figura 5. 7 Balance de materia (Parte 2) ........................................................ 52

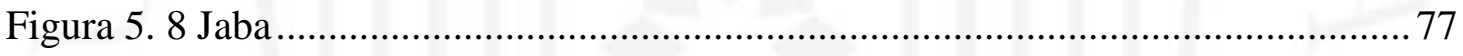

Figura 5. 9 Presentación de frasco de vidrio........................................................ 78

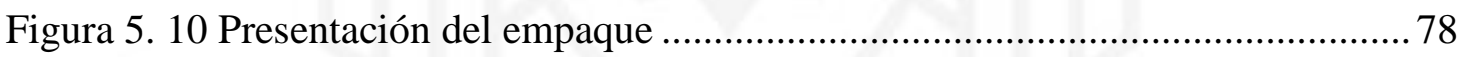

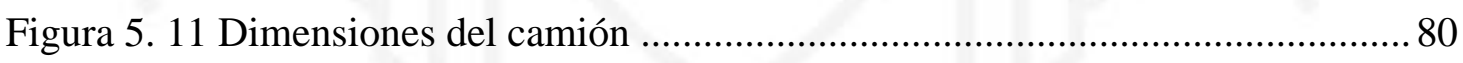

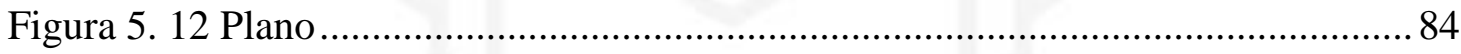

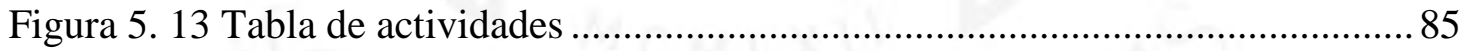

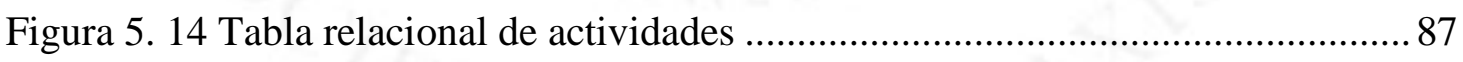

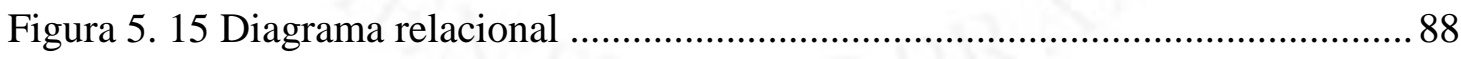

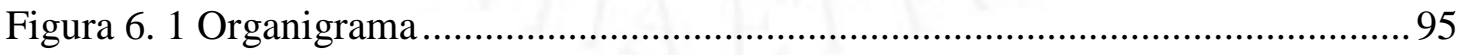




\section{ÍNDICE DE ANEXOS}

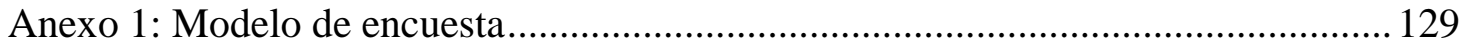

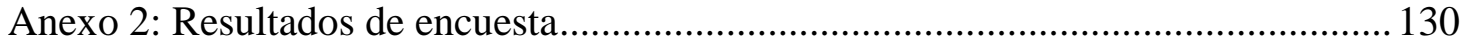

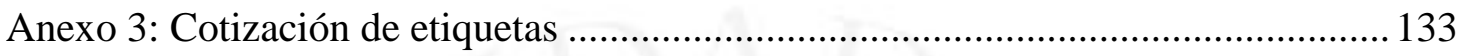

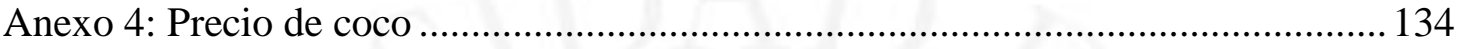

Anexo 5: Factor de conversión de fluorescente Phillips............................................ 135

Anexo 6: Flujo de fondos financieros ante un escenario pesimista con una variación del

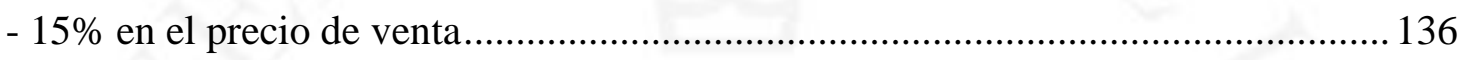

Anexo 7: Flujo de fondos financieros ante un escenario optimista con una variación del

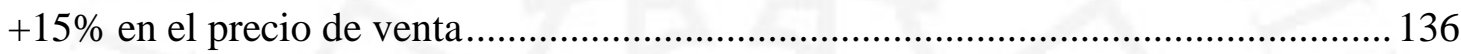

Anexo 8: Flujo de fondos financieros ante un escenario con el mínimo precio de venta

Anexo 9: Flujo de fondos financieros ante un escenario pesimista con una variación del

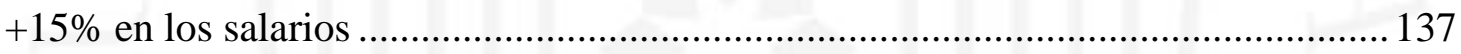

Anexo 10: Flujo de fondos financieros ante un escenario optimista con una variación

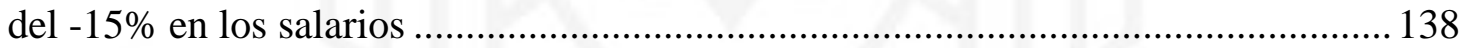

Anexo 11: Flujo de fondos financieros ante un escenario con el máximo salario en total 138

Anexo 12: Plano de planta 139 


\section{RESUMEN EJECUTIVO}

El presente estudio se ha realizado con el objetivo de determinar la factibilidad de instalar una planta productora de aceite de coco fabricado a partir de la pulpa de dicha fruta. Este producto es una alternativa saludable a los clásicos aceites utilizados.

En el primer capítulo, se analizaron los aspectos generales del proyecto donde se justificó la investigación del tema y se detallaron los objetivos generales y específicos.

En el segundo capítulo, se realizó el estudio de mercado donde se determinó la demanda del proyecto, la cual asciende a 69,772.00 Kg para el último año (2022). Asimismo, se estableció que el mercado meta es la población de Lima Metropolitana con estilo de vida sofisticado.

En el tercer capítulo, se analizó dónde se ubicaría la planta de producción, este análisis se realizó mediante el método de Ranking de Factores y se obtuvo como resultado que la mejor localización es el distrito de Lurín en Lima.

En el cuarto capítulo, se seleccionó el tamaño de planta donde la determinante fue la relación tamaño - mercado la cual asciende a 69,772.00 Kg/año.

En el quinto capítulo, se explicó la ingeniería del proyecto, en el cual se define técnicamente al producto, y se describe la tecnología existente para el proceso de producción. Luego, se detallaron las máquinas y equipos a utilizar. Adicionalmente, se halló la capacidad instalada de 77,921.89 Kg/ año. Asimismo, se analizó la inocuidad del producto mediante una matriz HACCP, se estudió el impacto ambiental mediante una matriz EIA, se evaluó la seguridad y salud ocupacional mediante una matriz IPER, y se definió el sistema de mantenimiento. Por último, se estableció el programa de producción con los requerimientos, la disposición de planta donde el área propuesta es de 436 m².

En el sexto capítulo, se explicó la formación organizacional, el perfil del personal y un organigrama que ubica de forma visual a los 20 trabajadores de la planta. 
En el sétimo capítulo, se determinó que la inversión requerida para implementar el proyecto asciende a S/ 1'262,177.60, el 50\% de esta será financiada y será amortizada mediante cuotas crecientes en un plazo de 5 años.

En el octavo capítulo, se realizó la evaluación económica la cual muestra un VAN de S/ 1'783,882.85, un TIR de 54\%, un beneficio - costo de 2.41 y un periodo de recupero de 3 años, 4 meses y 11 días. Mientras que la evaluación financiera muestra un VAN de S/ 2’110,177.91 un TIR de 78\%, un beneficio - costo de 4.34 y un periodo de recupero de 2 año 8 meses 5 días. Además, se analizaron ratios de liquidez, solvencia y rentabilidad.

En el noveno capítulo, se determinó el impacto social del proyecto en la zona de Lurín y de las provincias de los proveedores de la materia prima mediante indicadores sociales. Se obtuvo un valor agregado de S/. 7’470,858.29, una densidad de capital de 63,108.88 soles' empleo y una relación de intensidad de capital de 0.17. Finalmente, no se evaluó la generación de divisas debido a que el proyecto no tiene exportaciones ni importaciones

Palabras claves: aceite, coco, copra, prensado en frío, grasas. 


\section{EXECUTIVE SUMMARY}

The present study has been done with the objective of determining the feasibility of installing a coconut oil production plant from the pulp of that fruit. This product is a healthy alternative to the common oils used.

In the first chapter, the general aspects of the project were analyzed. The investigation of the topic was justified and the general and specific objectives were detailed.

In the second chapter, the market study was developed where the project demand was determined, which amounts to $69,772.00 \mathrm{Kg}$ for the last year (2022). Also, it was established that the target market is Metropolitan Lima's population with a sophisticated lifestyle.

In the third chapter, the location of the production plant was chosen, this analysis was carried out using the Factors Ranking method and it was obtained as a result that the best location is the district of Lurin in Lima.

In the fourth chapter, the plant size was analyzed, where the determinant was the size - market relation which amounts to $69,772.00 \mathrm{Kg} /$ year.

In the fifth chapter, the engineering of the project was explained, in which the product is technically defined, and the existing technology for the production process is described. Then, the machines and equipment to be used were detailed. Additionally, the installed capacity of 77,921.89 Kg / year was established. Likewise, the product safety was analyzed through a HACCP matrix, the environmental impact was studied through an EIA matrix, the occupational health and safety was evaluated through an IPER matrix, and the maintenance system was defined. Finally, the production program was established with the requirements and the plant layout where the proposed area is $436 \mathrm{~m} 2$.

In the sixth chapter, the organizational design and the profile of the personnel were explained. An organizational chart that visually locates the 20 workers of the plant was shown. 
In the seventh chapter, it was determined that the investment required to implement the project amounts S/ 1'262,177.60,50\% of this will be financed and will be amortized by increasing fees over a period of 5 years

In the eighth chapter, the economic evaluation was carried out which shows a NPV of S/ 1'783,882.85, an IRR of 54\%, a benefit - cost of 2.41 and a recovery period of 3 years, 4 months and 11 days. While the financial evaluation shows a NPV of S/ 2,110,177.91 a TIR of 78\%, a benefit - cost of 4.34 and a recovery period of 2 years, 8 months and 5 days. In addition, liquidity, solvency and profitability ratios were analyzed.

In the ninth chapter, the social impact of the project for Lurin zone and provinces of raw material suppliers was determined through social indicators. An added value of S/. 7'470,858.29, a capital density of 63,108.88 soles / employment and a capital intensity ratio of 0.17 were obtained. Finally, the generation of foreign currency was not evaluated because the project has no exports or imports.

Keywords: oil, coconut, copra, cold pressed, grease. 


\section{CAPÍTULO I: ASPECTOS GENERALES}

\subsection{Problemática}

Actualmente, el mercado peruano está tomando conciencia sobre la importancia de la alimentación saludable y el efecto dañino para la salud que causan las grasas trans saturadas, por lo que están optando por otras alternativas beneficiosas para la salud. Esta migración saludable es lenta ya que los productos suelen ser más caros que los demás; sin embargo, muchos consumidores intentan buscar alimentos sanos que estén dentro de su presupuesto, incorporando el aceite de oliva a su dieta diaria (Euromonitor Internacional, 2015).

De acuerdo a lo descrito anteriormente, el aceite de coco representa una alternativa atractiva pues este producto, a diferencia de otros aceites vegetales, ofrece una impresionante variedad de beneficios para la salud ya que al incluirlo en la alimentación diaria refuerza la tiroides, fortalece el sistema inmunológico, promueve la salud cardiaca, mantiene la piel sana y fomenta un metabolismo fuerte para la pérdida de peso (Mercola, Dr. Mercola, 2013). Además, el aceite de coco contiene principalmente el ácido láurico. Dicho componente es convertido, en el organismo, en mono laurina, la cual tiene propiedades anti-bacteriales y anti-protozoos (Mercola, Dr. Mercola, 2010)

Todos estos beneficios mencionados, convierten al aceite de coco en un alimento completo y muy beneficioso para la salud.

\subsection{Objetivos de la investigación Objetivo general}

Determinar la viabilidad técnica, económica, social, de mercado y financiera para la instalación de una planta productora de aceite de coco apto para uso alimenticio. 


\section{Objetivos específicos}

- Realizar un estudio de mercado que permita identificar la demanda del proyecto y la disponibilidad de insumos.

- Identificar y evaluar la tecnología y equipos requeridos para la elaboración de aceite de coco.

- Realizar una evaluación económica-financiera para determinar la rentabilidad del proyecto.

\subsection{Alcance y limitaciones de la investigación}

La presente investigación explorará el mercado peruano para verificar si la inserción de aceite de coco será atractiva para los clientes potenciales pertenecientes a Lima Metropolitana con estilo de vida sofisticado. Además, se analizará el tamaño de la planta que incluirá un análisis de ingeniería, organización, inversión y presupuesto. Finalmente se evaluará económica y financieramente la viabilidad de la planta productora de aceite de coco para su comercialización.

Los datos obtenidos mediante la encuesta realizada para determinar la demanda del proyecto puede verse afectada por datos irreales, lo cual se considera una limitación. Pues es probable que los encuestados no sean totalmente sinceros, que no brinden respuestas concienzudas o pueden dar información sesgada (Surveyanyplace, 2017). Sin embargo, se espera que la muestra elegida sea lo más representativa posibles.

Además, la investigación analiza un tiempo de estudio donde el mercado peruano está tomando conciencia sobre la importancia de la alimentación saludable, factor que puede variar de un tiempo a otro. 


\subsection{Justificación del tema}

\section{Técnica}

En el Perú se cuenta con la tecnología y equipos necesarios para la elaboración de aceite de coco. Las principales máquinas a utilizar son el deshidratador de frutas para la obtención de la copra, la trituradora de copra y una prensadora para la extracción del producto.

\section{Económica}

La industria de aceites y grasas se proyecta a crecer en 3\%, además se estima que los aceites y grasas saludables se desarrollen de manera más rápida, ya que los consumidores están migrando a estas alternativas sanas (Euromonitor Internacional, 2015). Por lo cual existe una demanda del producto en crecimiento que se puede satisfacer parcialmente con aceite de coco. Además la producción de copra, materia prima del aceite, crecerá más del 30\% hasta 2026 (El Comercio, 2017).

\section{Social}

Se genera oportunidad de crecimiento a los proveedores de la materia prima y también a la PEA desocupada local, la cual asciende a 579.15 miles de habitantes (INEI, 2016). A esta última parte de la población se le ofrecerá puestos de trabajos formales con los respectivos beneficios sociales de ley.

Además, el proyecto permite mejorar la calidad de vida de los consumidores pues el aceite de coco brinda diversos beneficios para la salud.

\subsection{Hipótesis del trabajo}

La instalación de una planta de producción de aceite de coco es factible ya que existe un mercado que aceptará el producto y además es técnica, económica, financiera y socialmente viable.

\subsection{Marco referencial de la investigación}

Como referencia para realizar el plan de investigación del proyecto se realizó una comparación entre diferentes tesis y artículos relacionados al tema estudiado. Por 
consiguiente, en las siguientes líneas se detallan las diferencias y similitudes entre las investigaciones revisadas y esta.

- Minolo Mardini, Sandro Giardano (2014). "Estudio de pre factibilidad para la instalación de una empresa de aceite de palta Hass (persea americana) mediante el método de centrifugado".

El estudio previamente mencionado sirve como referencia para verificar la existencia de tecnología utilizada en la obtención de aceite natural para el consumo humano. Sin embargo, el producto que propone es aceite de palta el cual varía en ciertas partes del proceso productivo por las mismas propiedades físicas y químicas de la palta.

- Schiappa-Pietra Fuentes, Romina A. (2014). "Estudio de pre factibilidad para la elaboración y comercialización de aceite de uva".

La tesis estudiada se basa en la producción de aceite de uva en base a la semilla de la fruta, respecto al proceso productivo es relativamente similar, lo cual sirve como referencia para el proceso de producción de aceite de coco y para verificar la rentabilidad de la introducción de un nuevo aceite natural al mercado.

- Morales Ruiz, Diana Belinda (1985). "Estudio preliminar para la instalación de una fábrica de aceite de coco".

En la tesis mencionada, se muestra un estudio similar al que se desarrollará ya que presenta el mismo producto final, sin embargo la metodología empleada es diferente de la que se empleará en la presente tesis (prensado en frío).

\subsection{Marco conceptual}

El producto a elaborar es el aceite de coco, el cual se presenta como una opción saludable con respecto a los demás aceites presentes en el mercado de la industria alimenticia.

Dicho aceite contiene ácidos grasos que se convierten en energía en vez de ser almacenados como grasa en el hígado. El aceite de coco soporta altas temperaturas de cocción sin dañarse, por lo tanto, combina con todo tipo de platos. (Mercola D. J., 2013). 
Además, dicho producto se destaca por su bajo nivel de ácidos grasos insaturados que lo hace muy resistente a la rancidez oxidativa (Maximixe Consult S. A., 2014), la cual es la deterioración organolépticamente detectable en aceites y grasas en presencia con el aire (Menacho, 2013).

Algunos de los compuestos principales que explican los beneficios del aceite de coco se detallan a continuación.

\section{- Ácido láurico}

El ácido láurico es un ácido graso saturado de cadena media, presente en los aceites láuricos hasta en un 50\%. Los aceites láuricos son los únicos aceites líquidos comestibles que contienen exclusivamente ácidos grasos saturados, por lo tanto, tienen alta estabilidad contra la oxidación (Mora, 2003).

\section{- Fitoesteroles}

Son compuestos naturales vegetales que se encuentran presentes en los aceites vegetales, frutos secos y legumbres. Son un tipo de colesterol ya que tienen la misma función; sin embargo, no tienen los efectos negativos secundarios asociados con el consumo de alimentos con altos niveles de colesterol (Alimentoscon, 2016).

\section{- Mono laurina}

Es un mono glicérido, el cual puede destruir los virus recubiertos de lípidos, como VIH, herpes, sarampión, gripe, bacterias patógenas y protozoos (Mercola, Dr. Mercola, 2010). 


\section{CAPÍTULO II: ESTUDIO DE MERCADO}

\subsection{Aspectos generales del estudio de mercado}

\subsubsection{Definición comercial del producto}

El producto propuesto es aceite de coco el cual se extrae principalmente de la pulpa de la fruta. El uso de este producto es sumamente amplio pues puede ser usado como aceite de cocina y como artículo de belleza. A continuación, se detallan los niveles del producto.

\section{Producto básico}

Aceite natural de coco para consumo humano.

\section{Producto real}

Aceite de coco de color blanco que brinda propiedades hidratantes y, particularmente, de sabor dulce (Kioseka Salud, 2015). Será presentado en un envase de vidrio con capacidad de 200 gr. la cual estará, debidamente, etiquetada donde se mostrará el logo de la empresa, componentes del producto, datos de la empresa y certificaciones de calidad. El nombre de la marca será "Cocoil”" el cual es un juego de palabras de coco y aceite en inglés (oil). Además, el producto, por sí mismo, presenta las vitaminas E, que actúa como antioxidantes y $\mathrm{K}$ que ayuda en el proceso de coagulación de la sangre.

\section{Producto aumentado}

Además de la información previamente mencionada, se añadirá a la etiqueta los principales usos y propiedades benéficas para la salud. Asimismo, se contará con una página web donde se describirá detalladamente todos los usos, beneficios y se recibirán reclamos, quejas y sugerencias para que el producto satisfaga las expectativas del cliente. 
Tabla 2. 1

\section{Modelo de negocios Canvas}

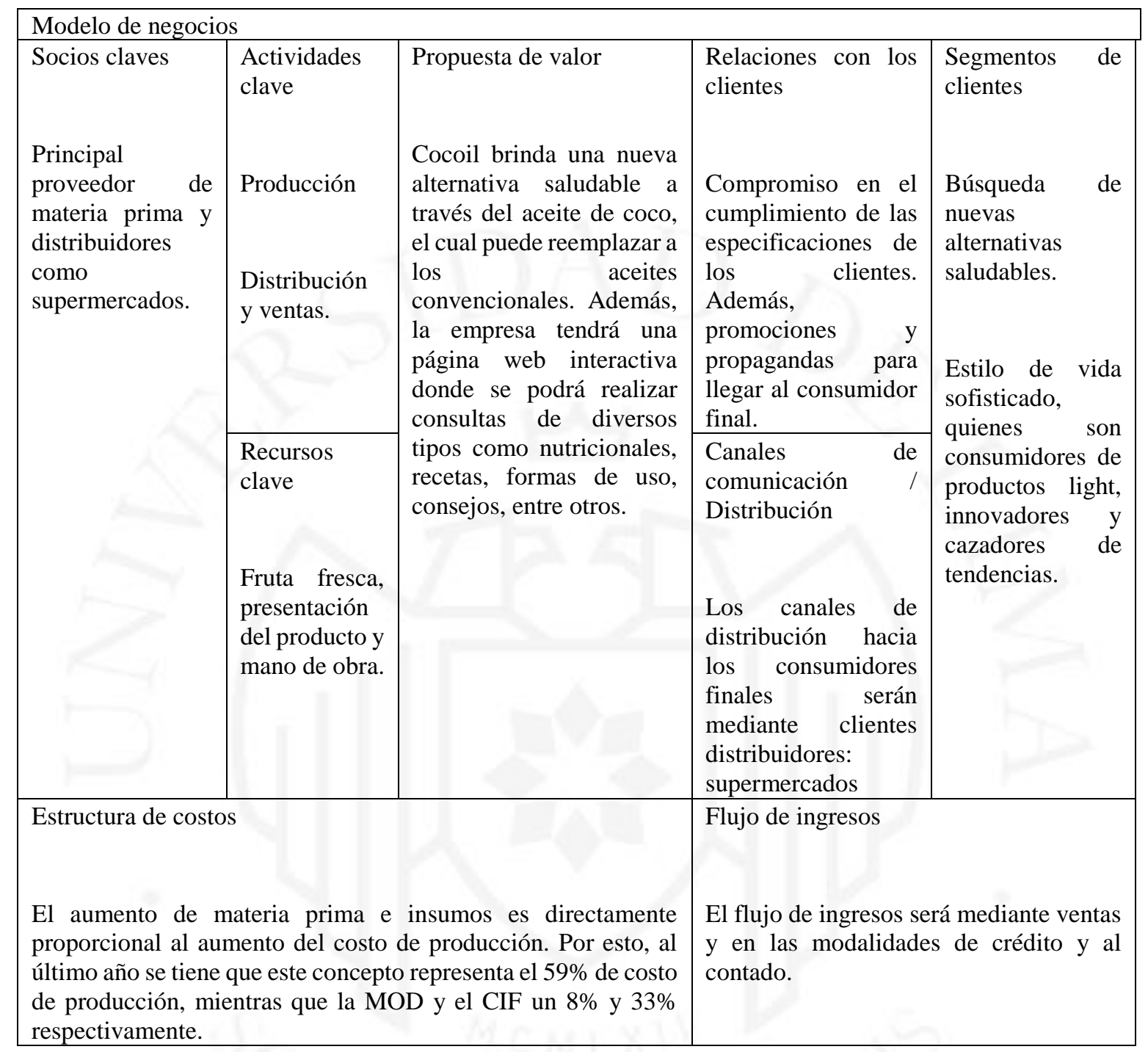

Elaboración propia

\subsubsection{Principales características del producto}

\subsubsection{Usos y características del producto}

\section{Usos}

El aceite de coco tiene múltiples usos, que van desde preparación de comidas saludables hasta tratamientos de belleza. A continuación, se detallarán estos usos. 
- Salud: Fortalece el sistema inmunológico, ayuda a mantener saludable el corazón y favorece un correcto funcionamiento de la tiroides y del cerebro (Mercola, Dr. Mercola, 2013).

- Belleza: Removedor de maquillaje, limpiador facial, exfoliante, jabón, pasta de dientes y como hidratante para piel. Además se puede utilizar en los ojos para suavizar las expresiones faciales y como desodorante (Mercola, Dr. Mercola, 2013).

- Cocina: El aceite de coco proporciona entre un 30\% y $60 \%$ de las calorías diarias, puede ser usado para freír en plancha o sartén y como aliño para ensaladas. (Aceite de Coco, 2015).

\section{Características}

El aceite de coco virgen contiene grasa saturada saludable que controla el peso, ayuda con la digestión y apoya la inmunidad debido a que contiene ácido láurico, ácido caprico y ácido caprílico. (El aceite de coco, 2015)

Tiene mayor resistencia a la temperatura que otras grasas con las que se acostumbra a cocinar. Es el único aceite de cocina que no pierde sus propiedades ni se oxida a altas temperaturas. (El aceite de coco, 2015)

Tabla 2.2

Partida arancelaria de aceite de coco

\begin{tabular}{|c|c|}
\hline Número de Partida & Descripción de Partida \\
\hline 1513.11 .00 .00 & Aceite de coco en bruto \\
\hline
\end{tabular}

Fuente: Superintendencia Nacional de Aduanas y de Administración Tributaria, SUNAT. (2016)

Tabla 2.3

Códigos numéricos de rama de actividad económica según CIIU - 3

\begin{tabular}{|c|c|}
\hline Sección / División / Grupo / Clase & Descripción de categorías de la CIIU Revisión 3 \\
\hline D - 1514011 & Aceite de coco, fabricación \\
\hline
\end{tabular}

Fuente: Instituto Nacional de Estadística e Informática, INEI. (2016) 


\subsubsection{Bienes sustitutos y complementarios}

Bienes sustitutos: Existen diversas variedades de aceite vegetal que pueden ser sustitutos del aceite de coco. Uno de los que más se parece a dicho producto es el aceite de oliva ya que posee cualidades y usos similares. El aceite de oliva extra virgen es la mejor grasa insaturada; sin embargo, no es el mejor aceite para cocinar. Debido a su estructura química, cocinar con él lo hace más susceptible al daño oxidativo (Mercola, Dr. Mercola, 2016).

Bienes complementarios: Sal, pimienta, comino, ajos, orégano, ensaladas y limón.

\subsubsection{Determinación del área geográfica que abarcará el estudio}

El proyecto pretende abastecer en exclusiva al mercado peruano, principalmente Lima Metropolitana cuya población asciende a 10’012,437 habitantes (INEI, 2016)

\subsubsection{Análisis del sector}

El producto mencionado está definido en la industria agroindustrial, para el análisis del nivel de atracción de este sector se realizó el modelo de las cinco fuerzas de Michael Porter.

\section{Poder de negociación de los clientes}

Dado en cuenta que el consumidor final es el cliente, el poder de negociación es bajo ya que el aceite de coco presentado tiene un precio relativamente menor con respecto a otras marcas. Además, se conoce que los consumidores peruanos pagan hasta $123 \%$ más en la compra de productos saludables, versus otras opciones no saludables. (Trigoso \& Salas, 2012)

\section{Poder de negociación de los proveedores}

Los cultivos de coco en el Perú son variados como se muestra en la tabla 2.3 y se encuentran concentrados principalmente en el departamento de San Martín. Además, la demanda de materia prima, la cual no es un producto diferenciado, asciende a 383 toneladas aproximadamente por lo que se puede concluir que el poder de negociación de los proveedores es bajo. 
Tabla 2. 4

Producción de coco por departamentos (Toneladas)

\begin{tabular}{|l|l|}
\hline Departamento & Producción \\
\hline San Martín & $14,476.00$ \\
\hline Loreto & $8,742.00$ \\
\hline Ucayali & $4,811.00$ \\
\hline Piura & $1,537.00$ \\
\hline Huánuco & $1,402.00$ \\
\hline Amazonas & 522.00 \\
\hline Junín & 415.00 \\
\hline Madre de Dios & 390.00 \\
\hline Ayacucho & 143.00 \\
\hline Tumbes & 140.00 \\
\hline Cajamarca & 90.00 \\
\hline Lambayeque & 54.00 \\
\hline
\end{tabular}

Fuente: Ministerio de Agricultura y Riego, MINAGRI. (2014)

\section{Amenaza de nuevos ingresantes}

La amenaza de nuevos ingresantes es alta ya que los productores de bienes sustitutos, que llevan mucho tiempo desarrollando distintas variedades de aceites, poseen la tecnología para lanzar una nueva línea de aceite de coco. Además, por ser empresas consolidadas en el mercado, podría generar que el consumidor se identifique más rápido con la marca.

\section{Amenaza de productos sustitutos}

Actualmente, existe una alta diferencia de precios entre el producto sustituto y el producto del proyecto, debido a que el rango de precios de 200 gr de aceite de oliva varía de 6 a 17 soles se consideró un factor de conversión de $0.918 \mathrm{~g} / \mathrm{ml}$ para el aceite de oliva (olivos, 2018), mientras que el del aceite de coco está entre 18 y 25 soles por el mismo contenido. Además, las ventas de aceite de oliva están creciendo rápidamente, registrándose un crecimiento en 15\% en el año 2015 (Euromonitor Internacional, 2015). Lo cual genera una alta amenaza de productos sustitutos. 


\section{Rivalidad entre competidores}

En el mercado actual existen muy pocas empresas productoras de aceite de coco para abastecer la demanda existente, por lo que la rivalidad entre competidores es baja. Además, no hay barreras de salida porque la maquinaria utilizada para la producción del aceite como el deshidratador de frutas, trituradora y prensadora no son especializadas.

\subsubsection{Determinación de la metodología que se empleará en la investigación de mercado}

El desarrollo de la investigación de mercado del actual proyecto ha requerido de cierta información que permitirá conocer las necesidades, el comportamiento, deseos y actitudes del cliente para poder gestionar correctamente el sector al cual se dirige el producto por comercializar.

Toda esta información ha sido recolectada de diversas fuentes, tanto primarias como secundarias. Dentro de las fuentes secundarias están las bases de datos de portales como: el Instituto Nacional de Estadística e Informática (INEI), Euromonitor International, la Asociación Peruana de Empresas de Investigación de Mercados (APEIM), entre otros. Además, algunas fuentes primarias como la realización de encuestas al público objetivo.

\subsection{Análisis de la demanda}

\subsubsection{Demanda histórica}

\subsubsection{Importaciones/exportaciones}

Se considerará la producción de aceite de oliva para todos los cálculos de la demanda ya que es un producto sustituto del aceite de coco y está dirigido al mercado objetivo de este proyecto. 
Tabla 2.5

Exportaciones e importaciones de aceite de oliva

\begin{tabular}{|c|c|c|}
\hline Año & $\begin{array}{c}\text { Importaciones } \\
\text { (TM) }\end{array}$ & $\begin{array}{c}\text { Exportaciones } \\
\text { (TM) }\end{array}$ \\
\hline 2013 & 473.06 & 611.58 \\
\hline 2014 & $1,004.63$ & $1,279.04$ \\
\hline 2015 & 798.59 & 871.08 \\
\hline 2016 & 755.97 & 490.37 \\
\hline 2017 & $1,321.04$ & 905.81 \\
\hline
\end{tabular}

Fuente: Infotrade (2018)

\subsubsection{Producción Nacional}

Tabla 2.6

Producción nacional de aceite de oliva

\begin{tabular}{|l|r|}
\hline Año & $\begin{array}{c}\text { Producción } \\
\text { (TM) }\end{array}$ \\
\hline 2013 & 433.64 \\
\hline 2014 & $1,976.30$ \\
\hline 2015 & 676.85 \\
\hline 2016 & 697.00 \\
\hline 2017 & 956.46 \\
\hline
\end{tabular}

Fuente: SIEA - MINAGRI (2018)

\subsubsection{Demanda Interna Aparente (DIA)}

Tabla 2.7

Demanda interna aparente

\begin{tabular}{|c|c|}
\hline Año & DIA (TM) \\
\hline 2013 & 295.11 \\
\hline 2014 & $* 422.32$ \\
\hline 2015 & 604.35 \\
\hline 2016 & 962.61 \\
\hline 2017 & $1,371.69$ \\
\hline 2018 & $* 1,184.84$ \\
\hline
\end{tabular}

Elaboración propia 
Al analizar los datos obtenidos, se observó que en el año 2014, la DIA ascendía a 1,701.89 toneladas, lo cual resulta atípico. Por lo tanto, se usó el promedio geométrico para suavizar dicho año y facilitar la proyección de la DIA, de este modo se consiguió el dato de 422.32 toneladas.

Tabla 2.8

Cálculos para hallar la DIA del año 2018

\begin{tabular}{|c|c|c|c|c|c|}
\cline { 2 - 6 } \multicolumn{1}{c|}{} & $\begin{array}{c}\text { Producción } \\
(\mathrm{TM})\end{array}$ & $\begin{array}{c}\text { Importaciones } \\
(\mathrm{TM})\end{array}$ & $\begin{array}{c}\text { Exportaciones } \\
(\mathrm{TM})\end{array}$ & DIA (TM) & $\begin{array}{c}\text { DIA ANUAL } \\
(\mathrm{TM})\end{array}$ \\
\hline Enero - Abril & 361 & 122.25 & 88.31 & 394.95 & $1,184.84$ \\
\hline
\end{tabular}

Fuente: SIEA - MINAGRI (2018), Veritrade (2018)

Para determinar la DIA del último año (2018), se utilizaron los datos de producción, importación y exportación del primer cuatrimestre del 2018 y se proyectó a un año, lo cual dio como resultado $1,184.84$ toneladas.

\subsubsection{Demanda potencial}

2.2.2.1 Patrones de consumo: incremento poblacional, consumo per cápita, estacionalidad

Tabla 2.9

Incremento poblacional nacional

\begin{tabular}{|c|c|c|}
\hline Año & Población & $\begin{array}{c}\text { Incremento } \\
\text { poblacional }\end{array}$ \\
\hline 2013 & $30,475,144$ & $1.13 \%$ \\
\hline 2014 & $30,814,175$ & $1.11 \%$ \\
\hline 2015 & $31,151,643$ & $1.10 \%$ \\
\hline 2016 & $31,488,625$ & $1.08 \%$ \\
\hline
\end{tabular}

Fuente: Instituto Nacional de Estadística e Informática, INEI. (2016) 
Tabla 2. 10

Consumo per cápita de aceite de oliva

\begin{tabular}{|c|c|}
\hline País & Consumo per cápita (kg/habitante) \\
\hline Argentina & 0.13 \\
\hline Chile & 0.40 \\
\hline Ecuador & 0.21 \\
\hline Perú & 0.02 \\
\hline
\end{tabular}

Fuente: Alimentos Argentinos (2015), La Nación (2015) y RPP Noticias (2015)

\subsubsection{Determinación de la demanda potencial}

Para determinar la demanda potencial, se observaron otras realidades como la de Argentina, Brasil y Chile para luego considerar la que tenga mayor similitud a la de Perú, la cual se pueda ver como un objetivo alcanzable a mediano o largo plazo.

Se considerará el consumo per cápita de Chile el cual será multiplicado por la población total del Perú para obtener la demanda potencial.

\section{Tabla 2. 11}

Demanda potencial de aceites de oliva 2015

\begin{tabular}{|l|l|}
\cline { 2 - 2 } \multicolumn{1}{c|}{} & Kg de aceite/ año \\
\hline Perú & $12,460,657.20$ \\
\hline
\end{tabular}

Elaboración propia

\subsubsection{Demanda mediante fuentes primarias}

\subsubsection{Diseño y Aplicación de Encuestas u otras técnicas}

A través de la realización de una encuesta piloto a personas que llevan un estilo de vida sofisticado y que viven en Lima Metropolitana se obtuvieron los siguiente datos.

El primer dato esencial que proporciona la encuesta es la intención de compra de los posibles consumidores, es decir, la predisposición del encuestado para realizar la compra del producto ofertado. 
El segundo dato será la intensidad de compra, es decir que tan decidido está el encuestado en comprar el producto en un rango desde poco probable hasta definitivamente lo compraría.

Finalmente, con estos indicadores se podrá obtener un factor de corrección de la demanda y así lograr una demanda real del proyecto.

Cabe mencionar que se encuestaron 384 personas, para obtener este dato se aplicó la siguiente fórmula.

$$
\frac{z^{2} \times p \times q}{e^{2}}=n
$$

Para este caso se usó un nivel de confianza de $96 \%$ y un error absoluto de $5 \%$.

\section{Resultados de la encuesta}

Se realizaron 384 encuestas, de las cuales 326 personas contestaron que sí comprarían el aceite de coco por lo que la intención de compra resulta en $84.90 \%$.

\section{Figura 2. 1}

Intención de compra

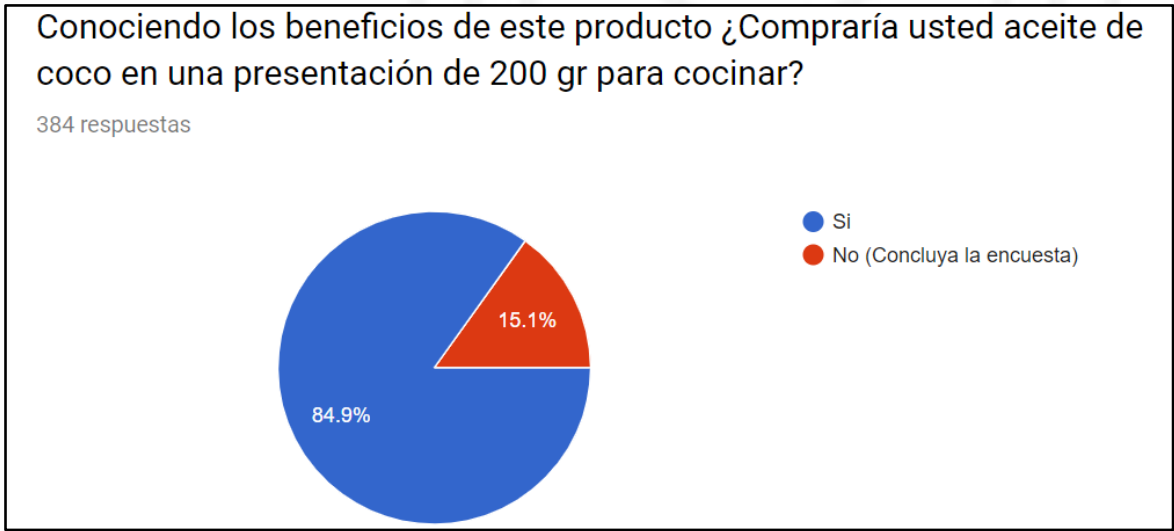

Elaboración propia

Asimismo, se les pidió a las personas encuestadas que respondieron sí, cuantificar del 1 al 10 dicha intención de compra, arrojando una intensidad de 69.05\%. 
Figura 2. 2

Intensidad de compra

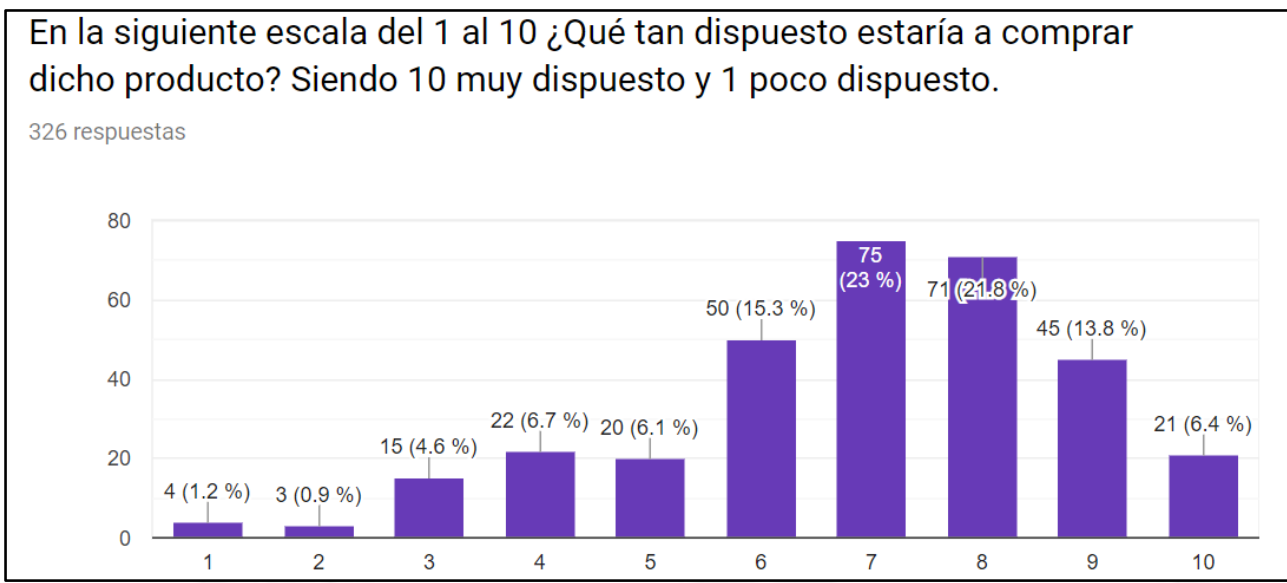

Elaboración propia

\subsubsection{Determinación de la demanda del proyecto}

La DIA hallada anteriormente es multiplicada por la intensidad e intención obtenidos de las encuestas, luego se multiplica por el porcentaje de personas que se encuentran en Lima Metropolitana y por estilo de vida sofisticado, este últimos se considera como el porcentaje del proyecto, para determinar la demanda real.

Tabla 2.12

Demanda del Proyecto

\begin{tabular}{|c|c|c|c|c|c|c|}
\hline Año & $\begin{array}{c}\text { DIA } \\
\text { (TM) }\end{array}$ & \%Encuesta & $\begin{array}{c}\text { \%Lima } \\
\text { Metropolitana }\end{array}$ & $\begin{array}{c}\% \text { Estilo de } \\
\text { Vida }\end{array}$ & $\begin{array}{c}\text { Demanda Proyecto } \\
\text { (TM) }\end{array}$ & $\begin{array}{c}\text { Demanda Proyecto } \\
(\mathrm{Kg})\end{array}$ \\
\hline 2018 & $1,184.84$ & $58.62 \%$ & $31.80 \%$ & $7.00 \%$ & 15.46 & $15,459.17$ \\
\hline 2019 & $2,092.24$ & $58.62 \%$ & $31.80 \%$ & $7.00 \%$ & 27.30 & $27,298.53$ \\
\hline 2020 & $2,860.61$ & $58.62 \%$ & $31.80 \%$ & $7.00 \%$ & 37.32 & $37,323.86$ \\
\hline 2021 & $3,911.16$ & $58.62 \%$ & $31.80 \%$ & $7.00 \%$ & 51.03 & $51,030.97$ \\
\hline 2022 & $5,347.52$ & $58.62 \%$ & $31.80 \%$ & $7.00 \%$ & 69.77 & $69,772.00$ \\
\hline
\end{tabular}

Fuente: INEI (2015) y Arellano (2015) 


\subsubsection{Proyección de la demanda}

Se realizó diferentes ejercicios para proyectar la demanda y finalmente se eligió la prueba con mayor $\mathrm{R}^{2}$.

Figura 2. 3

Tendencia exponencial

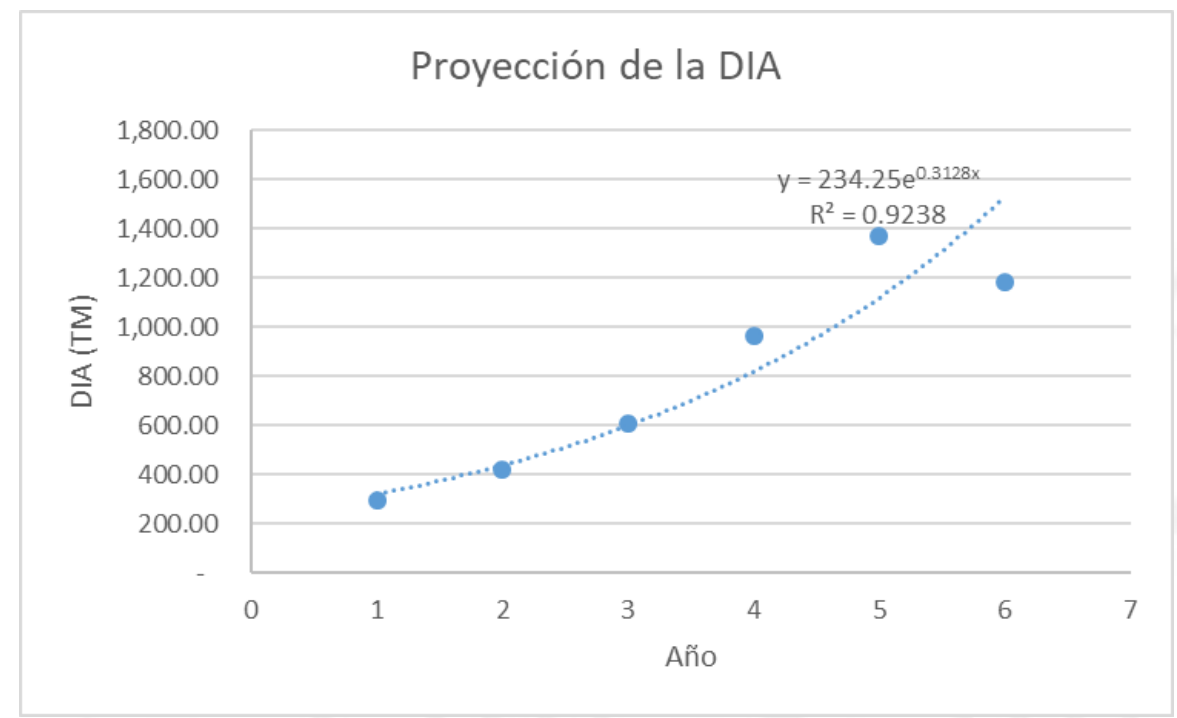

Elaboración propia

Tabla 2. 13

Proyección de la demanda

\begin{tabular}{|l|l|}
\hline Año & DIA (TM) \\
\hline 2018 & $1,184.84$ \\
\hline 2019 & $2,092.24$ \\
\hline 2020 & $2,860.61$ \\
\hline 2021 & $3,911.16$ \\
\hline 2022 & $5,347.52$ \\
\hline
\end{tabular}

Elaboración propia

\subsubsection{Consideraciones sobre la vida útil del proyecto}

La vida útil del proyecto se basa en el porcentaje de depreciación de la maquinaria y equipos, los cuales son los activos fijos más importantes para la elaboración del producto. Estos 
activos se deben depreciar en línea recta en un rango de $10 \%$ a 25\% anual (SUNAT, 2000). De acuerdo a la SUNAT los bienes se depreciarán con el porcentaje que determine el contribuyente, se optó por elegir $20 \%$ de depreciación anual, es decir 5 años de vida útil ya que en el inciso b) del artículo $22^{\circ}$ del Reglamento del Impuesto a la Renta, que posteriormente se modificó, considera este tiempo de vida útil.

En la siguiente tabla se detallarán las depreciaciones de los activos fijo que tendrá el proyecto.

Tabla 2. 14

Depreciación anual

\begin{tabular}{|l|c|}
\cline { 2 - 2 } \multicolumn{1}{c|}{} & Depreciaciones \\
\hline Maquinaria y equipo & $20 \%$ \\
\hline Equipos de procesamiento de datos & $25 \%$ \\
\hline Edificios y construcciones & $5 \%$ \\
\hline Otros activos fijos & $10 \%$ \\
\hline
\end{tabular}

Fuente: Actualidad Empresarial (2014)

\subsection{Análisis de la oferta}

\subsubsection{Empresas productoras, importadoras y comercializadoras}

A continuación se detallarán las principales empresas de aceite de coco.

\section{Tabla 2. 15}

Empresas productoras, importadoras y comercializadoras

\begin{tabular}{|l|l|l|}
\hline Empresas productoras & \multicolumn{1}{|c|}{$\begin{array}{c}\text { Empresas } \\
\text { comercializadoras }\end{array}$} & \multicolumn{1}{|c|}{ Empresas importadoras } \\
\hline Candela Perú & Candela Perú & Consorcio Industrial de Arequipa SA \\
\hline Bioselva S.A.C & Bioselva & Peruvian's Cook S.A.C. \\
\hline La Sanahoria S.A.C. & La Sanahoria & Natural Brands Food S.A.C. \\
\hline Coco Sonqo & Coco Sonqo & Kenex Corporation S.A.C. \\
\hline Naturally Divine & Naturally Divine & Wibgus S.A.C. \\
\hline Gatti & Gatti & \\
\hline
\end{tabular}

Elaboración propia 


\subsubsection{Competidores actuales y potenciales}

En el mercado peruano existen pocas empresas fabricantes de aceite de coco, por lo que se considera como competidores actuales a todas las productoras mencionadas anteriormente.

\section{Competidores potenciales}

En este punto se encuentran las empresas productoras de bienes sustitutos que llevan tiempo en el mercado elaborando variedades de aceite (vegetal, animal, otros), ya que estos tienen la tecnología necesaria para incursionar en la producción de aceite de coco, debido a que la maquinaria que se utiliza en la producción de aceites no es especializada.

En este rubro, se encuentra el mayor competidor potencial la empresa Alicorp quien mantenía el liderazgo con el 51\% del mercado de aceites con sus productos "Primor", “Capri” y "Primor Light" en la línea de aceites vegetales, y "Cocinero" y "Friol” en aceites compuestos (Alicorp, 2010). Además, es una empresa consolidada en el mercado.

\subsection{Determinación de la demanda para el proyecto}

\subsubsection{Segmentación del mercado}

Se segmentará el mercado para definir a dónde y a quiénes va dirigido este producto, así el mercado se dividirá en grupos más específicos para obtener con mayor facilidad el mercado objetivo, el cual ha sido segmentado de acuerdo a una serie de variables que se presentarán a continuación.

Tabla 2. 16

Variable para segmentar el mercado

\begin{tabular}{|l|l|}
\hline Población & Lima Metropolitana \\
\hline Estilo de vida & Sofisticado o afortunado \\
\hline
\end{tabular}

Elaboración propia 


\subsubsection{Selección del mercado meta}

La población del Perú asciende a 31'488,625 personas (Perú 21, 2016) de los cuales 10’012,437 habitantes pertenecen a Lima Metropolitana (APEIM, 2016), que representa el $31.80 \%$ de la población peruana.

Se determinó que la población que lleva un estilo de vida sofisticado optaría por adquirir aceites saludables ya que son consumidores de productos light, innovadores y cazadores de tendencias. Dicho segmento representa un 7\% de la población (Arellano, 2015).

Cabe mencionar que no se aplica directamente la segmentación del NSE A y B, ya que la producción de aceite de oliva utilizada para la determinación de la DIA ya está dirigida a estos sectores. El aceite de oliva es considerado un producto de nicho, son los NSE A y B los que valoran el cuidado y las sofisticación en su alimentación (Superintendencia del Mercado de Valores, 2014).

\subsubsection{Demanda específica para el proyecto}

Tabla 2. 17

Demanda específica para el proyecto

\begin{tabular}{|c|c|}
\hline Año & Demanda específica para el proyecto $(\mathrm{Kg})$ \\
\hline 2018 & $15,459.17$ \\
\hline 2019 & $27,298.53$ \\
\hline 2020 & $37,323.86$ \\
\hline 2021 & $51,030.97$ \\
\hline 2022 & $69,772.00$ \\
\hline
\end{tabular}

Elaboración propia

\subsection{Definición de la Estrategia de Comercialización}

\subsubsection{Políticas de comercialización y distribución}

El producto será comercializado en envases de vidrio de 200 gr de aceite coco debidamente etiquetado con la marca Cocoil. 
Se aplicará la estrategia de distribución intensiva, se ubicará el aceite de coco en el mayor número de puntos de ventas en supermercados, lo cual permite abarcar la mayor cantidad del mercado (Ancín, 2001). Esto facilita al cliente la compra del producto.

Se considerará como único canal de ventas a los supermercados. El precio al consumidor final será de 23 soles (incluye IGV y comisión de ventas 15\%).

Tabla 2. 18

Despliegue del precio

\begin{tabular}{|l|c|}
\hline Sin IGV y sin comisión & 16.95 \\
\hline Comisión (15\%) & 2.54 \\
\hline IGV & 3.51 \\
\hline Precio total & $\mathbf{2 3 . 0 0}$ \\
\hline
\end{tabular}

Elaboración propia

\subsubsection{Publicidad y promoción}

- Producto: El aceite de coco será presentado en un envase de vidrio de 200 gr. agradable a la vista, en él se describirán sus principales propiedades y beneficios con la finalidad de atraer al público objetivo.

- Plaza: Se distribuirá en supermercados, luego se proyectará a bodegas, estaciones de servicio, tiendas y ferias naturistas.

- Promoción: Se utilizarán la redes sociales para dar a conocer el producto y se realizarán degustaciones en supermercados, la cual consiste en ofrecer una muestra de aceite de coco con algún complemento para motivar al cliente a efectuar la compra. Este tipo de promoción es muy efectiva ya que los compradores tienen la posibilidad de probar el producto y decidir en el momento la adquisición del mismo.

- Precio: La estrategia de la empresa será comercializar el producto con un precio bajo o similar al de la competencia para que el producto se posicione en el mercado y capte la atención del mercado. 


\subsubsection{Análisis de precios}

\subsubsection{Tendencia histórica de los precios}

Tabla 2. 19

Tendencia histórica de los precios (Soles por 200 gr)

\begin{tabular}{|c|c|c|c|c|c|}
\hline Año & 2011 & 2012 & 2013 & 2014 & 2015 \\
\hline Aceite de oliva & 10 & 9.5 & 9.7 & 10 & 10.18 \\
\hline
\end{tabular}

Elaboración propia

\subsubsection{Precios actuales}

Para determinar los precios actuales en el mercado de aceite de coco, se realizaron visitas a distintos puntos de venta, como tiendas naturistas y supermercados. Además, para complementar, se consultaron las páginas web de las marcas de aceite que se encontraron.

Tabla 2. 20

Precios de aceite de coco al 2016

\begin{tabular}{|c|c|c|}
\hline Empresa & Cantidad (gr) & Precio (S/.) \\
\hline Candela Perú & 200 & 17.50 \\
\hline La Sanahoria & 200 & 17.70 \\
\hline Coco Sonqo & 200 & 21.64 \\
\hline Bioselva & 200 & 21.64 \\
\hline Diabien & 200 & 23.18 \\
\hline Naturally Divine & 200 & 24.25 \\
\hline Gatti & 200 & 24.80 \\
\hline
\end{tabular}

Elaboración propia

\subsection{Análisis de Disponibilidad de los insumos principales}

\subsubsection{Características principales de la materia prima}

El coco es un fruto exótico de aroma muy tropical cuyos beneficios y propiedades lo convierten en una fruta saludable ya que tiene sustancias nutritivas por contener elevado 
hierro y potasio. Esta fruta proviene del cocotero. Se usa para alimentación, como bebida, como aceite, etc. (Licata, 2016)

Es una fruta de sabor intenso y forma redonda con una capa externa fibrosa y otra capa intermedia con tres orificios en uno de sus extremos. La pulpa contiene aproximadamente $300 \mathrm{ml}$ de agua de coco en el interior por unidad. Cada fruto puede pesar hasta $2.5 \mathrm{Kgs} \mathrm{y}$ medir unos $25 \mathrm{~cm}$. (Licata, 2016). Un fruto no apto para producir copra presenta una epidermis de color uniforme verde amarillo o naranja y al sacudirlo, el agua contenida no hace sonido alguno (Ortega, Reyes, \& Torres, 2005).

Para el proceso de producción del aceite de coco se utilizan los cocos provenientes de cocoteros gigantes ya que el sabor es poco dulce. Este tipo de cocoteros prosperan en todo tipo de suelo y condiciones climáticas (Agricultura Urbana Perú, 2013) .

\subsubsection{Disponibilidad de la materia prima}

Como ya fue mencionado previamente, el coco no es un producto diferenciado y en el Perú existen diversos productores de esta materia prima quienes se podrían considerar como futuros proveedores de Cocoil. La siguiente tabla refleja las toneladas de cosecha de coco a nivel nacional.

Tabla 2. 21

Producción de coco a nivel nacional (Toneladas)

\begin{tabular}{|c|c|}
\hline Años & $\begin{array}{c}\text { Total } \\
\text { Nacional }\end{array}$ \\
\hline 2000 & $21,630.00$ \\
\hline 2001 & $20,939.00$ \\
\hline 2002 & $22,747.00$ \\
\hline 2003 & $22,623.00$ \\
\hline 2004 & $22,918.00$ \\
\hline 2005 & $23,154.00$ \\
\hline 2006 & $22,878.00$ \\
\hline 2007 & $24,724.00$ \\
\hline 2008 & $25,064.00$ \\
\hline 2009 & $23,967.00$ \\
\hline 2010 & $26,654.00$ \\
\hline & (continua)
\end{tabular}


(continuación)

\begin{tabular}{|l|l|}
\hline 2011 & $31,161.00$ \\
\hline 2012 & $33,577.00$ \\
\hline 2013 & $34,593.00$ \\
\hline 2014 & $34,946.00$ \\
\hline 2015 & $34,061.03$ \\
\hline 2016 & $35,055.52$ \\
\hline 2017 & $36,050.01$ \\
\hline 2018 & $37,044.51$ \\
\hline 2019 & $38,039.00$ \\
\hline 2020 & $39,033.49$ \\
\hline 2021 & $40,027.99$ \\
\hline 2022 & $41,022.48$ \\
\hline
\end{tabular}

Fuente: Oficina de Estudios Económicos y Estadísticos (2016)

Para una producción sin interrupciones es necesario que la disponibilidad de materia prima sea mayor al requerimiento de esta. Por lo tanto, para evaluar estos factores se proyecta la producción nacional y se considera un factor para estimar el requerimiento de materia prima hasta el último año de la vida útil del proyecto. La relación teórica de producto terminado y coco es de 1:3 respectivamente (Rivera, Lomeli, Roman, \& Vera, 2001).

Figura 2. 4

Tendencia polinómica

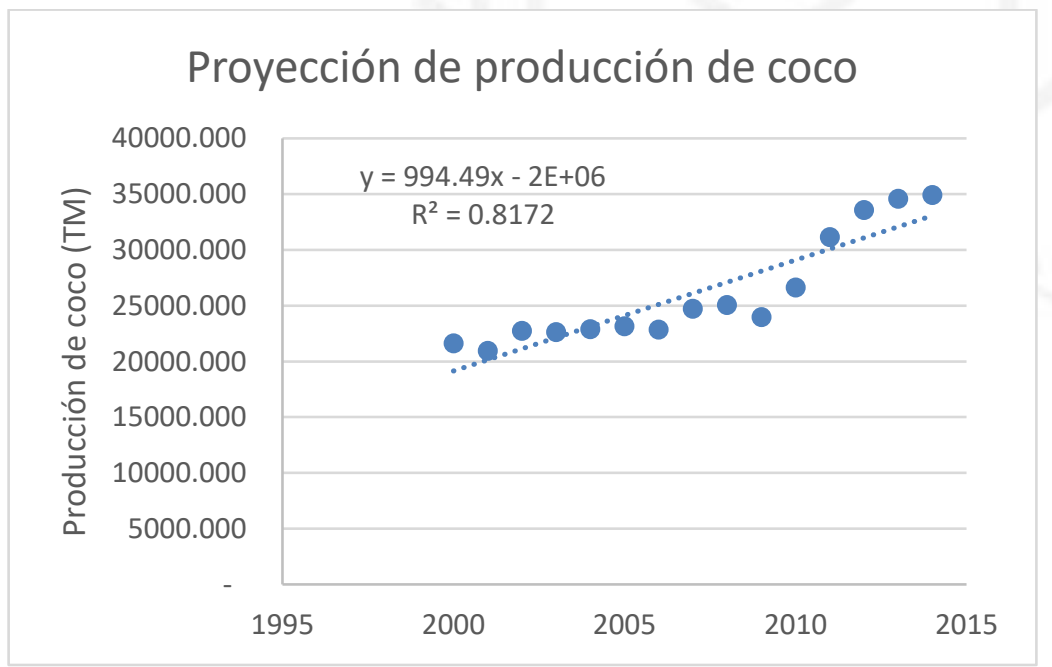

Elaboración propia 
Tabla 2.22

Proyección de producción de coco

\begin{tabular}{|r|r|}
\hline \multicolumn{1}{|c|}{ Años } & Total Nacional \\
\hline 2018 & $37,044.51$ \\
\hline 2019 & $38,039.00$ \\
\hline 2020 & $39,033.49$ \\
\hline 2021 & $40,027.99$ \\
\hline 2022 & $41,022.48$ \\
\hline
\end{tabular}

Elaboración propia

Tabla 2. 23

Requerimiento de materia prima

\begin{tabular}{|c|c|c|}
\hline Año & Producción del Proyecto $(\mathrm{Kg})$ & $\begin{array}{c}\text { Requerimiento } \\
\text { de MP }(\mathrm{Kg})\end{array}$ \\
\hline 2018 & $15,756.60$ & $46,312.00$ \\
\hline 2019 & $27,526.20$ & $80,905.36$ \\
\hline 2020 & $37,516.80$ & $110,269.86$ \\
\hline 2021 & $51,294.60$ & $150,765.75$ \\
\hline 2022 & $68,790.60$ & $202,190.21$ \\
\hline
\end{tabular}

Elaboración propia

En conclusión, la demanda del proyecto durante su vida útil requiere cantidades menores con respecto a la disponibilidad de la materia prima en el país, por lo que no se considera un factor limitante del proyecto para la producción del aceite.

\subsubsection{Costos de la materia prima}

Se toma como referencia los precios publicados en la página web del Gran Mercado Mayorista de Lima. El costo del coco en promedio se encuentra en S/ 1.50 por unidad. Para cálculos del proyecto se toma en cuenta valores en kilos, por lo tanto, al considerar que un coco pesa alrededor de 1.5 kilos la unidad, el kilo de coco costaría S/ 1.00. Además, se considera un costo adicional por transporte de $20 \%$ por kilo. 


\section{CAPÍTULO III. LOCALIZACIÓN DE PLANTA}

\subsection{Identificación y análisis detallado de los factores de localización}

En el siguiente capítulo, se analizarán una serie de factores con el fin de determinar la macro y micro localización de la planta. Luego, se utilizará el método de Ranking de Factores para cuantificar la importancia de cada uno para así obtener la mejor localización de la planta.

Tabla 3.1

Factores de marco localización

\begin{tabular}{|c|l|}
\hline A & Producción de materia prima \\
\hline B & Cercanía al mercado objetivo \\
\hline C & Disponibilidad de carreteras pavimentadas \\
\hline D & Costo de electricidad \\
\hline E & Costo de agua \\
\hline
\end{tabular}

Elaboración propia

Tabla 3.2

Factores de micro localización

\begin{tabular}{|l|l|}
\hline A & Cercanía al mercado objetivo \\
\hline B & Nivel de seguridad \\
\hline C & Costo del terreno \\
\hline
\end{tabular}

Elaboración propia

\subsection{Identificación y descripción de las alternativas de localización}

Para la macro localización se eligieron los departamentos de Loreto, San Martin y Lima. Los dos primeros fueron seleccionados principalmente por ser los mayores productores de la materia prima principal y el último porque en Lima es donde se encuentra el mercado objetivo.

Para la micro localización se seleccionaron los distritos de Lurín, Ancón y Santa Anita, los cuales son reconocidas zonas industriales accesibles para el proyecto. 


\subsection{Evaluación y selección de localización}

\subsubsection{Evaluación y selección de la macro localización}

\section{A. Producción de materia prima}

En la siguiente tabla se detallarán los departamentos con sus respectivas producciones de coco.

Tabla 3.3

Producción de coco por departamentos (Toneladas)

\begin{tabular}{|c|c|}
\hline Departamento & Producción \\
\hline San Martín & $16,569.00$ \\
\hline Loreto & $8,854.00$ \\
\hline Lima & 0.00 \\
\hline
\end{tabular}

Fuente: Oficina de Estudios Económicos y Estadísticos, OEEE. (2016)

\section{B. Cercanía al mercado objetivo}

El mercado objetivo es Lima Metropolitana, por lo que este factor comprende las distancias hacia Lima desde las tres opciones de departamentos que se eligieron.

Tabla 3.4

Distancias a Lima

\begin{tabular}{|c|c|}
\hline Departamento & Distancia $(\mathrm{Km})$ hacia Lima \\
\hline Loreto & $922 \mathrm{~km}$ (solo vía área) \\
\hline San Martín & 763 \\
\hline Lima & 0 \\
\hline
\end{tabular}

Fuente: Google Maps (2016)

\section{Disponibilidad de carreteras pavimentadas}

El acceso a carreteras pavimentadas es importante para facilitar el transporte de materia prima, insumos y productos terminado. Para así, optimizar el tiempo de viaje y minimizar los costos. 
Tabla 3.5

Kilómetros totales de carretera pavimentada por departamento

\begin{tabular}{|l|r|r|r|r|}
\cline { 2 - 5 } \multicolumn{1}{c|}{} & Nacional & Departamental & \multicolumn{1}{l|}{ Vecinal } & \multicolumn{1}{l|}{ Total } \\
\hline Lima & 1,180 & 123 & 174 & 1,477 \\
\hline Loreto & 43 & 109 & 19 & 171 \\
\hline San Martin & 697 & 150 & - & 847 \\
\hline
\end{tabular}

Fuente: Ministerio de Transporte y Comunicaciones (2014)

\section{Costo de electricidad}

La electricidad es una fuente de energía indispensable para el funcionamiento de la planta, por lo que se necesita que haya disponibilidad continua de esta durante toda la vida útil del proyecto. Además, el costo de este servicio se debe tener en cuenta porque afecta al costo de producción.

En la siguiente tabla se detalla la tarifa no residencial promedio de cada alternativa de localización.

Tabla 3.6

Tarifa de luz por departamento

\begin{tabular}{|c|c|c|c|}
\hline Departamento & Lima & San Martin & Loreto \\
\hline Tarifa (Cent/KW.h) & 47.96 & 61.95 & 55.73 \\
\hline
\end{tabular}

Fuente: Luz del Sur (2018)

\section{E. Costo de agua}

Analizar el costo del agua es necesario, ya que es un importe significativo a considerar, influye en el costo de producción y es indispensable contar con un caudal constante durante el tiempo de producción para el proceso de lavado y otras actividades cotidianas, con el fin de evitar contratiempos y demoras.

Tabla 3.7

Tarifa de agua por departamento

\begin{tabular}{|l|c|c|c|}
\hline Departamento & Lima & San Martin & Loreto \\
\hline Tarifa (Soles/m3) & 4.86 & 2.17 & 2.66 \\
\hline
\end{tabular}

Fuente: Sedapal (2018), Sedaloreto (2016), Emapa San Martín (2014) 


\section{Selección de la macro localización}

Tabla 3.8

Tabla de enfrentamiento para macro localización

\begin{tabular}{|c|c|c|c|c|c|c|r|}
\cline { 2 - 8 } \multicolumn{1}{c|}{} & A & B & C & D & E & Puntaje & Valoración \\
\hline A & & 0 & 1 & 1 & 1 & 3 & 0.27 \\
\hline B & 1 & & 1 & 1 & 1 & 4 & 0.36 \\
\hline C & 0 & 0 & & 1 & 1 & 1 & 0.18 \\
\hline D & 0 & 0 & 0 & & 1 & 1 & 0.09 \\
\hline E & 0 & 0 & 0 & 1 & Total & 11 & 0.09 \\
\hline
\end{tabular}

Elaboración propia

Tabla 3.9

Ranking de factores para la macro localización

\begin{tabular}{|c|c|c|c|c|c|c|c|}
\cline { 3 - 9 } \multicolumn{2}{c|}{} & \multicolumn{2}{c|}{ Loreto } & \multicolumn{2}{c|}{ San Martín } & \multicolumn{2}{c|}{ Lima } \\
\hline Factor & Ponderación & Calificación & Puntaje & Calificación & Puntaje & Calificación & Puntaje \\
\hline A & 27.27 & 4 & 109.1 & $\mathbf{6}$ & 163.6 & 2 & 54.5 \\
\hline B & 36.36 & 2 & 72.7 & 2 & 72.7 & $\mathbf{6}$ & 218.2 \\
\hline C & 18.18 & 2 & 36.4 & 4 & 72.7 & $\mathbf{6}$ & 109.1 \\
\hline D & 9.09 & 4 & 36.4 & 2 & 18.2 & $\mathbf{6}$ & 54.5 \\
\hline E & 9.09 & $\mathbf{6}$ & 54.5 & $\mathbf{6}$ & 54.5 & 2 & 18.2 \\
\hline
\end{tabular}

Elaboración propia

Tabla 3. 10

Escala de clasificación

\begin{tabular}{|ll|l|}
\hline \multicolumn{2}{|c|}{ Escala de calificación } \\
\hline$\cdot \quad$ Excelente & 6 \\
\hline$\cdot \quad$ Bueno & 4 \\
\hline$\cdot \quad$ Deficiente & 2 \\
\hline
\end{tabular}

Elaboración propia

De acuerdo a los resultados obtenidos en la tabla de ranking de factores, el departamento de Lima obtuvo el mayor puntaje. Por lo tanto, dicha alternativa será elegida para la macro localización de la planta. 


\subsubsection{Evaluación y selección de la micro localización}

\section{A. Cercanía al mercado objetivo}

Para determinar la cercanía al mercado objetivo se considerará un centro de gravedad desde la zona 7 (Miraflores, San Isidro, San Borja, Surco, La Molina) hacia las diferentes alternativas de localización. En la figura se puede observar que la alternativa más cercana a la zona 7 es Santa Anita, seguido por Lurín y Ancón.

Figura 3. 1

Centro de gravedad zona 7

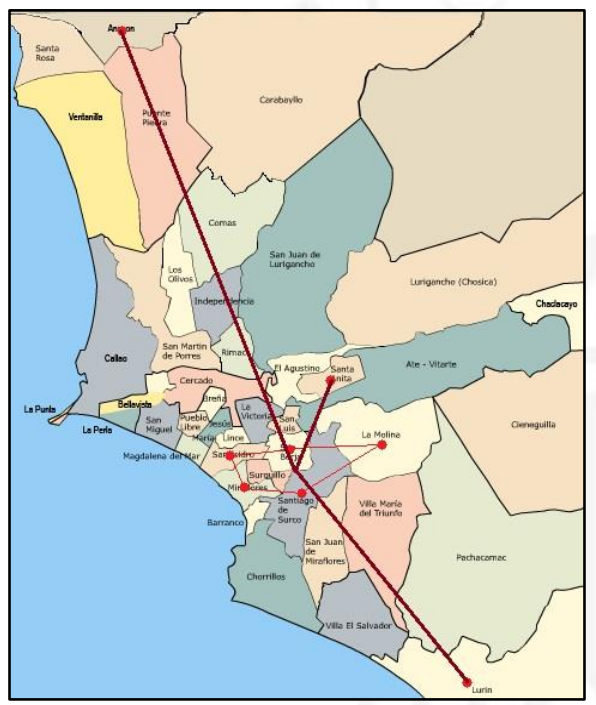

Fuente: Expat (2010)

\section{B. Nivel de seguridad}

Es un factor de relativa importancia que se debe tomar en cuenta. Se analizará el número de denuncias por robo y hurto en cada una de las alternativas de localización.

\section{Tabla 3. 11}

Número de denuncias por robo y hurto

\begin{tabular}{|c|c|}
\hline Distrito & Número de denuncias \\
\hline Santa Anita & 1,776 \\
\hline Ancón & 411 \\
\hline Lurín & 169 \\
\hline
\end{tabular}

Fuente: IDL (2014) 


\section{Costo de Terreno}

El costo del terreno es el factor más importante de todos ya que es absolutamente necesario alquilarlo o comprarlo, lo más óptimo sería buscar el costo más bajo posible ya que genera una importante salida de dinero. En este punto se analizarán los terrenos disponibles y habilitados para la construcción.

Tabla 3.12

Costo de terrenos por $\mathrm{m} 2$

\begin{tabular}{|c|c|}
\hline Distrito & Costo en dólares \\
\hline Ancón & $80-200$ \\
\hline Santa Anita & $1200-1300$ \\
\hline Lurín & $100-300$ \\
\hline
\end{tabular}

Fuente: Urbania (2016)

\section{Selección de la micro localización}

Tabla 3.13

Puntaje y valoración para la micro localización

\begin{tabular}{|c|c|c|c|c|c|}
\hline & A & $\mathrm{B}$ & $\mathrm{C}$ & Puntaje & Valoración \\
\hline A & 3 & 1 & 1 & 2 & 0.50 \\
\hline $\mathrm{B}$ & 0 & - & 1 & 1 & 0.25 \\
\hline $\mathrm{C}$ & 0 & 1 & 3 & 1 & 0.25 \\
\hline & & & Total & 4 & \\
\hline
\end{tabular}

Elaboración propia

Tabla 3. 14

Ranking de factores para la micro localización

\begin{tabular}{|c|c|c|c|c|c|c|c|}
\cline { 3 - 8 } \multicolumn{2}{c|}{} & \multicolumn{2}{c|}{ Ancón } & \multicolumn{2}{c|}{ Santa Anita } & \multicolumn{2}{c|}{ Lurín } \\
\hline Factor & Valoración & Puntaje & Ponderación & Puntaje & Ponderación & Puntaje & Ponderación \\
\hline A & 50.0 & 2 & 100.0 & 6 & 300.0 & 4 & 200.0 \\
\hline B & 25.0 & 4 & 100.0 & 2 & 50.0 & 6 & 150.0 \\
\hline C & 25.0 & 6 & 150.0 & 2 & 50.0 & 6 & 150.0 \\
\hline
\end{tabular}

Elaboración propia 
De acuerdo a los resultados obtenidos en la tabla de ranking de factores, Lurín obtiene el mayor puntaje frente a las otras dos alternativas. Por lo tanto, será el lugar elegido para la localización de la planta. 


\section{CAPÍTULO IV. TAMAÑo DE PLANTA}

\subsection{Relación tamaño-mercado}

La demanda del proyecto definida en el capítulo II de estudio de mercado representa un limitante para determinar el tamaño de planta requerido. Por lo tanto, se toma el valor de la demanda del último año (2022) del proyecto la cual asciende a 69,772.00 kg de producto terminado.

\subsection{Relación tamaño-recursos productivos}

Para determinar la relación tamaño-recurso productivo, se toma en cuenta la disponibilidad de materia prima y de mano de obra. Sin embargo, este último no se considera limitante para el desarrollo del proyecto.

Respecto a la materia prima, se dispone de 41,022.48 toneladas de coco para el año 2022, además la relación teórica de producto terminado y coco es de 1:3 respectivamente (Rivera, Lomeli, Roman, \& Vera, 2001). Así pues, al multiplicar ambos valores se obtiene como resultado una producción máxima de 14,357,867.83 kg de aceite de coco.

Dicho valor supera la demanda máxima del proyecto, por lo tanto, se concluye que este factor no representa una limitante, pues se dispone de materia prima suficiente para la elaboración del producto a lo largo del proyecto.

\subsection{Relación tamaño-tecnología}

Para el proceso de producción de aceite de coco se optó por el método de extracción por prensado en frío, lo cual permite mantener todas las propiedades del coco.

A continuación, se presenta la capacidad de la planta que se obtiene utilizando el método previamente mencionado. 
Tabla 4. 1

Capacidad de la planta (Kg/año)

\begin{tabular}{|c|c|c|c|c|c|c|c|c|c|}
\hline Máquina u Operación & $\begin{array}{l}\text { Cantidad a procesar } \\
\qquad(\mathrm{Kg} / \mathrm{h})\end{array}$ & $\begin{array}{l}\text { Capacidad } \\
(\mathrm{kg} / \mathrm{h})\end{array}$ & Cantidad & H/Turno & Turno/día & Día/semana & Semana/año & $\mathrm{F}$ & $\begin{array}{c}\text { Capacidad } \\
\text { de planta } \\
\text { (kg/año) }\end{array}$ \\
\hline Descascarador & 99.00 & 150.00 & 1.00 & 8.00 & 1.00 & 5.00 & 52.00 & 0.34 & $106,257.13$ \\
\hline Lavadora & 64.35 & 600.00 & 1.00 & 8.00 & 1.00 & 5.00 & 52.00 & 0.52 & $653,890.02$ \\
\hline Deshidratador & 47.30 & 120.00 & 1.00 & 8.00 & 1.00 & 5.00 & 52.00 & 0.71 & $177,929.26$ \\
\hline Molino & 45.41 & 479.00 & 1.00 & 8.00 & 1.00 & 5.00 & 52.00 & 0.74 & $739,827.38$ \\
\hline Prensa & 43.59 & 80.00 & 1.00 & 8.00 & 1.00 & 5.00 & 52.00 & 0.77 & $128,710.40$ \\
\hline Filtro prensa & 37.05 & 130.00 & 1.00 & 8.00 & 1.00 & 5.00 & 52.00 & 0.91 & $246,064.00$ \\
\hline Bomba & 37.05 & $2,037.96$ & 1.00 & 8.00 & 1.00 & 5.00 & 52.00 & 0.91 & $3,857,450.69$ \\
\hline Envasadora tapadora & 33.72 & 400.00 & 1.00 & 8.00 & 1.00 & 5.00 & 52.00 & 1.00 & $832,000.00$ \\
\hline Inspeccionar y seleccionar & 99.10 & 180.00 & 1.00 & 8.00 & 1.00 & 5.00 & 52.00 & 0.34 & $127,381.05$ \\
\hline Cortar & 63.07 & 135.00 & 1.00 & 8.00 & 1.00 & 5.00 & 52.00 & 0.53 & $150,127.81$ \\
\hline Verificar humedad & 45.41 & 90.00 & 1.00 & 8.00 & 1.00 & 5.00 & 52.00 & 0.74 & $139,007.23$ \\
\hline Control de calidad & 33.72 & 70.00 & 1.00 & 8.00 & 1.00 & 5.00 & 52.00 & 1.00 & $145,600.00$ \\
\hline Etiquetar & 33.72 & 60.00 & 1.00 & 8.00 & 1.00 & 5.00 & 52.00 & 1.00 & $124,800.00$ \\
\hline Encajonar & 33.72 & 72.00 & 1.00 & 8.00 & 1.00 & 5.00 & 52.00 & 1.00 & $149,760.00$ \\
\hline
\end{tabular}

Elaboración propia 
Se puede observar de la anterior tabla que el tamaño-tecnología es mayor que la demanda del proyecto, por lo tanto no restringe ya que la tecnología utilizada es suficiente para la producción del producto.

\subsection{Relación tamaño-inversión}

Para determinar el tamaño-inversión se considera el capital de trabajo, los activos fijos tangibles e intangibles requeridos para la planta productora de aceite de coco. Este valor asciende a 1'262,177.60 soles, dato que se detalla en el capítulo 7.1.

\subsection{Relación tamaño-punto de equilibrio}

Para el cálculo del punto de equilibrio se consideró la siguiente fórmula.

$$
P E=\frac{\text { Costos y gastos fijos }}{\text { Margen de contribución unitario }}
$$

Tabla 4.2

Punto de equilibrio

\begin{tabular}{|c|c|r|r|r|r|}
\multicolumn{2}{|l|}{} & & $\begin{array}{c}\text { Punto de } \\
\text { equilibrio } \\
\text { (Kg) }\end{array}$ & $\begin{array}{c}\text { Punto de } \\
\text { equilibrio } \\
\text { (Envases) }\end{array}$ \\
\hline $\begin{array}{c}\text { Costos fijos (S/.) } \\
\text { Margen de } \\
\text { contribución } \\
\text { unitario (S/./kg) }\end{array}$ & Precio unitario (S/. /Envase) & 16.95 & & \\
\cline { 2 - 3 } & Costo variable unitario (S/./Envases) & 1.86 & 15.09 & $\mathbf{1 5 , 9 8 7 . 9 8}$ & $\mathbf{7 9 , 9 3 9 . 9 0}$ \\
\hline
\end{tabular}

Elaboración propia

Tabla 4.3

Costos y gastos fijos

\begin{tabular}{|l|r|}
\hline \multicolumn{2}{|c|}{ Costos y gastos fijos (S/) } \\
\hline Planillas & $995,127.47$ \\
\hline Servicios de comunicaciones & $1,798.80$ \\
\hline Otros gastos & $156,400.00$ \\
\hline Servicios no fabriles de luz y agua & $3,260.24$ \\
\hline Depreciación & $50,009.57$ \\
\hline
\end{tabular}

Elaboración propia 


\subsection{Selección del tamaño de planta}

Tabla 4.4

Relación comparativa de tamaños de planta

\begin{tabular}{|c|r|c|}
\hline Relación & Cantidad & Unidades \\
\hline Tamaño - Mercado & $69,772.00$ & $\mathrm{Kg}$ \\
\hline Tamaño - Recursos productivos & $14,357,867.83$ & $\mathrm{Kg}$ \\
\hline Tamaño - Tecnología & $106,257.13$ & $\mathrm{Kg}$ \\
\hline Tamaño - Punto de equilibrio & $15,987.98$ & $\mathrm{Kg}$ \\
\hline Tamaño - Inversión & $1,262,177.60$ & Soles \\
\hline
\end{tabular}

Elaboración propia

De acuerdo a los tamaños analizados anteriormente se concluye que el factor limitante es el Tamaño - Mercado, el cual asciende a 69,772.00 Kg. 


\section{CAPÍTULO V. INGENIERÍA DEL PROYECTO}

\subsection{Definición técnica del producto}

\subsubsection{Especificaciones técnicas del producto}

Tabla 5. 1

Definición técnica del producto

\begin{tabular}{|c|c|c|}
\hline $\begin{array}{l}\text { Nombre del } \\
\text { producto }\end{array}$ & & Aceite de coco \\
\hline Descripción & $\begin{array}{l}\text { El aceite } \\
\text { Contien }\end{array}$ & $\begin{array}{l}\text { egetal de color blanco particularmente dulce e hidratante. } \\
\text { e ácido láurico hasta en un } 50 \% \text {. (CCM Salud, 2015) }\end{array}$ \\
\hline \multirow{5}{*}{$\begin{array}{l}\text { Características } \\
\text { física }\end{array}$} & Aspecto & Cremoso \\
\hline & Color & Blanco \\
\hline & Olor & Característico \\
\hline & Sabor & Agradable y dulce \\
\hline & Textura & Suave y acuosa \\
\hline $\begin{array}{l}\text { Características } \\
\text { químicas }\end{array}$ & \multicolumn{2}{|c|}{$\begin{array}{l}\text { Acidez: máximo } 0.15 \% \\
\text { pH: } 5\end{array}$} \\
\hline Conservación & \multicolumn{2}{|c|}{$\begin{array}{l}\text { A partir de los } 22 \text { - } 24 \text { grados centígrados el aceite de coco se vuelve líquido, mientras } \\
\text { que, por debajo de esta temperatura, será sólido. Se recomienda condiciones de } \\
\text { almacenamiento y distribución a temperatura ambiente o baja refrigeración para } \\
\text { conservar la calidad del producto. Asimismo, se debe proteger de la luz solar directa y se } \\
\text { recomienda guardar los frascos tapados. }\end{array}$} \\
\hline $\begin{array}{l}\text { Diseño del } \\
\text { producto }\end{array}$ & \multicolumn{2}{|c|}{$\begin{array}{l}\text { La marca "Cocoil" presenta el producto, aceite coco, en un envase de vidrio con } \\
\text { capacidad de } 200 \text { gr. Además, contará con información básica de las certificaciones del } \\
\text { producto. Es un producto de consumo directo con un tiempo de vida máximo de } 2 \text { años. }\end{array}$} \\
\hline
\end{tabular}

Fuente: El aceite de coco (2015) 


\subsubsection{Composición del producto}

El aceite de coco se compone de grasas saturadas en un porcentaje superior a las monoinsaturadas y poliinsaturadas. A continuación, se muestra la composición de 100 gramos de aceite de coco.

Tabla 5.2

Composición del aceite de coco.

\begin{tabular}{|c|c|}
\hline Calorías & $862 \mathrm{Kcal}$ \\
\hline Agua & 0 \\
\hline Proteínas & 0 \\
\hline Hidratos de Carbono & 0 \\
\hline Grasas & $100 \mathrm{gr}$ \\
\hline \multicolumn{2}{|l|}{ de las cuales } \\
\hline Saturadas & $86.5 \mathrm{gr}$ \\
\hline Ácido láurico & $44.6 \mathrm{gr}$ \\
\hline Ácido mirístico & $16.8 \mathrm{gr}$ \\
\hline Ácido palmítico & $8.2 \mathrm{gr}$ \\
\hline Ácido caprílico & $7.5 \mathrm{gr}$ \\
\hline Ácido cáprico & $6 \mathrm{gr}$ \\
\hline Ácido esteárico & $2.8 \mathrm{gr}$ \\
\hline Ácido caproico & $0.6 \mathrm{gr}$ \\
\hline Mono insaturadas & $5.8 \mathrm{gr}$ \\
\hline Ácido oleico & $5.8 \mathrm{gr}$ \\
\hline Poliinsaturadas & $1.8 \mathrm{gr}$ \\
\hline Ácido linoleico & $1.8 \mathrm{gr}$ \\
\hline Hierro & $0.04 \mathrm{mg}$ \\
\hline Vitamina $\mathbf{E}$ & $0.09 \mathrm{mg}$ \\
\hline Vitamina $\mathrm{K}$ & $0.5 \mathrm{ug}$ \\
\hline
\end{tabular}

Fuente: El aceite de coco (2015) 


\subsubsection{Diseño gráfico del producto}

Figura 5. 1

Vista frontal del producto

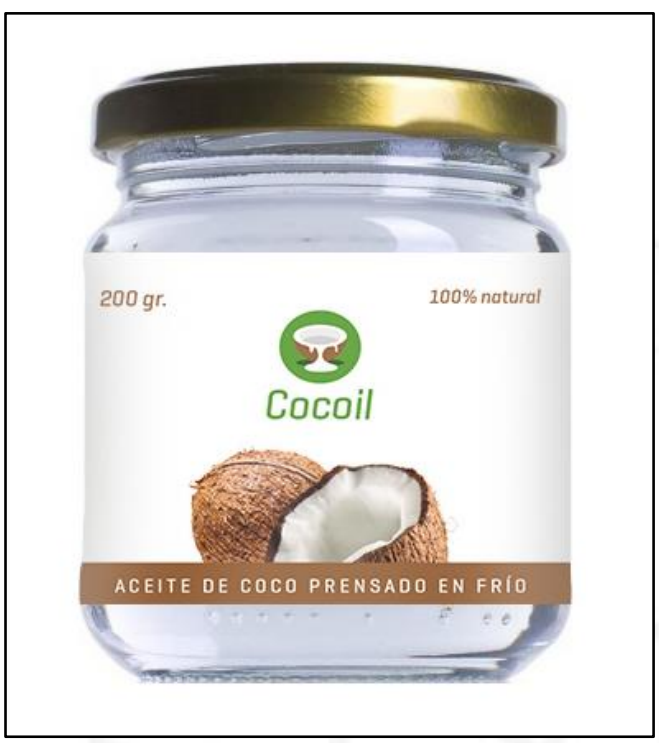

Elaboración propia

Figura 5.2

Vista trasera del producto

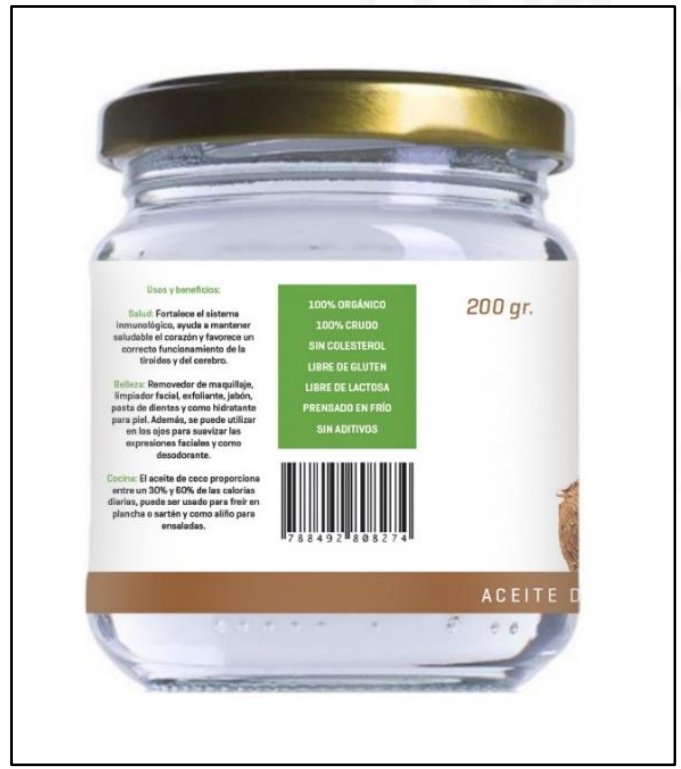

Elaboración propia 
Figura 5.3

Etiqueta referencial del producto

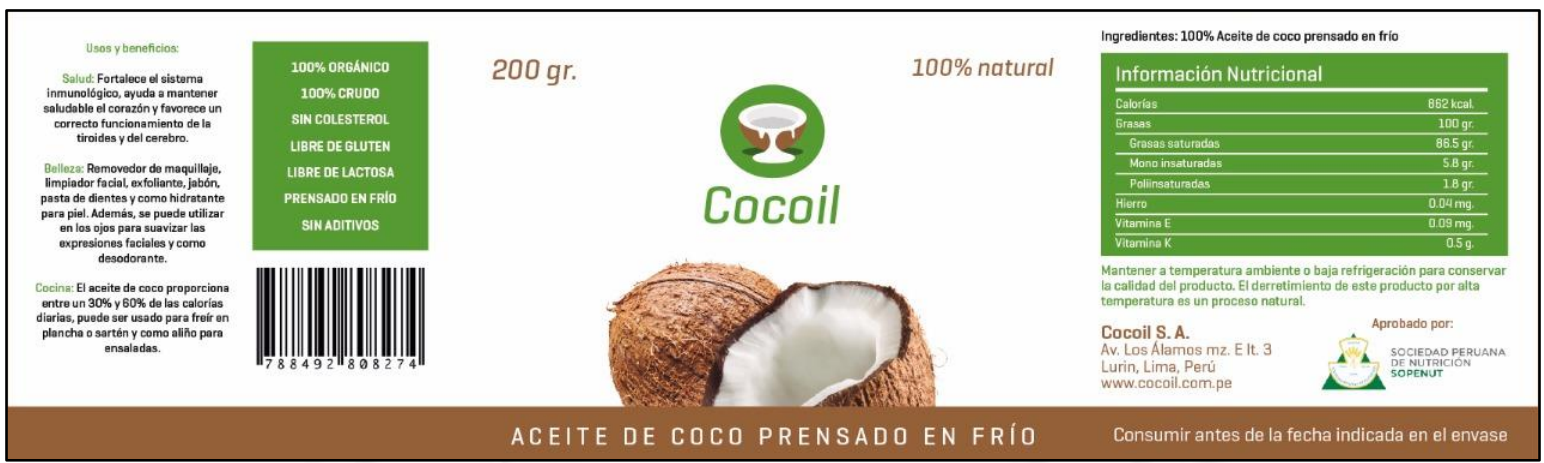

Elaboración propia

\subsubsection{Regulaciones técnicas al producto}

Dentro del marco regulatorio en el Perú se encuentran las normas técnicas, que son un conjunto de políticas que establecen procedimientos y mecanismos para crear un clima laboral apropiado para el desarrollo de cualquier negocio para cualquier ámbito, así como también garantizar la calidad y seguridad del producto (INDECOPI, 2010). En el caso del aceite de coco, se encuentran tres normas técnicas asociadas al producto.

Tabla 5.3

Norma Técnica Peruana

\begin{tabular}{|c|l|l|}
\hline NTP & \multicolumn{1}{|c|}{ Nombre } & \multicolumn{1}{|c|}{ Descripción } \\
\hline 209.247: 1986 & $\begin{array}{l}\text { Aceites y grasas comestibles. Aceite de } \\
\text { coco comestible }\end{array}$ & $\begin{array}{l}\text { Establece los requisitos que debe cumplir el } \\
\text { aceite de coco comestible. }\end{array}$ \\
\hline 350.033: 1974 & $\begin{array}{l}\text { Tapas para envases. Requisitos y método } \\
\text { de inspección de tapas roscada. }\end{array}$ & $\begin{array}{l}\text { Establece los requisitos y el método que se } \\
\text { emplea para la inspección de las tapas roscadas, } \\
\text { para los envases cuyas bocas corresponden a } \\
\text { este tipo de tapas. }\end{array}$ \\
\hline 209.038: 2009. & Alimentos envasados. Etiquetado. & $\begin{array}{l}\text { Establece la información que debe llevar todo } \\
\text { alimento envasado destinado al consumo } \\
\text { humano. }\end{array}$ \\
\hline
\end{tabular}

Fuente: INDECOPI (2010) 
De forma obligatoria se tiene la Ley de Inocuidad de los Alimentos (DL 1062), la cual tiene como objetivo garantizar la inocuidad de los alimentos destinados al consumo humano, a lo largo de toda la cadena alimentaria (Congerso de la República del Perú, 2008). De la misma forma, el producto debe contar con ciertas regulaciones impuestas por DIGESA, por esto contará con un registro sanitario.

\subsection{Tecnologías existentes y procesos de producción}

\subsubsection{Naturaleza de la tecnología requerida}

\subsubsection{Descripción de las tecnologías existentes}

\section{Obtención de aceite de coco mediante disolvente químico}

Este método es aplicable para la industria alimentaria, farmacéutica y de tratamiento de minerales. Tiene por objetivo extraer el aceite de coco, se emplea como agente disolvente el hexano.

La extracción del aceite se da en dos etapas, en la primera se realiza el contacto del hexano con el sólido para que se disuelva el componente soluble y en la segunda se separa la disolución del resto del sólido. El porcentaje de aceite de coco extraído con hexano es $74 \%$ con respecto a la copra ingresada. Algunos factores a tomar en cuenta en este método son el tipo de disolvente a utilizar, la temperatura, el tamaño de partícula y la agitación (Barrios, Nunes, \& Velasquez, 2015).

La extracción a través de disolventes tiene importantes desventajas porque necesita de periodos de tiempo extensos. Además, los productos logrados presentan partículas de los disolventes usados. (Luna, Palou, \& López, 2009).

\section{Extracción por prensado en caliente}

La copra molida se calienta (aproximadamente $70^{\circ} \mathrm{C}$ ) antes de ser exprimida, de esta forma se obtiene más aceite. Luego, se filtra para obtener un aceite puro y se procede a refinar y blanquear para que pueda ser usado en la industria de alimentos. Sin embrago, mediante este 
método se destruye una parte de las vitaminas y fitoesteroles que forman parte del aceite (Grasas y Aceites Vegetales, 2014).

\section{Extracción por prensado en frío}

En este proceso se logra menos aceite. La copra molida es exprimida a temperatura ambiente para que contenga más vitaminas y fitoesteroles.

El aceite obtenido por prensado en frío no necesita ser refinando a diferencia del obtenido por prensado en caliente. Gracias a ello sufre una menor pérdida de vitaminas y fiotosteroles (Grasas y Aceites Vegetales, 2014).

\subsubsection{Selección de la tecnología}

De acuerdo a lo descrito anteriormente, se optará por obtener el aceite mediante la extracción por prensado en frío. Ya que, gracias a este método, se obtiene un producto terminado rico en vitaminas y fitoesteroles en comparación con el prensado en caliente. Además, su operación es relativamente sencilla y baja en costos a diferencia de la extracción con solventes químicos.

\subsubsection{Proceso de producción}

\subsubsection{Descripción del proceso}

A continuación, se detalla el proceso de producción del aceite de coco a través de la extracción por prensado en frío.

\section{Inspección y selección de la materia prima}

En esta primera etapa, el coco es pesado y se verifica que sea apto para producir copra. Un fruto no apto para producir copra, presenta una epidermis de color uniforme verde, amarillo o naranja y al sacudirlo, el agua contenida no hace sonido alguno (Ortega, Reyes, \& Torres, 2005). Los frutos no aptos (aproximadamente 0.1\%) son desechados. 


\section{Descascarado y lavado}

En la zona de descascarado, los cocos ingresan a una máquina de corte de fibra donde se retira toda la cáscara fibrosa, la cual representa el 35\% del peso del coco (Ortega, Reyes, \& Torres, 2005). Luego, el fruto descascarado, es decir la carne del coco, ingresa a la máquina de lavado, mediante una faja trasportadora, para retirar cualquier tipo de residuos e impurezas.

\section{Corte y deshumedecido}

Seguido al lavado, el fruto limpio se corta por la mitad y se retira el agua de coco la cual representa el 25\% del peso del coco (Ortega, Reyes, \& Torres, 2005). Luego, el fruto será deshumedecido para llegar a niveles mínimos de humedad y así, lograr obtener la copra. Para comprobar la efectividad del proceso, se hace una verificación de color y humedad. Esta actividad consiste en medir el nivel de humedad (6-7\%) mediante la balanza de humedad y visualizar que la copra se haya tornado a un color oscuro. En caso no cumpla con la humedad requerida, la copra es ingresada nuevamente al deshidratador.

\section{Molienda y prensado}

A continuación, la copra ingresa al molino de bolas, mediante una faja transportadora, para reducir el tamaño de las partículas. Luego, la copra triturada es transportada mediante un tornillo sinfín a la prensa para obtener así el aceite, después, debe ser filtrado mediante un filtro prensa para retirar los residuos e impurezas. El aceite será transportado hacia el filtro mediante tuberías enchaquetadas.

\section{Control de calidad y envasado}

Finalmente, una muestra del producto pasa por un control de calidad donde se verifica que cumpla con los requisitos técnicos tales como nivel de acidez, $\mathrm{pH}$, color, y olor. En caso no cumplir con alguna característica especificada, se reprocesa. Luego el producto es elevado, mediante una bomba, hacia el tanque de almacenamiento en tránsito. Una vez en el tanque, 
el producto desciende hacia la envasadora tapadora. En seguida los frascos se etiquetan, luego se procede a encajonar en 12 unidades de 200 gramos y se almacena en un lugar a temperatura ambiente donde no tenga contacto directo con la luz solar. Es necesario mencionar que no se añadirán conservantes químicos al producto final ya que es importante para el consumidor que el producto no tenga ninguna alteración artificial. Cabe mencionar que desde el envasado hasta el encajonado el producto será transportado mediante una faja transportadora, la cual tiene una balanza incorporada al final. 


\subsubsection{Diagrama de proceso: DOP}

Figura 5. 4

DOP del aceite de coco (Parte 1)

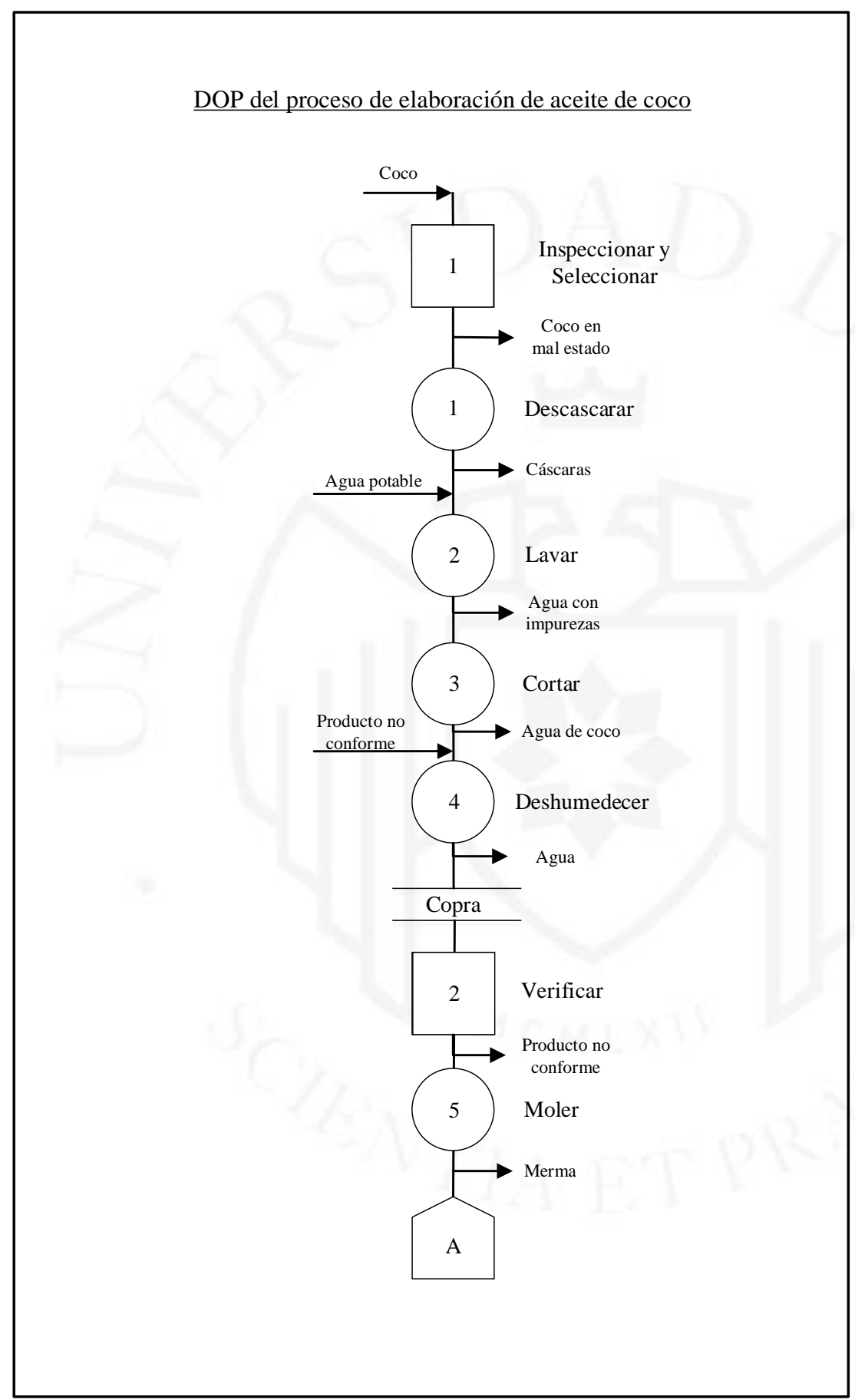

Elaboración propia 
Figura 5. 5

DOP del aceite de coco (Parte 2)

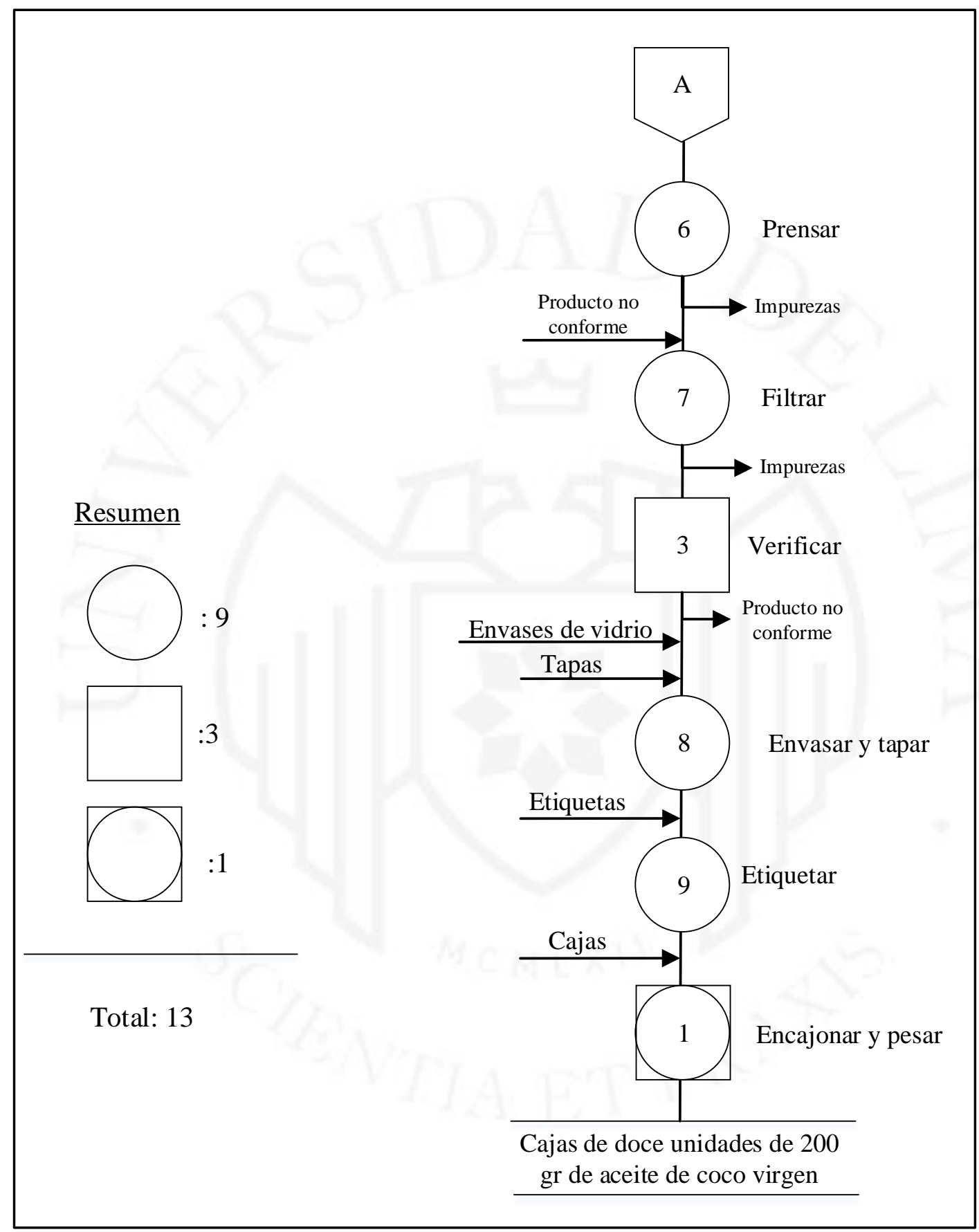

Elaboración propia 


\subsubsection{Balance de materia y energía}

Figura 5.6

Balance de materia (Parte 1)

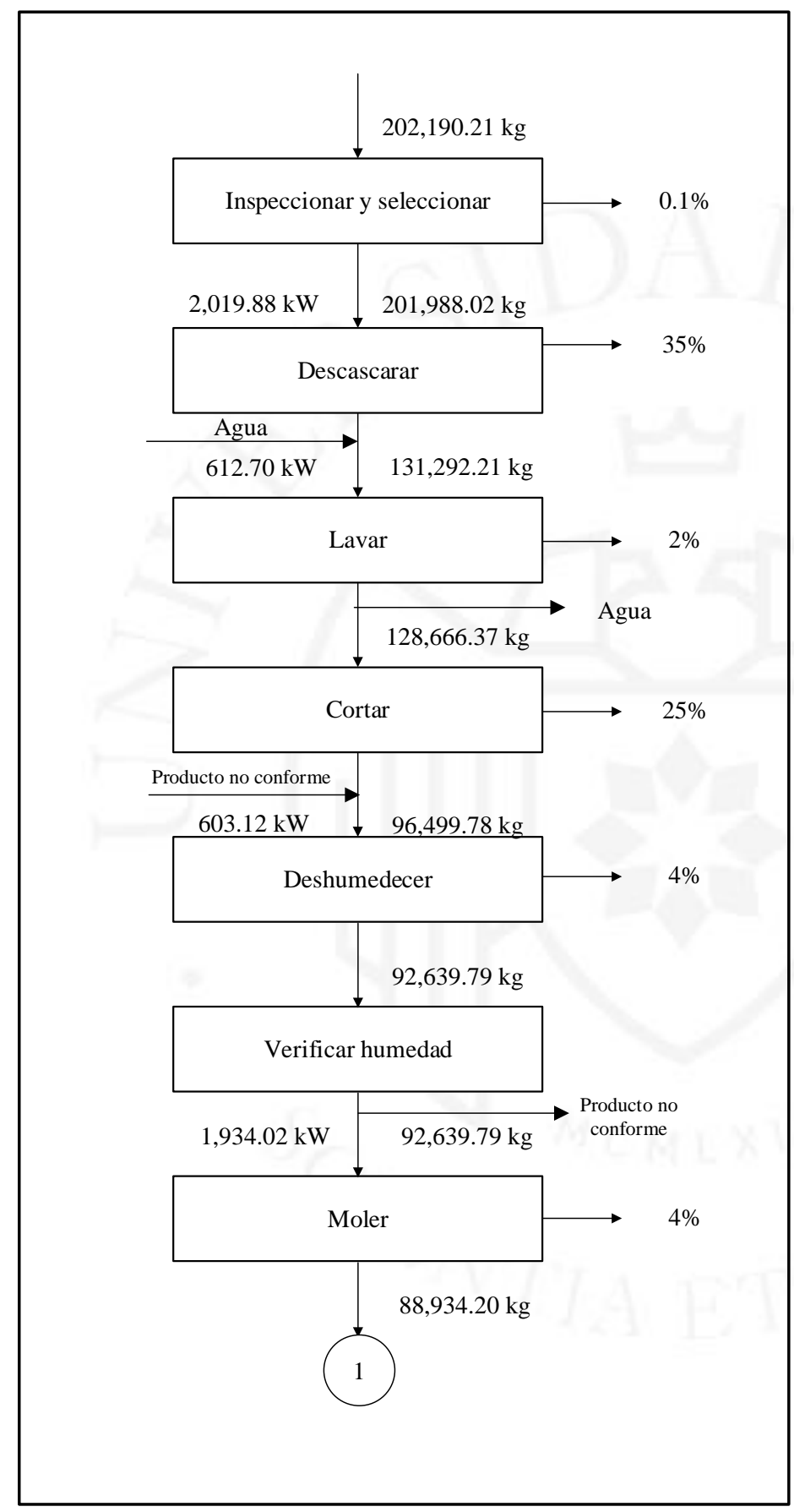

Elaboración propia 


\section{Figura 5.7}

\section{Balance de materia (Parte 2)}

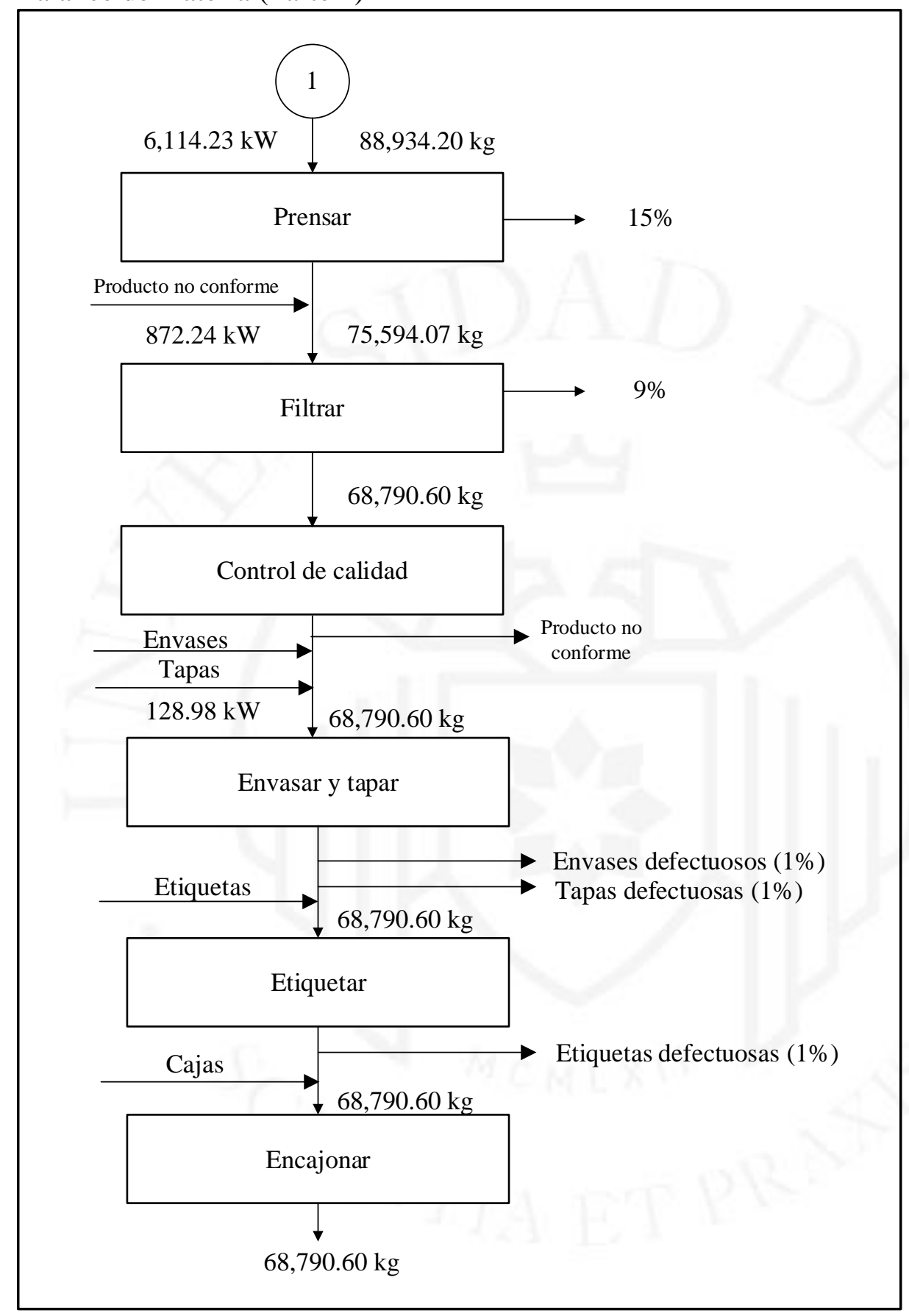

Elaboración propia 


\subsection{Características de las instalaciones y equipos}

\subsubsection{Selección de la maquinaria y equipos}

Tabla 5.4

Maquinaria y equipos

\begin{tabular}{|l|l|}
\hline Etapas & Maquinaria o equipo \\
\hline Inspeccionar y seleccionar & Báscula industrial \\
\hline Descascarar & Descascaradora \\
\hline Lavar & Máquina lavadora \\
\hline Deshumedecer & Deshidratadora \\
\hline Verificar humedad & Balanza de humedad \\
\hline Moler & Molino de bolas \\
\hline Prensar & Prensa \\
\hline Filtrar & Filtro prensa \\
\hline Verificar & Medidor de acidez y de $\mathrm{pH}$ \\
\hline Envasar y tapar & Envasadora tapadora \\
\hline
\end{tabular}

Fuente: Morales (1985) y Canal 6 Tecpan (2014) 


\subsubsection{Especificaciones de la maquinaria}

Tabla 5. 5

Especificaciones de las máquinas e instrumentos (Parte 1)

\begin{tabular}{|c|c|c|c|c|c|}
\hline Máquinas & Bascula industrial & Descascarador & Lavadora & $\begin{array}{c}\text { Balanza de } \\
\text { humedad }\end{array}$ & Deshidratador \\
\hline Imagen & & & & & \\
\hline Especificaciones & $\begin{array}{l}\text { Capacidad: } 150 \\
\text { Kg. } \\
\text { Potencia: } 0.2 \\
\text { KW-h } \\
\text { Altura: } 0.8 \mathrm{~m} . \\
\text { Largo: } 0.6 \mathrm{~m} . \\
\text { Ancho: } 0.45 \mathrm{~m} . \\
\text { Precio: } 30 \mathrm{USD}\end{array}$ & $\begin{array}{l}\text { Capacidad: } 150 \mathrm{Kg} / \mathrm{h} \\
\text { Potencia: } 1.5 \mathrm{KW}-\mathrm{h} \\
\text { Altura: } 1 \mathrm{~m} . \\
\text { Largo: } 1 \mathrm{~m} . \\
\text { Ancho: } 0.8 \mathrm{~m} . \\
\text { Precio: } 500 \mathrm{USD}\end{array}$ & $\begin{array}{l}\text { Capacidad: } 600 \mathrm{Kg} / \mathrm{h} \text {. } \\
\text { Potencia: } 2.8 \mathrm{KW}-\mathrm{h} \\
\text { Altura: } 1.3 \mathrm{~m} . \\
\text { Largo: } 3 \mathrm{~m} . \\
\text { Ancho: } 1.1 \mathrm{~m} . \\
\text { Precio: } 5000 \mathrm{USD}\end{array}$ & $\begin{array}{l}\text { Capacidad: } 200 \mathrm{gr} \\
\text { Potencia: mínima } \\
\text { Altura: } 0.18 \mathrm{~m} . \\
\text { Largo: } 0.38 \mathrm{~m} . \\
\text { Ancho: } 0.2 \mathrm{~m} . \\
\text { Precio: } 760 \text { euros }\end{array}$ & $\begin{array}{l}\text { Capacidad: } 120 \mathrm{Kg} / \mathrm{h} \text {. } \\
\text { Potencia: } 0.75 \mathrm{KW}-\mathrm{h} \\
\text { Altura: } 0.73 \mathrm{~m} . \\
\text { Largo: } 0.8 \mathrm{~m} . \\
\text { Ancho: } 0.5 \mathrm{~m} . \\
\text { Precio: } 1800 \mathrm{USD}\end{array}$ \\
\hline
\end{tabular}

Fuente: Alibaba (2016) 


\section{Tabla 5. 6}

Especificaciones de las máquinas e instrumentos (Parte 2)

\begin{tabular}{|l|l|l|l|l|}
\hline Máquinas & Molino de bolas & Prensa & Filtro Prensa & Envasadora tapadora \\
\hline Imagen & & & \\
& & & \\
& & &
\end{tabular}

Fuente: Alibaba (2016) y Tecmaq (2016) 


\section{Tabla 5.7}

Especificaciones de las máquinas e instrumentos (Parte 3)

\begin{tabular}{|c|c|c|c|c|c|}
\hline Máquinas & Tornillo sinfín & Faja transportadora & Faja transportadora & Bomba & Caretilla hidráulica \\
\hline Imagen & & & & & \\
\hline Especificaciones & $\begin{array}{l}\text { Velocidad: } 100 \mathrm{rpm} . \\
\text { Potencia: } 1.5 \mathrm{KW}-\mathrm{h} \\
\text { Altura: } 0.2 \mathrm{~m} . \\
\text { Largo: } 4 \mathrm{~m} . \\
\text { Ancho: } 0.2 \mathrm{~m} . \\
\text { Precio: } 500 \mathrm{USD}\end{array}$ & $\begin{array}{l}\text { Potencia: } 0.746 \mathrm{KW}-\mathrm{h} \\
\text { Altura: } 0.75-0.95 \mathrm{~m} . \\
\text { Largo: } 5.00 \mathrm{~m} . \\
\text { Ancho: } 0.75 \mathrm{~m} . \\
\text { Precio: } 2,500 \mathrm{USD}\end{array}$ & $\begin{array}{l}\text { Potencia: } 0.746 \mathrm{KW}-\mathrm{h} \\
\text { Altura: } 0.75-0.95 \mathrm{~m} . \\
\text { Largo: } 1.65 \mathrm{~m} . \\
\text { Ancho: } 0.21 \mathrm{~m} . \\
\text { Precio: } 1,250 \mathrm{USD}\end{array}$ & $\begin{array}{l}\text { Potencia: } 0.37 \mathrm{KW}-\mathrm{h} \\
\text { Altura: } 0.36 \mathrm{~m} . \\
\text { Largo: } 0.5 \mathrm{~m} . \\
\text { Ancho: } 0.19 \mathrm{~m} . \\
\text { Precio: } 199.90 \text { soles } \\
\text { Caudal máximo: } 37 \\
\text { 1/min }\end{array}$ & $\begin{array}{l}\text { Capacidad: } 2 \text { ton. } \\
\text { Potencia: Manual } \\
\text { Altura: } 0.5 \mathrm{~m} . \\
\text { Largo: } 1.8 \mathrm{~m} . \\
\text { Ancho: } 0.7 \mathrm{~m} . \\
\text { Precio: } 118 \text { USD }\end{array}$ \\
\hline
\end{tabular}

Fuente: Alibaba (2016), Sodimac (2016) y Indutec Perú (2016) 
Tabla 5.8

Especificaciones de las máquinas e instrumentos (Parte 4)

\begin{tabular}{|c|c|c|}
\hline Máquinas & Medidor de $\mathrm{pH}$ & Kit de análisis \\
\hline Imagen & & \\
\hline Especificaciones & $\begin{array}{l}\mathrm{pH}: 0 \text { hasta } 14 \mathrm{pH} \text {, exactitud } \pm 0,02 \mathrm{pH} \\
\text { Altura: } 0.197 \mathrm{~m} \\
\text { Largo: } 0.33 \mathrm{~m} . \\
\text { Ancho: } 0.20 \mathrm{~m} . \\
\text { Precio: } 250 \mathrm{USD}\end{array}$ & $\begin{array}{l}\text { Rango: de } 0 \% \text { a } 1 \% \text { de acidez } \\
\text { Altura: } 0.06 \mathrm{~m} \\
\text { Largo: } 0.2 \mathrm{~m} \\
\text { Ancho: } 0.12 \mathrm{~m} \\
\text { Precio: } 222.80 \text { USD }\end{array}$ \\
\hline
\end{tabular}

Fuente: Testo (2016) y Hanna Instruments (2016) 


\subsection{Capacidad instalada}

\subsubsection{Cálculo de la capacidad instalada}

Tabla 5.9

Capacidad instalada

\begin{tabular}{|c|c|c|c|c|c|c|c|c|c|c|c|}
\hline \multicolumn{12}{|c|}{ Capacidad instalada } \\
\hline Máquina u Operación & $\begin{array}{c}\text { Cantidad a } \\
\text { procesar } \\
(\mathrm{Kg} / \mathrm{h})\end{array}$ & $\begin{array}{c}\text { Capacidad } \\
(\mathrm{kg} / \mathrm{h})\end{array}$ & Cantidad & H/Turno & Turno/día & Día/semana & Semana/año & $\mathrm{E}$ & $\mathrm{U}$ & $\mathrm{F}$ & $\begin{array}{l}\text { Capacidad } \\
\text { instalada } \\
\text { (kg/año) }\end{array}$ \\
\hline Descascarador & 102.77 & 150.00 & 1.00 & 8.00 & 1.00 & 5.00 & 52.00 & 0.80 & 0.92 & 0.34 & $77,921.89$ \\
\hline Lavadora & 66.80 & 600.00 & 1.00 & 8.00 & 1.00 & 5.00 & 52.00 & 0.80 & 0.92 & 0.52 & $479,519.35$ \\
\hline Deshidratador & 49.10 & 120.00 & 1.00 & 8.00 & 1.00 & 5.00 & 52.00 & 0.80 & 0.92 & 0.71 & $130,481.46$ \\
\hline Molino & 47.14 & 479.00 & 1.00 & 8.00 & 1.00 & 5.00 & 52.00 & 0.80 & 0.92 & 0.74 & $542,540.08$ \\
\hline Prensa & 45.25 & 80.00 & 1.00 & 8.00 & 1.00 & 5.00 & 52.00 & 0.80 & 0.92 & 0.77 & $94,387.63$ \\
\hline Filtro prensa & 38.46 & 130.00 & 1.00 & 8.00 & 1.00 & 5.00 & 52.00 & 0.80 & 0.92 & 0.91 & $180,446.93$ \\
\hline Bomba & 38.46 & $2,037.96$ & 1.00 & 8.00 & 1.00 & 5.00 & 52.00 & 0.80 & 0.92 & 0.91 & $2,828,797.17$ \\
\hline Envasadora & 35.00 & 400.00 & 1.00 & 8.00 & 1.00 & 5.00 & 52.00 & 0.80 & 0.92 & 1.00 & $610,133.33$ \\
\hline Tapadora & 102.88 & 400.00 & 1.00 & 8.00 & 1.00 & 5.00 & 52.00 & 0.80 & 0.92 & 1.00 & $610,133.33$ \\
\hline Inspeccionar y seleccionar & 65.47 & 900.00 & 1.00 & 8.00 & 1.00 & 5.00 & 52.00 & 0.80 & 0.92 & 0.34 & $467,063.83$ \\
\hline Cortar & 47.14 & $2,400.00$ & 1.00 & 8.00 & 1.00 & 5.00 & 52.00 & 0.80 & 0.92 & 0.53 & $1,957,221.83$ \\
\hline Verificar humedad & 35.00 & 900.00 & 1.00 & 8.00 & 1.00 & 5.00 & 52.00 & 0.80 & 0.92 & 0.74 & $1,019,386.37$ \\
\hline Control de calidad & 35.00 & 900.00 & 1.00 & 8.00 & 1.00 & 5.00 & 52.00 & 0.80 & 0.92 & 1.00 & $1,372,800.00$ \\
\hline Etiquetar & 35.00 & 360.00 & 1.00 & 8.00 & 1.00 & 5.00 & 52.00 & 0.80 & 0.92 & 1.00 & $549,120.00$ \\
\hline Encajonar & 102.77 & 360.00 & 1.00 & 8.00 & 1.00 & 5.00 & 52.00 & 0.80 & 0.92 & 1.00 & $549,120.00$ \\
\hline
\end{tabular}

Elaboración propia 
La capacidad instalada asciende a 77,921.89 $\mathrm{kg}$ al año y el cuello de botella está en el proceso de descascarado.

\subsubsection{Cálculo detallado del número de máquinas requeridas}

Para realizar el cálculo de la utilización se consideraron paros por limpieza de 15 minutos, por calentamiento y enfriamiento de las máquinas de 15 y 10 minutos respectivamente. La suma total asciende a 40 minutos de paro al día entre el tiempo que trabaja la maquinaría (480 minutos al día) resulta $8.33 \%$, es decir $91.67 \%$ de utilización.

Tabla 5. 10

Cálculo del número de máquinas

\begin{tabular}{|c|c|c|c|c|c|c|c|c|}
\hline Máquina & $\begin{array}{c}\text { Cantidad a } \\
\text { procesar } \\
(\mathrm{Kg} / \mathrm{año})\end{array}$ & $\begin{array}{c}\text { Cantidad a } \\
\text { procesar } \\
(\mathrm{Kg} / \mathrm{h})\end{array}$ & $\begin{array}{c}\text { Capacidad } \\
(\mathrm{Kg} / \mathrm{h})\end{array}$ & $\begin{array}{c}\text { NHR } \\
(\text { Hora/año })\end{array}$ & E (\%) & U (\%) & $\begin{array}{c}\text { Número } \\
\text { de } \\
\text { máquinas }\end{array}$ & $\begin{array}{c}\text { Númáquinas } \\
\text { de }\end{array}$ \\
\hline Descascarador & $201,988.02$ & 99.00 & 150.00 & $2,080.00$ & $80 \%$ & $91.67 \%$ & 0.90 & 1.00 \\
\hline Lavadora & $131,292.21$ & 64.35 & 600.00 & $2,080.00$ & $80 \%$ & $91.67 \%$ & 0.15 & 1.00 \\
\hline Deshidratador & $96,499.78$ & 47.30 & 120.00 & $2,080.00$ & $80 \%$ & $91.67 \%$ & 0.54 & 1.00 \\
\hline Molino & $92,639.79$ & 45.41 & 479.00 & $2,080.00$ & $80 \%$ & $91.67 \%$ & 0.13 & 1.00 \\
\hline Prensa & $88,934.20$ & 43.59 & 80.00 & $2,080.00$ & $80 \%$ & $91.67 \%$ & 0.74 & 1.00 \\
\hline Filtro prensa & $75,594.07$ & 37.05 & 130.00 & $2,080.00$ & $80 \%$ & $91.67 \%$ & 0.39 & 1.00 \\
\hline Bomba & $75,594.07$ & 37.05 & $2,037.96$ & $2,080.00$ & $80 \%$ & $91.67 \%$ & 0.02 & 1.00 \\
\hline Envasadora tapadora & $68,790.60$ & 33.72 & 400.00 & $2,080.00$ & $80 \%$ & $91.67 \%$ & 0.11 & 1.00 \\
\hline
\end{tabular}

Elaboración propia

\subsection{Resguardo de la calidad y/o inocuidad del producto}

\subsubsection{Calidad de la materia prima, de los insumos, del proceso y del producto}

Todo el proceso de producción del aceite de coco se encuentra parametrizado para resguardar la seguridad y calidad del producto final.

Se identifica peligros específicos, así como las medidas respectivas para su control mediante el sistema HACCP. Esto permite avalar la inocuidad de los alimentos. (SENASA, 2014). 
Tabla 5. 11

Hoja de trabajo de análisis y riesgos

\begin{tabular}{|c|c|c|c|c|c|}
\hline Etapa de proceso & Peligros & $\begin{array}{c}\text { ¿Algún peligro } \\
\text { significativo para la } \\
\text { seguridad del alimento? }\end{array}$ & Justifique su decisión de la columna & $\begin{array}{l}\text { ¿Qué medios preventivos } \\
\text { pueden ser aplicados? }\end{array}$ & $\begin{array}{l}\text { ¿Es esa } \\
\text { etapa un } \\
\text { PPC? }\end{array}$ \\
\hline $\begin{array}{l}\text { Inspección y selección } \\
\text { de la materia prima }\end{array}$ & $\begin{array}{l}\text { Permitir el paso de } \\
\text { materia prima no apta }\end{array}$ & Sí & Verificaciones de control constantes & $\begin{array}{c}\text { Proceso en condiciones } \\
\text { adecuadas y revisión } \\
\text { sensorial. }\end{array}$ & SÍ \\
\hline Descascarado & $\begin{array}{l}\text { Contaminación física y } \\
\text { golpe }\end{array}$ & $\mathrm{NO}$ & $\begin{array}{l}\text { Pasa por un proceso de lavado } \\
\text { posteriormente }\end{array}$ & & NO \\
\hline Lavado & Mal lavado & SI & El total de impurezas no se retiran & $\begin{array}{c}\text { Proceso en condiciones } \\
\text { adecuadas y revisión visual }\end{array}$ & NO \\
\hline Corte & $\begin{array}{l}\text { Contaminación física, } \\
\text { caída de tierra e insectos. }\end{array}$ & SI & $\begin{array}{l}\text { Proceso rápido y en condiciones } \\
\text { adecuadas }\end{array}$ & $\begin{array}{c}\text { Capacitación constante de } \\
\text { operarios. }\end{array}$ & NO \\
\hline Deshumedecido & $\begin{array}{l}\text { Presencia de agua mayor } \\
\text { al porcentaje permitido }\end{array}$ & NO & $\begin{array}{l}\text { Materia prima se reprocesa sin } \\
\text { efectos posteriores }\end{array}$ & & SI \\
\hline Moler & Mal procedimiento & NO & $\begin{array}{c}\text { Mantenimientos preventivos para } \\
\text { asegurar el buen mantenimiento de la } \\
\text { máquina }\end{array}$ & & NO \\
\hline Prensar & Mal procedimiento & NO & $\begin{array}{l}\text { Aceite prensado no apto para seguir } \\
\text { con el proceso }\end{array}$ & & NO \\
\hline Filtrar & Mal procedimiento & SI & Aceite filtrado no apto para consumo & $\begin{array}{c}\text { Control de calidad en } \\
\text { laboratorio y mantenimiento } \\
\text { de la maquinaria }\end{array}$ & SI \\
\hline Envasar y tapar & $\begin{array}{l}\text { Contaminación, } \\
\text { Mal procedimiento }\end{array}$ & SI & $\begin{array}{c}\text { Aceite contaminado no apto para } \\
\text { consumo } \\
\text { Envase mal tapado puede ocasionar } \\
\text { posible contaminación } \\
\end{array}$ & $\begin{array}{c}\text { Proceso en condiciones } \\
\text { adecuadas y revisión visual } \\
\text { Capacitación constante de } \\
\text { operarios. } \\
\end{array}$ & SI \\
\hline Etiquetar & No presenta riesgo & NO & $\begin{array}{l}\text { Envase mal etiquetado no brinda } \\
\text { información correcta del producto }\end{array}$ & & NO \\
\hline Encajonar & No presenta riesgo & NO & $\begin{array}{l}\text { Envase mal encajonado puede } \\
\text { ocasionar rotura de envases. }\end{array}$ & & NO \\
\hline
\end{tabular}

Elaboración propia 


\subsubsection{Estrategias de mejora}

Tabla 5.12

Monitoreo

\begin{tabular}{|c|c|c|c|c|c|c|c|c|c|}
\hline $\begin{array}{c}\text { Puntos de } \\
\text { control críticos }\end{array}$ & $\begin{array}{c}\text { Peligros } \\
\text { Significativos }\end{array}$ & $\begin{array}{c}\text { Límites críticos } \\
\text { para cada medida } \\
\text { preventiva }\end{array}$ & ¿Qué? & ¿Cómo? & Frecuencia & $\begin{array}{c}\text { ¿A } \\
\text { quién? }\end{array}$ & $\begin{array}{l}\text { Acciones } \\
\text { correctoras }\end{array}$ & Registros & Verificación \\
\hline $\begin{array}{l}\text { Inspección y } \\
\text { selección de la } \\
\text { materia prima }\end{array}$ & Descomposición & $\begin{array}{c}\text { Peso, dureza, color } \\
\text { y otras } \\
\text { características } \\
\text { físicas detectadas } \\
\text { visualmente. } \\
\text { Un fruto no apto } \\
\text { para producir copra } \\
\text { presenta una } \\
\text { epidermis de color } \\
\text { uniforme verde } \\
\text { amarillo o naranja y } \\
\text { al sacudirlo, el agua } \\
\text { contenida no hace } \\
\text { sonido alguno }\end{array}$ & $\begin{array}{c}\text { Materia } \\
\text { prima }\end{array}$ & Sensorial & $\begin{array}{l}\text { Cada } \\
\text { muestra } \\
\text { recibida }\end{array}$ & Operario & $\begin{array}{l}\text { Devolución al } \\
\text { proveedor }\end{array}$ & $\begin{array}{l}\text { Documentación } \\
\text { del proveedor }\end{array}$ & $\begin{array}{c}\text { Verificar } \\
\text { nuevamente }\end{array}$ \\
\hline Deshumedecido & $\begin{array}{l}\text { Presencia de } \\
\text { agua mayor al } \\
\text { porcentaje } \\
\text { permitido }\end{array}$ & $6-7 \%$ & $\begin{array}{c}\text { Una } \\
\text { muestra } \\
\text { de la } \\
\text { copra }\end{array}$ & $\begin{array}{c}\text { Balanza de } \\
\text { humedad }\end{array}$ & $\begin{array}{l}\text { Cada } \\
\text { muestra } \\
\text { recibida }\end{array}$ & $\begin{array}{l}\text { Auxiliar } \\
\text { de } \\
\text { control } \\
\text { de } \\
\text { calidad } \\
\end{array}$ & $\begin{array}{c}\text { Regresar al } \\
\text { deshumedecedor }\end{array}$ & $\begin{array}{c}\text { Documentación } \\
\text { de calidad }\end{array}$ & $\begin{array}{l}\text { Nueva } \\
\text { muestra }\end{array}$ \\
\hline Filtrar & $\begin{array}{c}\text { Mal } \\
\text { procedimiento }\end{array}$ & $\begin{array}{c}\text { Olor y color: } \\
\text { característico } \\
\text { Acidez: máximo } \\
0.15 \% \\
\text { pH: } 5\end{array}$ & $\begin{array}{l}\text { Guía de } \\
\text { calidad }\end{array}$ & $\begin{array}{c}\text { Sensorial } \\
\text { Kit de } \\
\text { acidez de } \\
\text { aceite } \\
\text { Medidor de } \\
\text { PH }\end{array}$ & $\begin{array}{c}\text { Todo } \\
\text { producto que } \\
\text { ingresa al } \\
\text { filtrado }\end{array}$ & $\begin{array}{l}\text { Auxiliar } \\
\text { de } \\
\text { control } \\
\text { de } \\
\text { calidad }\end{array}$ & $\begin{array}{l}\text { Regresar al } \\
\text { filtrado }\end{array}$ & $\begin{array}{c}\text { Documentación } \\
\text { de calidad }\end{array}$ & $\begin{array}{l}\text { Luego del } \\
\text { reproceso } \\
\text { controlar } \\
\text { nuevamente }\end{array}$ \\
\hline Envasar y tapar & Contaminación & $100 \%$ hermético & $\begin{array}{l}\text { Guía de } \\
\text { calidad }\end{array}$ & Visualmente & $\begin{array}{c}\text { Todos los } \\
\text { envases }\end{array}$ & Operario & $\begin{array}{c}\text { Regresar al } \\
\text { envasado }\end{array}$ & $\begin{array}{c}\text { Documentación } \\
\text { de control de } \\
\text { producto final }\end{array}$ & $\begin{array}{l}\text { Luego de } \\
\text { envasar }\end{array}$ \\
\hline
\end{tabular}

Fuente: Ortega, Reyes, y Torres (2005) y AMV Ediciones (1988) 


\subsection{Estudio de Impacto Ambiental}

Con el fin de determinar, prevenir y corregir los potenciales impactos ambientales negativos del proyecto se realizará una evaluación que permitirá identificar los posibles impactos originados por cada etapa del proceso de producción del aceite de coco y determinar las medidas correctivas aplicables para cada situación.

Tabla 5.13

EIA

\begin{tabular}{|c|c|c|c|c|}
\hline $\begin{array}{c}\text { Etapas del } \\
\text { Proceso }\end{array}$ & Salidas & Aspecto Ambiental & Impacto Ambiental & Medidas Correctoras \\
\hline \multirow{2}{*}{$\begin{array}{l}\text { Descascarado del } \\
\text { fruto }\end{array}$} & Ruido & $\begin{array}{l}\text { Ruido generado por el } \\
\text { descascarado }\end{array}$ & $\begin{array}{l}\text { Afectación a la salud de } \\
\text { los trabajadores }\end{array}$ & $\begin{array}{l}\text { Uso de protección } \\
\text { auditiva }\end{array}$ \\
\hline & Residuos & $\begin{array}{l}\text { Residuos sólidos } \\
\text { (Cáscara fibrosa) }\end{array}$ & $\begin{array}{l}\text { Potencial contaminación } \\
\text { de suelo y agua }\end{array}$ & $\begin{array}{l}\text { Venta de cáscaras para } \\
\text { alimento de ganado }\end{array}$ \\
\hline & Residuos & \begin{tabular}{|ll}
$\begin{array}{l}\text { Residuos } \\
\text { (impurezas) }\end{array}$ & sólidos \\
\end{tabular} & $\begin{array}{l}\text { Potencial contaminación } \\
\text { de suelo y agua }\end{array}$ & $\begin{array}{l}\text { Manejo adecuado de } \\
\text { residuos sólidos }\end{array}$ \\
\hline Corte & Residuos & $\begin{array}{l}\text { Residuos líquidos } \\
\text { (agua de coco) }\end{array}$ & $\begin{array}{l}\text { Potencial contaminación } \\
\text { de suelo y agua }\end{array}$ & Venta de agua de coco \\
\hline Molido & \begin{tabular}{|l|}
$\begin{array}{l}\text { Ruido } \\
\text { partículas }\end{array}$ \\
\end{tabular} & \begin{tabular}{|lr} 
Ruido & $\mathrm{y}$ \\
desprendimiento de & de \\
partículas & \\
\end{tabular} & $\begin{array}{l}\text { Afectación a la salud de } \\
\text { los trabajadores }\end{array}$ & $\begin{array}{l}\text { Uso de protección } \\
\text { auditiva y lentes de } \\
\text { seguridad }\end{array}$ \\
\hline Prensado & Residuos & $\begin{array}{l}\text { Potencial derrame del } \\
\text { aceite }\end{array}$ & $\begin{array}{l}\text { Potencial contaminación } \\
\text { del suelo }\end{array}$ & $\begin{array}{l}\text { Venta de residuos para } \\
\text { alimento de ganado }\end{array}$ \\
\hline Filtro & Residuos & $\begin{array}{l}\text { Residuos sólidos } \\
\text { (Torta) }\end{array}$ & $\begin{array}{l}\text { Potencial contaminación } \\
\text { del suelo }\end{array}$ & $\begin{array}{l}\text { Venta de residuos para } \\
\text { alimento de ganado }\end{array}$ \\
\hline $\begin{array}{l}\text { Envasado } \\
\text { tapado }\end{array}$ & $\begin{array}{l}\text { Envases } \\
\text { tapas }\end{array}$ & $\begin{array}{l}\text { Envases y tapas en mal } \\
\text { estado }\end{array}$ & $\begin{array}{l}\text { Potencial contaminación } \\
\text { del suelo }\end{array}$ & $\operatorname{Rec}$ \\
\hline Etiquetado & Etiquetas & $\begin{array}{l}\text { Etiquetas en mal } \\
\text { estado }\end{array}$ & $\begin{array}{l}\text { Potencial contaminación } \\
\text { del suelo }\end{array}$ & Reciclar \\
\hline Encajonado & Cajas & Cajas en mal estado & $\begin{array}{l}\text { Potencial contaminación } \\
\text { del suelo }\end{array}$ & Reciclar \\
\hline \multirow[b]{2}{*}{ Almacenamiento } & \multirow[b]{2}{*}{ Rumas } & \multirow[b]{2}{*}{ Rumas de cajas } & $\begin{array}{l}\text { Potencial contaminación } \\
\text { del suelo }\end{array}$ & $\begin{array}{l}\text { Manejo adecuado de } \\
\text { residuos sólidos }\end{array}$ \\
\hline & & & $\begin{array}{l}\text { Peligro de accidente por } \\
\text { caída de cajas }\end{array}$ & $\begin{array}{l}\text { Mantener el } \\
\text { almacenamiento de cajas } \\
\text { en condiciones seguras }\end{array}$ \\
\hline \multirow{4}{*}{$\begin{array}{l}\text { Distribución } \\
\text { venta }\end{array}$} & Combustible & $\begin{array}{l}\text { Consumo } \\
\text { combustible }\end{array}$ & $\begin{array}{l}\text { Reducción de recursos } \\
\text { naturales }\end{array}$ & $\begin{array}{l}\text { Cambio de combustible a } \\
\text { gas natural }\end{array}$ \\
\hline & Gases & $\begin{array}{l}\text { Emisión de gases de } \\
\text { escape }\end{array}$ & Contaminación del aire & $\begin{array}{l}\text { Mantenimiento periódico } \\
\text { de los vehículos }\end{array}$ \\
\hline & \multirow{2}{*}{ Ruido } & \multirow{2}{*}{$\begin{array}{l}\text { Ruido de los camiones } \\
\text { de transporte }\end{array}$} & \multirow{2}{*}{$\begin{array}{l}\text { Molestia a los vecinos de } \\
\text { la zona }\end{array}$} & $\begin{array}{l}\text { Uso de sistema de } \\
\text { silenciadores }\end{array}$ \\
\hline & & & & $\begin{array}{l}\text { Uso muy limitado de } \\
\text { claxon }\end{array}$ \\
\hline
\end{tabular}

Elaboración propia 


\subsection{Seguridad y Salud ocupacional}

Tabla 5. 14

IPER

\begin{tabular}{|c|c|c|c|c|c|c|c|c|}
\hline \multirow{3}{*}{ PROCESO } & \multicolumn{2}{|c|}{ PELIGROS } & \multirow{3}{*}{$\begin{array}{l}\text { INCIDENTES } \\
\text { POTENCIALES }\end{array}$} & \multicolumn{4}{|c|}{ EVALUACIÓN DE RIESGOS } & \multirow{3}{*}{$\begin{array}{c}\text { PLAN DE ACCIÓN } \\
\text { MEDIDAS DE CONTROL } \\
\end{array}$} \\
\hline & \multirow{2}{*}{$\begin{array}{l}\text { FUENTE, } \\
\text { SITUACIÓN }\end{array}$} & \multirow[b]{2}{*}{ ACTO } & & \multicolumn{4}{|c|}{ SEGURIDAD } & \\
\hline & & & & $\begin{array}{c}\text { Probabilidad } \\
\text { (P) }\end{array}$ & $\begin{array}{l}\text { Severidad } \\
(\mathbf{S})\end{array}$ & $\begin{array}{c}\text { Evaluación } \\
\text { del Riesgo }\end{array}$ & $\begin{array}{l}\text { Nivel de } \\
\text { Riesgo }\end{array}$ & \\
\hline $\begin{array}{l}\text { Inspección y } \\
\text { selección }\end{array}$ & $\begin{array}{l}\text { Selección de } \\
\text { coco por } \\
\text { calidad de } \\
\text { estado físico }\end{array}$ & $\begin{array}{c}\text { Separar cocos } \\
\text { malas de las } \\
\text { buenas con los } \\
\text { brazos }\end{array}$ & $\begin{array}{l}\text { Tendinitis de } \\
\text { muñeca y hombro }\end{array}$ & 9 & 6 & 54 & Importante & Rotación de operarios \\
\hline Pesado & $\begin{array}{l}\text { Pesado de } \\
\text { cocos en } \\
\text { balanza }\end{array}$ & $\begin{array}{c}\text { Colocar la fruta } \\
\text { una por una en la } \\
\text { balanza }\end{array}$ & $\begin{array}{l}\text { Sobreesfuerzo de } \\
\text { brazos y hombros } \\
\text { por acciones } \\
\text { repetitivas }\end{array}$ & 9 & 6 & 54 & Importante & Rotación de operarios \\
\hline Descascarar & Máquina & $\begin{array}{c}\text { Colocación } \\
\text { manual de cocos } \\
\text { a la máquina }\end{array}$ & $\begin{array}{l}\text { Atrapamiento de } \\
\text { mano }\end{array}$ & 9 & 8 & 72 & Crítico & $\begin{array}{c}\text { Enclavamiento, la máquina } \\
\text { deja trabajar si se abre este } \\
\text { dispositivo }\end{array}$ \\
\hline Lavado & Piso húmedo & $\begin{array}{c}\text { Observación del } \\
\text { proceso de lavado }\end{array}$ & $\begin{array}{l}\text { Caídas por piso } \\
\text { húmedo }\end{array}$ & 9 & 8 & 72 & Crítico & $\begin{array}{c}\text { Limpieza frecuente de áreas } \\
\text { de trabajo }\end{array}$ \\
\hline Corte & $\begin{array}{l}\text { Objeto } \\
\text { afilado }\end{array}$ & $\begin{array}{l}\text { Corte manual del } \\
\text { coco sin cáscara }\end{array}$ & $\begin{array}{l}\text { Lesiones cortantes } \\
\text { en dedos o manos } \\
\text { del trabajador }\end{array}$ & 9 & 8 & 72 & Crítico & Uso de guantes \\
\hline Deshumedecido & - & - & - & 0 & 0 & 0 & Nulo & - \\
\hline
\end{tabular}

(continúa) 


\section{(continuación)}

\begin{tabular}{|c|c|c|c|c|c|c|c|c|}
\hline $\begin{array}{c}\text { Verificación de } \\
\text { humedad }\end{array}$ & $\begin{array}{l}\text { Medición de } \\
\text { humedad }\end{array}$ & $\begin{array}{l}\text { Medición de la humedad } \\
\text { sentado }\end{array}$ & Lumbalgia & 9 & 6 & 54 & Importante & Silla ergonómica \\
\hline Molido & $\begin{array}{c}\text { Ruido y } \\
\text { desprendimiento } \\
\text { de partículas }\end{array}$ & $\begin{array}{l}\text { Observación del proceso } \\
\text { de molido }\end{array}$ & $\begin{array}{c}\text { Pérdida } \\
\text { sensorial del } \\
\text { oído e irritación } \\
\text { ocular }\end{array}$ & 5 & 8 & 40 & Importante & $\begin{array}{l}\text { Uso de protección auditiva y } \\
\text { lentes de seguridad }\end{array}$ \\
\hline Prensado & Ruido & $\begin{array}{l}\text { Observación del proceso } \\
\text { de prensado }\end{array}$ & $\begin{array}{c}\text { Pérdida } \\
\text { sensorial del } \\
\text { oído }\end{array}$ & 5 & 8 & 40 & Importante & Uso de protección auditiva \\
\hline Filtrado & Piso aceitoso & $\begin{array}{c}\text { Observación del proceso } \\
\text { de filtrado }\end{array}$ & $\begin{array}{c}\text { Caídas por piso } \\
\text { aceitoso }\end{array}$ & 9 & 8 & 72 & Crítico & $\begin{array}{l}\text { Limpieza frecuente de áreas de } \\
\text { trabajo }\end{array}$ \\
\hline Envasado & Ruido & $\begin{array}{l}\text { Observación del proceso } \\
\text { de envasado }\end{array}$ & $\begin{array}{c}\text { Pérdida } \\
\text { sensorial del } \\
\text { oído }\end{array}$ & 5 & 8 & 40 & Importante & Uso de protección auditiva \\
\hline Tapado & Ruido & $\begin{array}{c}\text { Observación del proceso } \\
\text { de tapado }\end{array}$ & $\begin{array}{c}\text { Pérdida } \\
\text { sensorial del } \\
\text { oído }\end{array}$ & 5 & 8 & 40 & Importante & Uso de protección auditiva \\
\hline Etiquetado & $\begin{array}{l}\text { Movimientos } \\
\text { repetitivos }\end{array}$ & $\begin{array}{c}\text { Movimientos repetitivos } \\
\text { de extremidades } \\
\text { superiores al etiquetar } \\
\text { envases }\end{array}$ & $\begin{array}{l}\text { Tendinitis } \\
\text { muñeca y } \\
\text { hombros }\end{array}$ & 9 & 6 & 54 & Importante & Rotación de operarios \\
\hline Encajonado & $\begin{array}{l}\text { Encajonar } \\
\text { manual }\end{array}$ & $\begin{array}{c}\text { Posturas forzadas para } \\
\text { agrupar envases en cajas }\end{array}$ & Lumbalgia & 9 & 6 & 54 & Importante & Rotación de operarios \\
\hline Almacenamiento & $\begin{array}{c}\text { Mala } \\
\text { manipulación de } \\
\text { cajas }\end{array}$ & Caída de cajas & Golpe en pie & 9 & 4 & 36 & Moderado & Uso de botas de punta de acero \\
\hline
\end{tabular}

Elaboración propia 


\subsection{Sistema de mantenimiento}

La estrategia de gestión de mantenimiento debe permitir a la empresa reducir tiempos muertos y costos por mal funcionamiento de las máquinas, para así incrementar la productividad y tener una mejor competitividad en el mercado.

Los principales mantenimientos a realizar son el mantenimiento preventivo y el mantenimiento correctivo.

\section{Mantenimiento preventivo}

Este mantenimiento será la principal estrategia de la empresa para reducir los tiempos muertos y maximizar el tiempo operativo de las maquinas.

Para la aplicación debida del mantenimiento se hará uso de los manuales de las máquinas dados por el fabricante, respetando las fechas de aplicación de mantenimiento indicadas. Además, se debe tener en cuenta que cada máquina contará con su hoja de ruta específica donde se detallarán los distintos mantenimientos y su respectiva periodicidad. Como política de la empresa, el mantenimiento de los equipos críticos será bimestral ya que, si no reflejan datos verídicos podrían afectar directamente la producción.

Tabla 5. 15

Plan de mantenimiento preventivo

\begin{tabular}{|l|l|}
\hline \multicolumn{1}{|c|}{ Actividad } & \multicolumn{1}{c|}{ Periodicidad } \\
\hline Limpieza de máquinas & Todos los días \\
\hline Engrasado de las máquinas & Quincenal \\
\hline Revisión general de las máquinas & Quincenal \\
\hline - Calibración de balanzas & - Bimestral \\
- Descascarador & - Semestral \\
- Lavadora & - Anual \\
- Deshidratador & - Bimestral \\
- Molino de bolas & - Anual \\
- Prensa & - Bimestral \\
- Filtro prensa & - Semestral \\
- Envasadora tapadora & - Bimestral \\
- Tornillo sinfín & - Semestral \\
- Montacargas & Anual \\
\hline
\end{tabular}

Elaboración propia 


\section{Mantenimiento correctivo}

En este mantenimiento se cambiará o reparará cualquier equipo y se realizará cuando la maquinaria presente alguna falla o posible falla, es decir, cuando la maquinaria lo requiera.

\subsection{Programa de producción}

\subsubsection{Factores para la programación de la producción}

El programa de producción se basa en la demanda del proyecto y se considera un stock de seguridad para garantizar la cobertura de un semana. Cabe mencionar, que el horizonte del proyecto es de cinco de años, por lo tanto al finalizar el periodo se liquidará la empresa. En este escenario no se va a considerar stock de seguridad en el 2022.

El programa de producción anual que se llevará a cabo en la vida útil de este proyecto considera un trabajo de 52 semanas al año o 4.3 semanas al mes, 5 días a la semana, 1 turno al día y 8 horas efectivas por turno.

\subsubsection{Programa de producción}

Tabla 5.16

Programa de producción durante la vida útil del proyecto

\begin{tabular}{|c|c|c|c|c|c|c|}
\hline Año & Demanda Proyecto $(\mathrm{Kg})$ & $\begin{array}{c}\text { Demanda } \\
\text { envases }\end{array}$ & $\begin{array}{c}\text { Stock de } \\
\text { seguridad }\end{array}$ & $\begin{array}{c}\text { Inventario } \\
\text { inicial }\end{array}$ & $\begin{array}{c}\text { Producción } \\
\text { envases }\end{array}$ & Producción kg \\
\hline 2018 & $15,459.17$ & $77,296.00$ & $1,487.00$ & & $78,783.00$ & $15,756.60$ \\
\hline 2019 & $27,298.53$ & $136,493.00$ & $2,625.00$ & $1,487.00$ & $137,631.00$ & $27,526.20$ \\
\hline 2020 & $37,323.86$ & $186,620.00$ & $3,589.00$ & $2,625.00$ & $187,584.00$ & $37,516.80$ \\
\hline 2021 & $51,030.97$ & $255,155.00$ & $4,907.00$ & $3,589.00$ & $256,473.00$ & $51,294.60$ \\
\hline 2022 & $69,772.00$ & $348,860.00$ & & $4,907.00$ & $343,953.00$ & $68,790.60$ \\
\hline
\end{tabular}

Elaboración propia 


\subsection{Requerimiento de insumos, servicios y personal}

\subsubsection{Materia prima, insumos y otros materiales}

Para hacer el cálculo de la materia prima, insumo y otros materiales para cada año de la vida útil de proyecto, se considerará un factor que nos da la relación de producto terminado y materia prima, insumo u otro material.

\section{Materia prima}

Con respecto a la materia prima, la relación a considerar entre esta y el producto terminado es 0.34 Kg PT / Kg MP. Por lo tanto, se obtiene los requerimientos por año en el siguiente cuadro.

Tabla 5.17

Requerimiento anual de materia prima $(\mathrm{Kg})$

\begin{tabular}{|c|c|c|}
\hline Año & Producción del Proyecto $(\mathrm{Kg})$ & Requerimiento de MP $(\mathrm{Kg})$ \\
\hline 2018 & $15,756.60$ & $46,312.00$ \\
\hline 2019 & $27,526.20$ & $80,905.36$ \\
\hline 2020 & $37,516.80$ & $110,269.86$ \\
\hline 2021 & $51,294.60$ & $150,765.75$ \\
\hline 2022 & $68,790.60$ & $202,190.21$ \\
\hline
\end{tabular}

Elaboración propia

\section{Envases}

La producción de aceite de coco requerirá de envases como insumos (incluye tapas y cajas). De la misma manera que la materia prima, se considerará una relación entre $\mathrm{Kg}$ de producto terminado y numero de envase. Los envases tienen una presentación de 200 gr de aceite de coco, es decir la relación de producto terminado y envases es $0.2 \mathrm{Kg}$ PT / envase. La siguiente tabla muestra los requerimientos anuales de los envases.

Tabla 5. 18

Requerimiento anual de envases (unidades)

\begin{tabular}{|c|c|c|c|}
\hline Año & Producción del Proyecto (Kg) & Requerimiento de envases (Unid.) & $\begin{array}{c}\text { Requerimiento considerando } \\
\text { merma } 1 \%\end{array}$ \\
\hline 2018 & $15,756.60$ & $78,783.00$ & $79,571.00$ \\
\hline 2019 & $27,526.20$ & $137,631.00$ & $139,008.00$ \\
\hline 2020 & $37,516.80$ & $187,584.00$ & $189,460.00$ \\
\hline 2021 & $51,294.60$ & $256,473.00$ & $259,038.00$ \\
\hline 2022 & $68,790.60$ & $343,953.00$ & $347,393.00$ \\
\hline
\end{tabular}

Elaboración propia 


\section{Etiquetas}

Por último, es necesario que los envases lleven una etiqueta adhesiva y que cumpla con los estándares de calidad y normas técnicas.

Al igual que la materia prima y los envases, para hallar el requerimiento de etiquetas se considerará una relación, esta vez, con relación al número de envases requeridos por año. Cada envase llevará consigo una etiqueta, por lo tanto, la relación envase y etiqueta es 1:1. Con este dato, se obtiene la siguiente tabla de requerimientos anuales de etiquetas.

Tabla 5. 19

Requerimiento anual de etiquetas (Unid.)

\begin{tabular}{|c|c|c|c|}
\hline Año & Requerimiento de envases (Unid.) & $\begin{array}{c}\text { Requerimiento de etiquetas } \\
\text { (Unid.) }\end{array}$ & $\begin{array}{c}\text { Requerimiento } \\
\text { considerando merma } 1 \%\end{array}$ \\
\hline 2018 & $78,783.00$ & $78,783.00$ & $79,571.00$ \\
\hline 2019 & $137,631.00$ & $137,631.00$ & $139,008.00$ \\
\hline 2020 & $187,584.00$ & $187,584.00$ & $189,460.00$ \\
\hline 2021 & $256,473.00$ & $256,473.00$ & $259,038.00$ \\
\hline 2022 & $343,953.00$ & $343,953.00$ & $347,393.00$ \\
\hline
\end{tabular}

Elaboración propia

\subsubsection{Servicios: energía eléctrica, agua, vapor, combustible, etc.}

\section{Energía eléctrica}

Para hallar el consumo de energía eléctrica se toma como referencia la potencia de cada equipo (KW-h). Para determinar el consumo teórico de energía anual requerida se considera que el tiempo de trabajo de la planta es 52 semanas al año o 4.3 semanas al mes, 5 días a la semana, 1 turno al día y 8 horas efectivas por turno.

Tabla 5. 20

Requerimiento teórico anual de energía eléctrica por maquinaria. ( $\mathrm{kW}$-año)

\begin{tabular}{|c|c|c|c|c|}
\hline Máquina & Número de máquinas & $\begin{array}{c}\text { Potencia }(\mathrm{kW}- \\
\mathrm{h})\end{array}$ & $\begin{array}{c}\mathrm{kW} \text { totales por } \\
\text { hora }(\mathrm{kW}-\mathrm{h})\end{array}$ & $\begin{array}{c}\mathrm{kW} \text { totales por } \\
\text { año }(\mathrm{kW}-\mathrm{año})\end{array}$ \\
\hline Báscula industrial & 1.00 & 0.20 & 0.20 & 416.00 \\
\hline Descascarador & 1.00 & 1.50 & 1.50 & $3,120.00$ \\
\hline Lavadora & 1.00 & 2.80 & 2.80 & $5,824.00$ \\
\hline Deshidratador & 1.00 & 0.75 & 0.75 & $1,560.00$ \\
\hline
\end{tabular}


(continuación)

\begin{tabular}{|c|c|c|c|c|}
\hline Molino & 1.00 & 10.00 & 10.00 & $20,800.00$ \\
\hline Prensa & 1.00 & 5.50 & 5.50 & $11,440.00$ \\
\hline Filtro prensa & 1.00 & 1.50 & 1.50 & $3,120.00$ \\
\hline Envasadora tapadora & 1.00 & 0.75 & 0.75 & $1,560.00$ \\
\hline Faja transportadora & 1.00 & 0.75 & 0.75 & $1,551.68$ \\
\hline Faja transportadora & 2.00 & 0.75 & 1.49 & $3,103.36$ \\
\hline Tornillo sin fin & 1.00 & 1.50 & 1.50 & $3,120.00$ \\
\hline Bomba & 1.00 & 0.37 & 0.37 & 775.84 \\
\hline \multicolumn{2}{|r|}{} & & Total & $56,390.88$ \\
\hline
\end{tabular}

Elaboración propia

Para encontrar el requerimiento real anual se hallará con un porcentaje de utilización de la planta por año (Producción real / Producción teórica).

Tabla 5. 21

Capacidad teórica anual

\begin{tabular}{|c|c|c|}
\hline Máquina & Capacidad $(\mathrm{Kg} / \mathrm{h})$ & Capacidad teórica (Kg/año) \\
\hline Descascarador & 150.00 & $312,000.00$ \\
\hline Lavadora & 600.00 & $1,248,000.00$ \\
\hline Deshidratador & 120.00 & $249,600.00$ \\
\hline Molino & 479.00 & $166,400.00$ \\
\hline Prensa & 80.00 & $270,400.00$ \\
\hline Filtro prensa & 130.00 & $4,238,956.80$ \\
\hline Bomba & $2,037.96$ & $832,000.00$ \\
\hline Envasadora tapadora & 400.00 & \\
\hline
\end{tabular}

Elaboración propia

Tabla 5. 22

Porcentaje anual de utilización de la planta

\begin{tabular}{|c|c|c|c|}
\hline Año & Producción (Kg/año) & Capacidad teórica anual (Kg/año) & \% de utilización \\
\hline 2018 & $15,756.60$ & $166,400.00$ & $9.47 \%$ \\
\hline 2019 & $27,526.20$ & $166,400.00$ & $16.54 \%$ \\
\hline 2020 & $37,516.80$ & $166,400.00$ & $22.55 \%$ \\
\hline 2021 & $51,294.60$ & $166,400.00$ & $30.83 \%$ \\
\hline 2022 & $68,790.60$ & $166,400.00$ & $41.34 \%$ \\
\hline
\end{tabular}

Elaboración propia 
Finalmente, con el dato del porcentaje de utilización de planta se podrá estimar el requerimiento anual de energía eléctrica real.

Tabla 5. 23

Requerimiento anual de energía eléctrica por maquinaria real. (KW-año)

\begin{tabular}{|c|c|c|c|}
\hline Año & $\begin{array}{c}\text { Requerimiento } \\
\text { teórico anual (kW } \\
\text { /año) }\end{array}$ & $\%$ de utilización & $\begin{array}{c}\text { Requerimiento real anual } \\
\text { por toda la maquinaria } \\
(\mathrm{kW} / \mathrm{año})\end{array}$ \\
\hline 2018 & $56,390.88$ & $9.47 \%$ & $5,339.71$ \\
\hline 2019 & $56,390.88$ & $16.54 \%$ & $9,328.29$ \\
\hline 2020 & $56,390.88$ & $22.55 \%$ & $12,713.97$ \\
\hline 2021 & $56,390.88$ & $30.83 \%$ & $17,383.10$ \\
\hline 2022 & $56,390.88$ & $41.34 \%$ & $23,312.27$ \\
\hline
\end{tabular}

Elaboración propia

Para determinar la cantidad de energía eléctrica requerida por iluminación, se utilizó la siguiente fórmula para hallar la cantidad de fuentes luminosas. $I * A=N 1 * N 2 * L * F C$

Tabla 5.24

Determinación de fuentes luminosas

\begin{tabular}{|c|c|c|c|c|c|c|c|c|c|}
\hline & \multirow{2}{*}{ I (lux) } & \multirow{2}{*}{$\mathrm{A}(\mathrm{m} 2)$} & \multirow{2}{*}{$\mathrm{N} 2$} & \multirow{2}{*}{ L (lumen) } & \multicolumn{3}{|c|}{$\mathrm{FC}$} & \multirow{2}{*}{$\mathrm{Fc}$} & \multirow{2}{*}{ N1 } \\
\hline & & & & & $\mathrm{Cu}$ & LLD & LDD & & \\
\hline Fabril & 300.00 & 213.35 & 2.00 & $2,850.00$ & $100 \%$ & $75 \%$ & $100 \%$ & $75 \%$ & 14.97 \\
\hline Administrativo & 500.00 & 290.11 & 2.00 & $2,850.00$ & $100 \%$ & $75 \%$ & $100 \%$ & $75 \%$ & 33.93 \\
\hline
\end{tabular}

Elaboración propia

Tabla 5. 25

Requerimiento de energía no fabril

\begin{tabular}{|c|c|c|c|}
\hline & Cantidad & kW h (mes) & kW h (año) \\
\hline $\begin{array}{l}\text { Equipos } \\
\text { fluorescentes }\end{array}$ & 34.00 & 212.16 & $2,545.92$ \\
\hline Laptop & 8.00 & 120.00 & $1,440.00$ \\
\hline Refrigeradora & 1.00 & 30.00 & 360.00 \\
\hline Impresora & 2.00 & 10.00 & 120.00 \\
\hline Horno microondas & 1.00 & 36.00 & 432.00 \\
\hline & & Total & $4,897.92$ \\
\hline
\end{tabular}

Fuente: MINEM (2016) 
Tabla 5.26

Requerimiento de energía fabril sin maquinaria

\begin{tabular}{|l|r|r|r|}
\cline { 2 - 4 } \multicolumn{1}{c|}{} & \multicolumn{1}{c|}{ Cantidad } & $\mathrm{kW} \mathrm{h}(\mathrm{mes})$ & $\mathrm{kW} \mathrm{h}(\mathrm{año})$ \\
\hline $\begin{array}{l}\text { Equipos } \\
\text { fluorescentes }\end{array}$ & 15.00 & 93.53 & $1,122.34$ \\
\hline Impresora & 1.00 & 5.00 & 60.00 \\
\hline Horno microondas & 1.00 & 36.00 & 432.00 \\
\hline Laptop & 6.00 & 90.00 & $1,080.00$ \\
\hline
\end{tabular}

Fuente: MINEM (2016)

Tabla 5.27

Requerimiento de energía total

\begin{tabular}{|c|c|c|c|}
\hline Año & $\begin{array}{c}\text { Requerimiento anual } \\
\text { otros (kW/año) }\end{array}$ & $\begin{array}{c}\text { Requerimiento anual no } \\
\text { fabril (kW/año) }\end{array}$ & Requerimiento anual total (kW/año) \\
\hline 2018 & $8,034.05$ & $4,897.92$ & $12,931.97$ \\
\hline 2019 & $12,022.62$ & $4,897.92$ & $16,920.54$ \\
\hline 2020 & $15,408.31$ & $4,897.92$ & $20,306.23$ \\
\hline 2021 & $20,077.43$ & $4,897.92$ & $24,975.35$ \\
\hline 2022 & $26,006.61$ & $4,897.92$ & $30,904.53$ \\
\hline
\end{tabular}

Elaboración propia

\section{Agua}

De la misma manera que la energía eléctrica, se considera para hallar el consumo teórico de agua anual requerido, que el tiempo de trabajo de la planta es 52 semanas o 4.3 semanas al mes, 5 días a la semana, 1 turno al día y 8 horas efectivas por turno.

Para hallar el consumo de agua, se tomará como referencia dos variables. La primera será el volumen requerido de la misma en la máquina lavadora de la línea de producción $(1 / h)$ y de la cantidad de materia prima a lavar $(\mathrm{Kg} / \mathrm{h})$; mientras que la segunda será el consumo promedio de agua por trabajador de uso industrial.

Tabla 5.28

Consumo teórico anual de agua potable. (L / año)

\begin{tabular}{|l|l|l|l|}
\hline Máquina & Número de máquinas & Consumo teórico $(1 / \mathrm{h})$ & Consumo teórico anual $(1 /$ año $)$ \\
\hline Lavadora & 1.00 & 600 & $1,248,000$ \\
\hline
\end{tabular}

Elaboración propia 
La tabla anterior muestra un requerimiento teórico anual total de agua potable de 1, 248,000 1/año. Para encontrar el requerimiento real anual se obtendrá el porcentaje de utilización de la máquina por año (Kg lavados / Consumo teórico). Según el diagrama de bloques, se podrá obtener la cantidad de kilogramos de materia prima lavada anualmente.

Tabla 5. 29

Consumo real anual de agua potable por maquinaria (1/año)

\begin{tabular}{|c|c|c|c|}
\hline Año & $\begin{array}{c}\text { Consumo teórico anual } \\
(\mathrm{L} / \mathrm{año})\end{array}$ & $\%$ de utilización & $\begin{array}{c}\text { Consumo real } \\
\text { anual (L/año) }\end{array}$ \\
\hline 2018 & $1,248,000.00$ & $2.41 \%$ & $30,072.70$ \\
\hline 2019 & $1,248,000.00$ & $4.21 \%$ & $52,535.90$ \\
\hline 2020 & $1,248,000.00$ & $5.74 \%$ & $71,603.73$ \\
\hline 2021 & $1,248,000.00$ & $7.84 \%$ & $97,899.74$ \\
\hline 2022 & $1,248,000.00$ & $10.52 \%$ & $131,292.21$ \\
\hline
\end{tabular}

Elaboración propia

Por otro lado, la dotación de agua es interpretada como el consumo de agua por trabajador. En esta segunda variable, se considerará el consumo en litros por día del uso de sanitario, lavado de manos y aseo básico (no incluye ducha).

Tabla 5.30

Determinación de la dotación del agua por persona

\begin{tabular}{|c|c|}
\hline Tipo de consumo & Consumo (L/Persona-día) \\
\hline Sanitario & 35.67 \\
\hline Lavado de manos & 6.02 \\
\hline Aseo & 0.29 \\
\hline Total & $\mathbf{4 1 . 9 8}$ \\
\hline
\end{tabular}

Fuente: Escuela de Ingeniería de Antioquia (2009)

Para estimar el consumo de agua por trabajador se diferenciara los trabajadores fabriles y no fabriles. Además, se considerará que el número de trabajadores no varía durante la vida útil del proyecto y los mismos parámetros de horarios. 
Tabla 5. 31

Dotación de agua total

\begin{tabular}{|c|c|c|c|c|c|}
\cline { 2 - 6 } \multicolumn{1}{c|}{} & $\begin{array}{c}\text { Consumo } \\
\text { (L/Persona-día) }\end{array}$ & $\begin{array}{c}\text { Número de } \\
\text { trabajadores }\end{array}$ & $\begin{array}{c}\text { Consumo Total } \\
(\text { L/día })\end{array}$ & $\begin{array}{c}\text { Consumo Total } \\
\text { (L/mes) }\end{array}$ & $\begin{array}{c}\text { Consumo Total } \\
\text { (L/año) }\end{array}$ \\
\hline Fabril & 41.98 & 12.00 & 503.76 & $10,914.80$ & $130,977.60$ \\
\hline No fabril & 41.98 & 8.00 & 335.84 & $7,276.53$ & $87,318.40$ \\
\hline
\end{tabular}

Elaboración propia

Tabla 5. 32

Consumo total fabril de agua

\begin{tabular}{|c|c|c|c|}
\hline Año & $\begin{array}{c}\text { Consumo Total de } \\
\text { producción (L/Año) }\end{array}$ & $\begin{array}{c}\text { Consumo Total de } \\
\text { personas (L/año) }\end{array}$ & $\begin{array}{c}\text { Consumo Fabril Total } \\
\text { (L/Año) }\end{array}$ \\
\hline 2018 & $30,072.70$ & $130,977.60$ & $161,050.30$ \\
\hline 2019 & $52,535.90$ & $130,977.60$ & $183,513.50$ \\
\hline 2020 & $71,603.73$ & $130,977.60$ & $202,581.33$ \\
\hline 2021 & $97,899.74$ & $130,977.60$ & $228,877.34$ \\
\hline 2022 & $131,291.21$ & $130,977.60$ & $262,269.81$ \\
\hline
\end{tabular}

Elaboración propia

Tabla 5. 33

Consumo total no fabril de agua

\begin{tabular}{|c|c|c|}
\hline Año & $\begin{array}{c}\text { Consumo no } \\
\text { Fabril Total } \\
\text { (L/Año) }\end{array}$ & $\begin{array}{c}\text { Consumo } \\
\text { Total (L/mes) }\end{array}$ \\
\hline 2018 & $87,318.40$ & $7,276.53$ \\
\hline 2019 & $87,318.40$ & $7,276.53$ \\
\hline 2020 & $87,318.40$ & $7,276.53$ \\
\hline 2021 & $87,318.40$ & $7,276.53$ \\
\hline 2022 & $87,318.40$ & $7,276.53$ \\
\hline
\end{tabular}

Elaboración propia 


\subsubsection{Determinación del número de operarios y trabajadores indirectos}

El personal de la planta se compone por trabajadores directos (operarios que participan directamente en la producción del aceite de coco), así como también, por trabajadores indirectos. A continuación, se mostrará el cálculo para determinar la cantidad de colaboradores de la empresa.

\section{Número de operarios}

Tabla 5.34

Cálculo del número de operarios

\begin{tabular}{|c|c|c|c|c|c|c|c|c|}
\hline Operación & $\begin{array}{c}\text { Cantidad a } \\
\text { procesar } \\
(\mathrm{Kg} / \mathrm{año})\end{array}$ & $\begin{array}{c}\text { Cantidad a } \\
\text { procesar } \\
(\mathrm{Kg} / \mathrm{h})\end{array}$ & $\begin{array}{c}\text { Capacidad } \\
(\mathrm{Kg} / \mathrm{h})\end{array}$ & $\begin{array}{c}\text { NHR } \\
(\mathrm{Hora} / \mathrm{año})\end{array}$ & $\mathrm{E}(\%)$ & $\mathrm{U}(\%)$ & $\begin{array}{c}\text { Número } \\
\text { de } \\
\text { operarios }\end{array}$ & $\begin{array}{c}\text { Número } \\
\text { de }\end{array}$ \\
\hline Inspeccionar y seleccionar & $202,190.21$ & 97.21 & 180.00 & $2,080.00$ & $80 \%$ & $91.67 \%$ & 0.74 & 1.00 \\
\hline Cortar & $128,666.37$ & 61.86 & 135.00 & $2,080.00$ & $80 \%$ & $91.67 \%$ & 0.62 & 1.00 \\
\hline Verificar humedad & $92,639.79$ & 44.54 & 90.00 & $2,080.00$ & $80 \%$ & $91.67 \%$ & 0.67 & 1.00 \\
\hline Control de calidad & $68,790.60$ & 33.07 & 70.00 & $2,080.00$ & $80 \%$ & $91.67 \%$ & 0.64 & 1.00 \\
\hline Etiquetar & $68,790.60$ & 33.07 & 60.00 & $2,080.00$ & $80 \%$ & $91.67 \%$ & 0.75 & 1.00 \\
\hline Encajonar & $68,790.60$ & 33.07 & 72.00 & $2,080.00$ & $80 \%$ & $91.67 \%$ & 0.63 & 1.00 \\
\hline
\end{tabular}

Elaboración propia

\section{Número de trabajadores indirectos}

Tabla 5.35

Número de trabajadores indirectos de producción

\begin{tabular}{|l|c|}
\hline \multicolumn{1}{|c|}{ Cargo } & No de personas \\
\hline Jefe de Producción & 1.00 \\
\hline Jefe Control de Calidad & 1.00 \\
\hline Auxiliar de Control de Calidad & 1.00 \\
\hline Jefe de Mantenimiento & 1.00 \\
\hline Auxiliar de Mantenimiento & 1.00 \\
\hline Auxiliar de Almacén & 1.00 \\
\hline Operarios & 6.00 \\
\hline
\end{tabular}

Elaboración propia 


\subsubsection{Servicios de terceros}

El servicio de terceros es importante porque facilita que la empresa se centre en su esencia, aumente la productividad y mejore la operación (Portafolio, 2015). La planta contará con servicio de terceros en el aspecto de transporte, vigilancia y soporte técnico.

\section{Transporte}

El servicio de transporte se encargará de transportar el producto terminado una vez a la semana hacia los supermercados. Los proveedores postulantes para trabajar con Cocoil deberán pasar por una homologación de proveedores para cumplir ciertos requisitos que serán indispensables para el funcionamiento correcto en planta. Además, deberán cumplir las políticas de seguridad, calidad y controles dentro y fuera de la empresa.

\section{Vigilancia}

El servicio de vigilancia constará de un vigilante durante el horario de operación y otro agente por el turno nocturno. Ambos se encargarán de la vigilancia y de salvaguardar la seguridad de la planta, así como también, de los trabajadores de esta. Al final de cada turno, el personal de seguridad deberá elaborar reportes para tener registrados casi incidentes, incidentes, accidentes y observaciones.

\section{Soporte técnico}

El servicio de soporte técnico se encargará de la asistencia a los usuarios de equipos informáticos para asegurar el perfecto funcionamiento de la empresa sin contratiempos. Adicional a esto, el soporte técnico tiene como responsabilidad realizar los mantenimientos preventivos programados y los mantenimientos correctivos de los equipos electrónicos en caso necesiten de esta.

\subsection{Disposición de planta}

\subsubsection{Características físicas del proyecto}

El área requerida total para el óptimo funcionamiento del proyecto es de $436 \mathrm{~m}^{2}$ y estará ubicado en el distrito de Lurín en Lima Metropolitana. 
Tabla 5.36

Área requerida para el proyecto

\begin{tabular}{|c|c|c|c|}
\hline & Áreas & $\mathrm{m} 2$ & Total \\
\hline \multirow{6}{*}{ Fabril } & Almacén PT & 19.98 & \multirow{6}{*}{212.17} \\
\hline & Almacén MMPP & 54.40 & \\
\hline & Zona producción & 87.64 & \\
\hline & Calidad & 14.50 & \\
\hline & $\begin{array}{l}\text { Patio de carga y } \\
\text { descarga }\end{array}$ & 27.65 & \\
\hline & SSHH producción & 8.00 & \\
\hline \multirow{6}{*}{ No fabril } & $\begin{array}{l}\text { SSHH administrativo } \\
\text { (2) }\end{array}$ & 23.00 & \multirow{6}{*}{223.61} \\
\hline & Administrativo & 39.00 & \\
\hline & Comedor & 17.38 & \\
\hline & Tópico & 12.00 & \\
\hline & Estacionamiento & 114.23 & \\
\hline & Pasadizo & 18.00 & \\
\hline & Total terreno & 436.00 & \\
\hline
\end{tabular}

Elaboración propia

El detalle del área requerida para cada zona puede verse en las líneas posteriores.

\subsubsection{Determinación de las zonas físicas requeridas Área de almacenes}

Se requiere de dos almacenes, uno para materia prima e insumos y otro para producto terminado. Dichos almacenes deben estar ubicados en lugares que faciliten su acceso y llegada a este sin mayor esfuerzo (Diaz, Jarufe, \& Noriega, 2007). Los cálculos para determinar las áreas requeridas se realizaron en base a la demanda del último año del proyecto.

\section{Almacén de materia prima e insumos}

Para el almacén de materia prima se recibirán jabas de 52.2 x 36.2 x $31.5 \mathrm{~cm}$ las cuales contendrán 12 cocos de, aproximadamente, $1.5 \mathrm{~kg}$ cada uno. Dichas jabas serán apiladas una sobre otra hasta 7 niveles, se considera un techo de 2.5 metros. Además, se conoce que el requerimiento de materia prima para el último año del proyecto asciende a 202,190.21 kg de coco anuales, para calcular el área del almacén de materia prima e insumos se considerará reposición mensual, es decir, $16,849.18 \mathrm{~kg}$. 
Con esta información, se calculó que el número total de jabas requeridas, para una la demanda mensual de cocos, es de 937 unidades ya que cada jaba contiene $18 \mathrm{~kg}$. Entonces, al dividir el total de jabas entre la cantidad de jabas apiladas (7) se obtiene 134 posiciones a nivel del piso. Estas posiciones al ser multiplicadas por el área cuadrada de cada jaba $\left(0.19 \mathrm{~m}^{2}\right)$ se obtiene un área requerida de $25.32 \mathrm{~m}^{2}$ para almacenar la materia prima.

Figura 5.8

Jaba

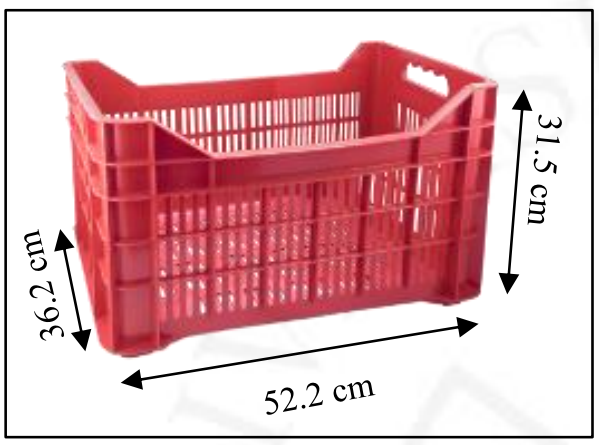

Fuente: Basa (2016)

Para el área que ocuparán los insumos (cajas y envases) también se considerará el requerimiento mensual. Cada caja contendrá 12 envases con sus respectivas tapas. Las dimensiones de la caja son 33.5 × 25 × $10 \mathrm{~cm}$ y las de un frasco son $8 \mathrm{~cm}$ de diámetro y $8 \mathrm{~cm}$ de altura. Con esta información, se calculó que el número de cajas necesarias para almacenar los frascos vacíos mensualmente es de 2,389 que serán apilados en 10 niveles. Entonces, al dividir el número de cajas entre el número de niveles, se obtiene 239 posiciones a nivel del piso. Con esta información, se multiplican las posiciones por el área ocupada de cada caja $\left(0.08 \mathrm{~m}^{2}\right)$ y se obtiene un área para insumos de $20.02 \mathrm{~m}^{2}$.

Adicional a las áreas calculadas, se considera un $20 \%$ más de espacio para el tránsito de los elementos móviles, así se obtiene un área de $54.40 \mathrm{~m}^{2}$ para el almacén de materias primas e insumos. 
Figura 5. 9

Presentación de frasco de vidrio

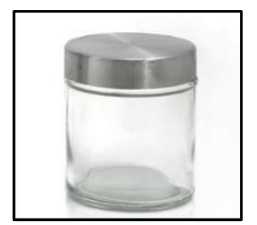

Fuente: Levys Bazar (2016)

Figura 5. 10

Presentación del empaque

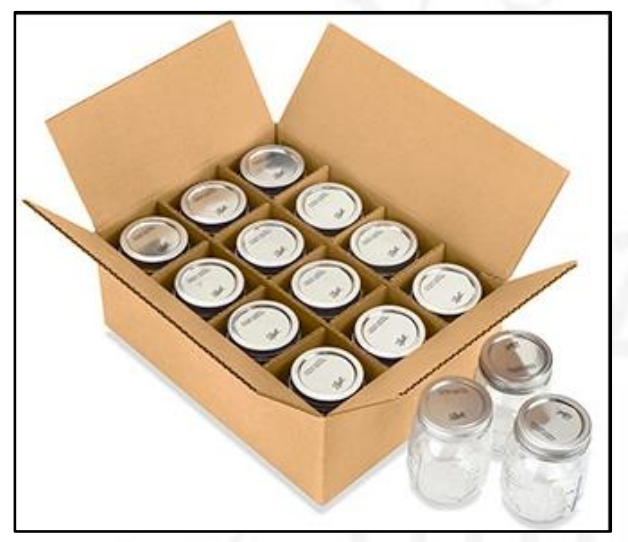

Fuente: ULINE (2016)

\section{Almacén de producto terminado}

Para el área que ocupará el producto terminado, se considerará reposición semanal. El producto terminado será almacenado en pallets y con un máximo de 5 niveles de cajas. Con esta información, se calculó que el número de pallets necesarios para almacenar las cajas con producto terminado es de 10. Cabe resaltar que cada pallet tiene un contenido de 60 cajas y que mide $100 \mathrm{x}$ 120 x $14.4 \mathrm{~cm}$. Entonces, al multiplicar el número de pallets por el área que ocupa cada uno (1.2 $\mathrm{m}^{2}$ ) se obtiene el área requerida para almacenar producto terminado. Adicional a esto, se considera un espacio entre pallets almacenados de $10 \mathrm{~cm}$ y un $20 \%$ más para el tránsito de los elementos móviles.

Finalmente, se adiciona una zona de $4.5 \mathrm{~m}^{2}$ que servirá de oficina para el auxiliar de almacén. Todo esto da un área total para el almacén de productos terminados de $19.98 \mathrm{~m}^{2}$. 


\section{Área de oficinas}

El área de oficinas contará con los módulos de trabajo para los distintos cargos requeridos para el proyecto. Se dispondrá de $10 \mathrm{~m}^{2}$ para los jefes, $4.5 \mathrm{~m}^{2}$ para los asistentes y $23 \mathrm{~m}^{2}$ para gerencia general, así se asegurará que cada trabajador cuente con el espacio suficiente y adecuado para un óptimo desempeño laboral. Esta área se distribuirá en dos niveles, en el primer piso se ubicarán las áreas que tengan mayor relación con el área de producción.

Tabla 5. 37

Requerimiento área para oficinas

\begin{tabular}{|c|c|c|c|c|}
\hline Cargo & $\begin{array}{c}\mathrm{N}^{\mathrm{o}} \mathrm{de} \\
\text { personas }\end{array}$ & $\begin{array}{c}\text { Espacio } \\
\text { requerido }(\mathrm{m} 2)\end{array}$ & Nivel & $\mathrm{m}^{2}$ \\
\hline Jefe de Distribución y Logística & 1.00 & 10.00 & 1.00 & \multirow{5}{*}{39.00} \\
\hline Asistente de Distribución y Logística & 1.00 & 4.50 & 1.00 & \\
\hline Jefe de Producción & 1.00 & 10.00 & 1.00 & \\
\hline Jefe de Mantenimiento & 1.00 & 10.00 & 1.00 & \\
\hline Auxiliar de Mantenimiento & 1.00 & 4.50 & 1.00 & \\
\hline Gerente General & 1.00 & 23.00 & 2.00 & \multirow{6}{*}{62.00} \\
\hline Jefe de Administración y Finanzas & 1.00 & 10.00 & 2.00 & \\
\hline Asistente de Administración y Finanzas & 1.00 & 4.50 & 2.00 & \\
\hline Jefe Comercial & 1.00 & 10.00 & 2.00 & \\
\hline Asistente de Marketing & 1.00 & 4.50 & 2.00 & \\
\hline Jefe de Recursos Humanos & 1.00 & 10.00 & 2.00 & \\
\hline
\end{tabular}

Elaboración propia

\section{Zona de calidad}

Tabla 5. 38

Zona de calidad

\begin{tabular}{|c|c|c|}
\hline Cargo & $\mathrm{N}^{\mathrm{o}}$ de personas & Espacio requerido (m2) \\
\hline Jefe Control de Calidad & 1.00 & 10.00 \\
\hline Auxiliar de Control de Calidad & 1.00 & 4.50 \\
\hline Área total & \multicolumn{2}{|c|}{$14.50 \mathrm{~m} 2$} \\
\hline
\end{tabular}

Elaboración propia 


\section{Patio de carga y descarga}

Dicha zona se utilizará, principalmente, para la descarga de materia prima requerida en el proceso de producción y para el despacho de las cajas de producto terminado.

Para determinar el área requerida, se usará como referencia un camión de dimensiones de $8 \times 2.4 \mathrm{~m}$ y se considera un $20 \%$ adicional a cada lado para las maniobras necesarias, lo que aumenta las medidas a 9.6 x $2.88 \mathrm{~m}$. Por lo que se requerirá un área de $27.65 \mathrm{~m}^{2}$.

Figura 5. 11

Dimensiones del camión

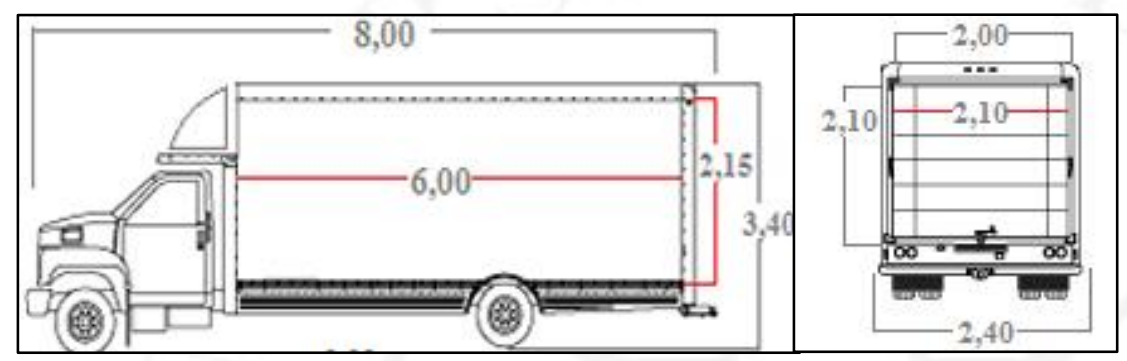

Fuente: Autointegra (2016)

\section{Área de comedor}

Se destinará una zona de comedor para los trabajadores, este se ubicará dentro del centro de trabajo y en un lugar que no ofrezcan riesgos de contaminación ambiental (Diaz, Jarufe, \& Noriega, 2007).

Se requiere de $1.58 \mathrm{~m}^{2}$ por empleado que se encontrará almorzando, se cuenta con 20 trabajadores y la hora de refrigerio se hará en dos turnos, uno de administración y otro de producción, por lo que se requerirá un área aproximada de $15.80 \mathrm{~m}^{2}$.

Cabe mencionar que el horario de refrigerio del personal de mantenimiento será junto con el de los administrativos para que realice el mantenimiento preventivo de las máquinas mientras que estás no estén operando.

\section{Área de estacionamiento}

Se reservará un área de $15.86 \mathrm{~m}^{2}$ por estacionamiento para cada vehículo y se contará con espacio para 6. Así el área total será de $95.19 \mathrm{~m}^{2}$, adicionalmente se considerará un 20\% adicional para maniobras, por lo que se requerirá un área de $114.23 \mathrm{~m}^{2}$. 


\subsubsection{Cálculo de áreas para cada zona}

Para calcular los espacios físicos necesarios para el funcionamiento de la planta se utilizará el método de Guerchet..

Para el cálculo del factor " $\mathrm{k}$ " se utilizó la siguiente fórmula:

$$
\mathrm{k}=\frac{\mathrm{h}_{\mathrm{EM}}}{2 * \mathrm{~h}_{\mathrm{EE}}}=\frac{1.31}{2 * 1.17}=0.56
$$

Tabla 5.39

Guerchet de elementos estáticos

\begin{tabular}{|c|c|c|c|c|c|c|c|c|c|c|c|}
\hline Máquinas & $\mathrm{n}$ & $\mathrm{N}$ & $\mathrm{l}(\mathrm{m})$ & $\mathrm{a}(\mathrm{m})$ & $\mathrm{h}(\mathrm{m})$ & $\mathrm{Ss}(\mathrm{m} 2)$ & $\mathrm{Sg}(\mathrm{m} 2)$ & $\mathrm{Se}(\mathrm{m} 2)$ & $\mathrm{St}(\mathrm{m} 2)$ & $\mathrm{Ss} * \mathrm{n}$ & $\mathrm{Ss}{ }^{\mathrm{n}} * \mathrm{~h}$ \\
\hline Báscula industrial & 1.00 & 1.00 & 0.60 & 0.45 & 0.80 & 0.27 & 0.27 & 0.30 & 0.84 & 0.27 & 0.22 \\
\hline Descascarador & 1.00 & 1.00 & 1.00 & 0.80 & 1.00 & 0.80 & 0.80 & 0.89 & 2.49 & 0.80 & 0.80 \\
\hline Lavadora & 1.00 & - & 3.00 & 1.10 & 1.30 & 3.30 & - & 1.84 & 5.14 & 3.30 & 4.29 \\
\hline Deshidratador & 1.00 & 1.00 & 0.80 & 0.50 & 0.73 & 0.40 & 0.40 & 0.45 & 1.25 & 0.40 & 0.29 \\
\hline Bomba & 1.00 & - & 0.50 & 0.19 & 0.36 & 0.09 & - & 0.05 & 0.15 & 0.09 & 0.03 \\
\hline Molino & 1.00 & - & 0.90 & 0.90 & 0.90 & 0.81 & - & 0.45 & 1.26 & 0.81 & 0.73 \\
\hline Tornillo sin fin & 1.00 & - & 4.00 & 0.20 & 0.20 & 0.80 & - & 0.45 & 1.25 & 0.80 & 0.16 \\
\hline Prensa & 1.00 & - & 1.75 & 0.90 & 1.65 & 1.58 & - & 0.88 & 2.45 & 1.58 & 2.60 \\
\hline Filtro prensa & 1.00 & - & 3.60 & 1.30 & 1.30 & 4.68 & - & 2.61 & 7.29 & 4.68 & 6.08 \\
\hline Envasadora tapadora & 1.00 & 1.00 & 2.50 & 2.00 & 1.60 & 5.00 & 5.00 & 5.58 & 15.58 & 5.00 & 8.00 \\
\hline Faja transportadora & 1.00 & 1.00 & 5.00 & 0.75 & 0.95 & 3.75 & 3.75 & 4.19 & 11.69 & 3.75 & 3.56 \\
\hline Faja transportadora & 2.00 & - & 1.65 & 0.21 & 0.95 & 0.35 & - & 0.19 & 1.08 & 0.69 & 0.66 \\
\hline Mesa de corte & 1.00 & 1.00 & 1.10 & 0.60 & 0.90 & 0.66 & 0.66 & 0.74 & 2.06 & 0.66 & 0.59 \\
\hline Pallet & 1.00 & - & 1.00 & 1.20 & 0.14 & 1.20 & - & 0.67 & 1.87 & 1.20 & 0.17 \\
\hline
\end{tabular}

Elaboración propia

Tabla 5.40

Guerchet de elementos móviles

\begin{tabular}{|c|c|c|c|c|c|c|c|c|}
\hline Máquinas & $\mathrm{n}$ & $\mathrm{N}$ & $\mathrm{l}(\mathrm{m})$ & $\mathrm{a}(\mathrm{m})$ & $\mathrm{h}(\mathrm{m})$ & $\mathrm{Ss}(\mathrm{m} 2)$ & $\mathrm{Ss}{ }^{*} \mathrm{n}$ & $\mathrm{Ss}{ }^{*} \mathrm{n} * \mathrm{~h}$ \\
\hline Carretilla hidráulica & 1.00 & & 1.80 & 0.70 & 0.50 & 1.26 & 1.26 & 0.63 \\
\hline Operarios & 6.00 & 1.00 & & & 1.65 & 0.50 & 3.00 & 4.95 \\
\hline
\end{tabular}

Elaboración propia 


\subsubsection{Dispositivos de seguridad industrial y señalización}

La seguridad del personal es muy importante debido a que estos se enfrentan a constantes riesgos laborales que pueden causar alguna enfermedad o lesión. Por eso, es necesario tener políticas de prevención y protección.

El uso del equipo de protección personal (EPP) es necesario en el área operativa. El EPP disminuye el riesgo y brinda protección al personal contra accidentes que afecten su integridad física. El EPP deberá cumplir estándares internacionales.

Tabla 5.41

Equipos de protección personal

\begin{tabular}{|l|l|l|l|}
\hline EPPS & Casco & Lentes de seguridad & Botas punta de acero \\
\hline Imagen & &
\end{tabular}

Elaboración propia

Tabla 5.42

Dispositivos de seguridad

\begin{tabular}{|l|l|l|l|l|}
\hline EPPS & Tapones auditivos & Guantes & Enclavamiento \\
\hline Imagen & & &
\end{tabular}

Elaboración propia

Además, la planta contará con señalización visible relacionada a la seguridad en cada área y clasificado por colores. Se espera que el personal respete y obedezca las señales y carteles 
colocados en las instalaciones de la empresa. A continuación, se muestran algunas señales de seguridad.

Tabla 5.43

Señalización

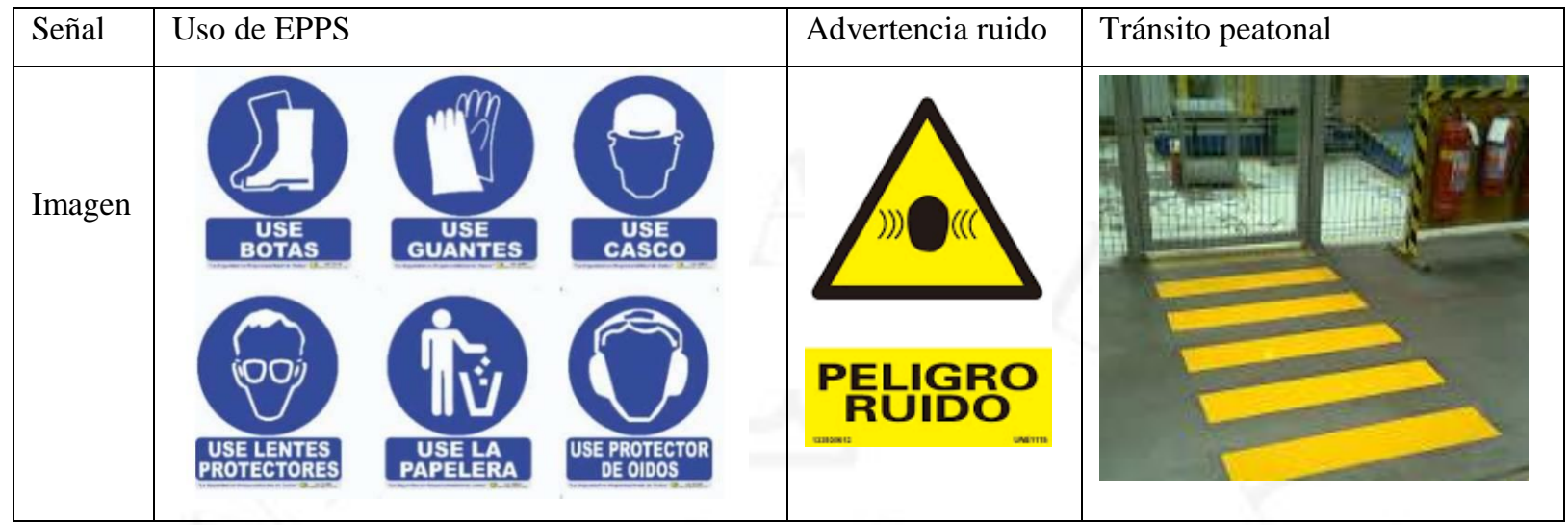

Elaboración propia

Finalmente, la empresa debe cumplir con la ley $\mathrm{N}^{\circ} 29783$ para promover una cultura de prevención en el país y evitar accidentes (Ministro de Trabajo y Promoción del Empleo, 2012). A continuación, se muestran algunas obligaciones para cumplir la norma.

Tabla 5.44

Señales de seguridad

\begin{tabular}{|l|l|l|l|}
\hline Señal & Salida de emergencia & Extintor & Alarma industrial \\
\hline Imagen & & & \\
\hline
\end{tabular}

Elaboración propia 


\subsubsection{Disposición general}

Figura 5. 12

Plano

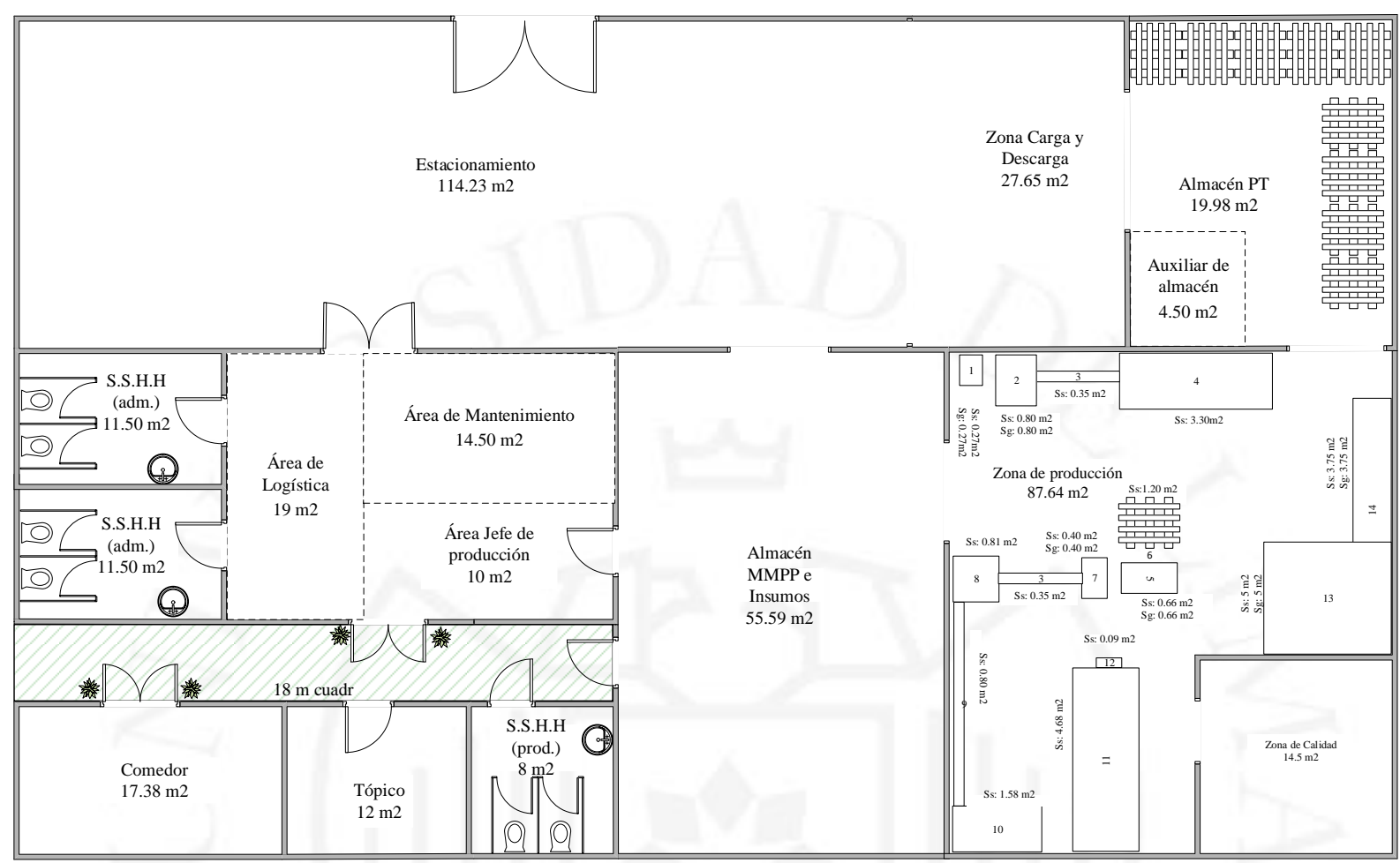

\begin{tabular}{|c|c|c|c|c|c|c|}
\hline \multirow{2}{*}{$\begin{array}{l}\text { Les } \\
\text { 1. Báscula industrial } \\
\text { 2. Descascaradora } \\
\text { 3. Faja transportadora } \\
\text { 4. Lavadora } \\
\text { 5. Mesa de corte } \\
\text { 6. Pallet } \\
\text { 7. Deshidratador }\end{array}$} & \multirow{2}{*}{$\begin{array}{l}\text { 8. Molino } \\
\text { 9. Tomillo sin fin } \\
\text { 10. Prensa } \\
\text { 11. Filtro prensa } \\
\text { 12. Bomba } \\
\text { 13. Envasadora tapadora } \\
\text { 14. Faja transpottadora grande }\end{array}$} & & \multicolumn{4}{|c|}{$\begin{array}{l}\text { Estudio De factibilidad para la instalación de una planta de producción de aceite de coco } \\
\text { Escuela de Ingeniería - Facultad de Ingeniería Industrial }\end{array}$} \\
\hline & & $\begin{array}{l}\text { Escala: } \\
\text { 1:100 }\end{array}$ & $\begin{array}{c}\text { Área: } \\
436 \mathrm{~m} 2\end{array}$ & $\begin{array}{c}\text { Fecha: } \\
\text { Diciembre } 2018\end{array}$ & $\begin{array}{l}\text { Dibujantes: } \\
\text { Chamorro Chávez Carmen Jesús } \\
\text { Noli Alva Adela Devly }\end{array}$ & $\begin{array}{l}20110300 \\
20112095\end{array}$ \\
\hline
\end{tabular}

Nota: Ver plano a escala en Anexo Plano de Planta.

Elaboración propia

\subsubsection{Disposición de detalle}

Luego de calcular los espacios físicos requeridos en la planta, se procede a realizar la disposición de detalle con una tabla relacional y el diagrama relacional de actividades. Esto permite la correcta distribución de los espacios basándose en la proximidad que deben tener las áreas productivas, administrativas y de servicios. 
Figura 5. 13

Tabla de actividades

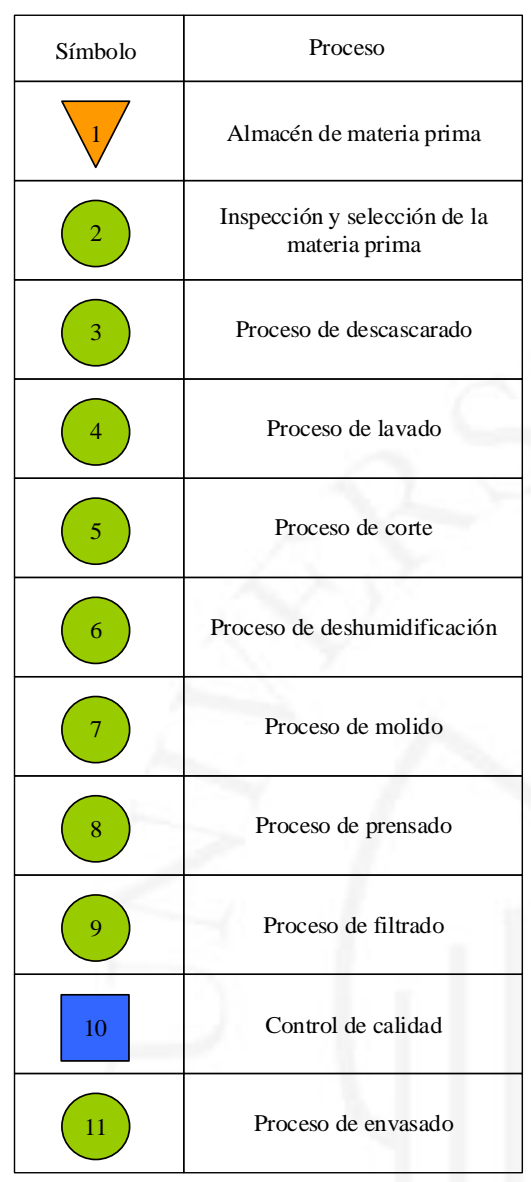

\begin{tabular}{|c|c|}
\hline Símbolo & Proceso \\
\hline & Proceso de tapado \\
\hline & Proceso de etiquetado \\
\hline & Proceso de encajonado \\
\hline & $\begin{array}{l}\text { Almacén de producto } \\
\text { terminado }\end{array}$ \\
\hline & Patio de carga y descarga \\
\hline & Oficinas administrativas \\
\hline & Estacionamiento \\
\hline & Comedor \\
\hline & Tópico \\
\hline & $\begin{array}{l}\text { Servicios higiénicos } \\
\text { (producción) }\end{array}$ \\
\hline & $\begin{array}{l}\text { Servicios higiénicos } \\
\text { (administración) }\end{array}$ \\
\hline
\end{tabular}

Elaboración propia

Tabla 5. 45

\section{Lista de motivos}

\begin{tabular}{|rl|}
\hline \multicolumn{2}{|c|}{ Motivos } \\
\hline 0. & Sin relación \\
\hline 1. & Secuencia de operaciones \\
\hline 2. & Abastecimiento de materiales \\
\hline 3. & Control \\
\hline 4. & Gestión de logística \\
\hline 5. & Servicio \\
\hline
\end{tabular}

Elaboración propia 
Tabla 5.46

Escala de valores para la proximidad de las actividades

\begin{tabular}{|l|l|}
\hline Código & \multicolumn{1}{|c|}{ Valor de proximidad } \\
\hline A & Absolutamente necesario \\
\hline E & Especialmente necesario \\
\hline I & Importante \\
\hline O & Normal u ordinario \\
\hline U & Sin importancia \\
\hline $\mathrm{X}$ & No recomendable \\
\hline
\end{tabular}

Elaboración propia 
Figura 5. 14

Tabla relacional de actividades

\begin{tabular}{|c|c|c|}
\hline Símbolo & Proceso & \\
\hline 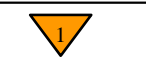 & Almacén de materia prima & \\
\hline & Inspección y selección de la materia prima & \\
\hline & Proceso de descascarado & \\
\hline & Proceso de lavado & \\
\hline & Proceso de corte & \\
\hline & Proceso de deshumidificación & \\
\hline & Proceso de molido & \\
\hline & Proceso de prensado & \\
\hline & Proceso de filtrado & \\
\hline 10 & Control de calidad & $00 / 0 / 0 / 000$ \\
\hline & Proceso de envasado & \\
\hline & Proceso de tapado & 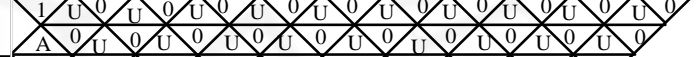 \\
\hline & Proceso de etiquetado & \\
\hline & Proceso de encajonado & $00 / 0 / 0000 / 00 / 00$ \\
\hline & Almacén de producto terminado & \\
\hline$\square$ & Patio de carga y descarga & \\
\hline & Oficinas administrativas & \\
\hline & Estacionamiento & \\
\hline & Comedor & \\
\hline & Tópico & \\
\hline & Servicios higiénicos (producción) & \\
\hline 22 & Servicios higiénicos (administración) & \\
\hline
\end{tabular}

Elaboración propia 
Figura 5. 15

Diagrama relacional

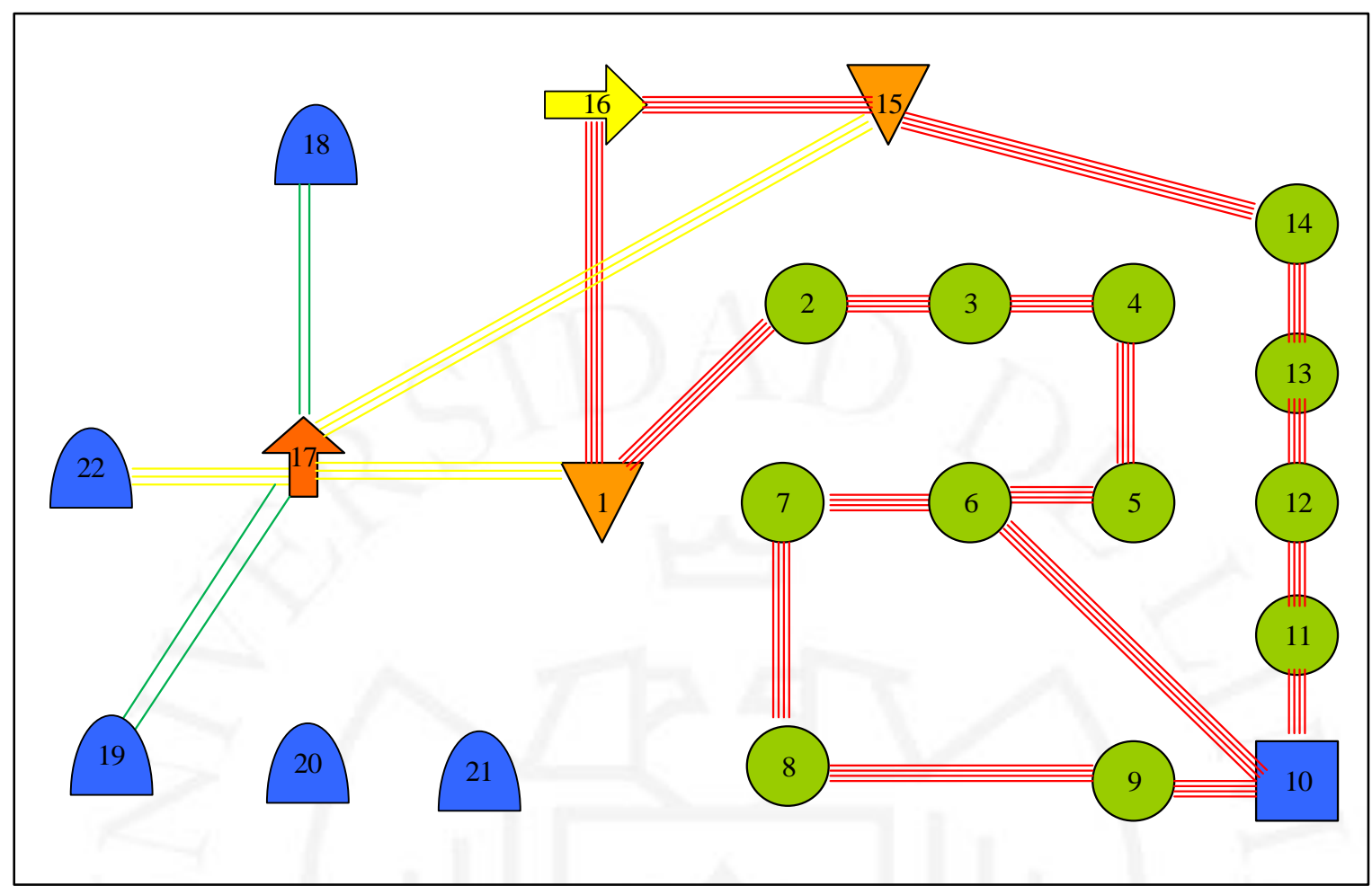

Elaboración propia 


\subsection{Cronograma de implementación del proyecto}

\section{Tabla 5.47}

\section{Cronograma}

\begin{tabular}{|l|l|l|l|l|l|l|l|l|l|l|}
\hline & Actividad & $\begin{array}{l}\text { Duración } \\
\text { (meses) }\end{array}$ & $\begin{array}{l}\text { Dic.- } \\
18\end{array}$ & $\begin{array}{l}\text { Ene.- } \\
19\end{array}$ & $\begin{array}{l}\text { Feb.- } \\
19\end{array}$ & $\begin{array}{l}\text { Mar.- } \\
19\end{array}$ & $\begin{array}{l}\text { Abr.- } \\
19\end{array}$ & $\begin{array}{l}\text { May.- } \\
19\end{array}$ & $\begin{array}{l}\text { Jun.- } \\
19\end{array}$ & $\begin{array}{l}\text { Jul.- } \\
19\end{array}$ \\
\hline 1 & Estudio de pre factibilidad & 1 & & & & & & & & \\
\hline 2 & Estudio de factibilidad & 1 & & & & & & & & \\
\hline 3 & Análisis de capital propio & 1 & & & & & & & & \\
\hline 4 & Búsqueda de financiamiento & 1 & & & & & & & & \\
\hline 5 & Compra de terreno & 1 & & & & & & & & \\
\hline 6 & Construcción de la planta & 3 & & & & & & & & \\
\hline 7 & $\begin{array}{l}\text { Compra de maquinaria de } \\
\text { producción }\end{array}$ & 2 & & & & & & & & \\
\hline 8 & $\begin{array}{l}\text { Instalación de maquinaria } \\
\text { Compra de equipos } \\
\text { administrativos }\end{array}$ & 1 & & & & & & & & \\
\hline 10 & $\begin{array}{l}\text { Proceso de selección y } \\
\text { contratación de personal }\end{array}$ & 1 & & & & & & & & \\
\hline 11 & Organización de la empresa & 1 & & & & & & & & \\
\hline 12 & Pruebas y puesta en marcha & 1 & & & & & & & & \\
\hline
\end{tabular}

Elaboración propia 


\section{CAPÍTULO VI. ORGANIZACIÓN Y ADMINISTRACIÓN}

\subsection{Formación de la Organización empresarial}

Se constituirá una sociedad anónima cerrada (SAC) compuesta por dos socios inicialmente. Para el buen funcionamiento de la empresa, se requiere de personal calificado que cumpla con una serie de requisitos y perfiles necesarios para cada puesto de trabajo. Además, para asegurar el éxito operativo, es necesaria la capacitación constante de los operarios y del personal administrativo.

\subsection{Requerimientos de personal directivo, administrativo y de servicios}

En este punto, se analizarán las funciones y los perfiles necesarios de los principales puestos.

Tabla 6. 1

Gerencia General

\begin{tabular}{|c|c|}
\hline Cargo & Gerente General \\
\hline Funciones & $\begin{array}{l}\text { - Dirigir, coordinar, proponer y controlar las diferentes actividades para el buen } \\
\text { funcionamiento de la empresa. } \\
\text { - } \quad \text { Realizar la planificación estratégica y ejecución de la empresa- } \\
\text { - Supervisar la gestión y el logro de objetivos. }\end{array}$ \\
\hline Requisitos & 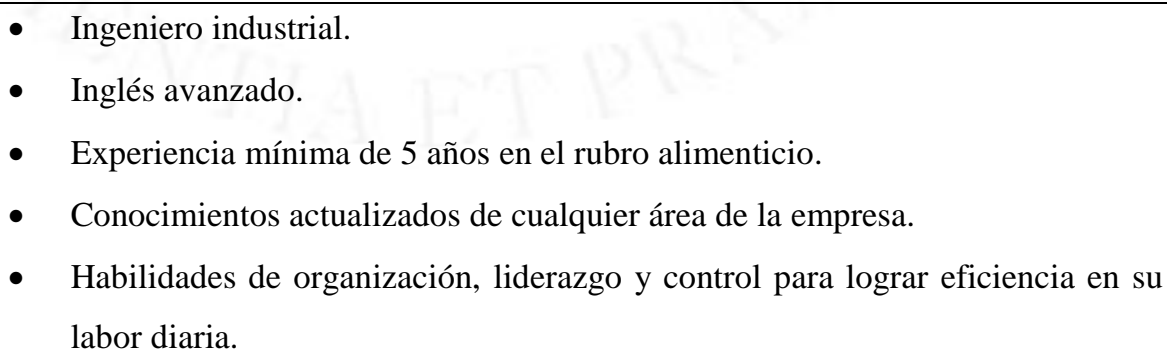 \\
\hline Sueldo estimado & 7,000 soles mensuales \\
\hline
\end{tabular}

Elaboración propia 
Tabla 6.2

Distribución y logística

\begin{tabular}{|c|c|c|}
\hline Cargo & Jefe de Distribución y Logística & Asistente de Distribución y Logística \\
\hline Fun & 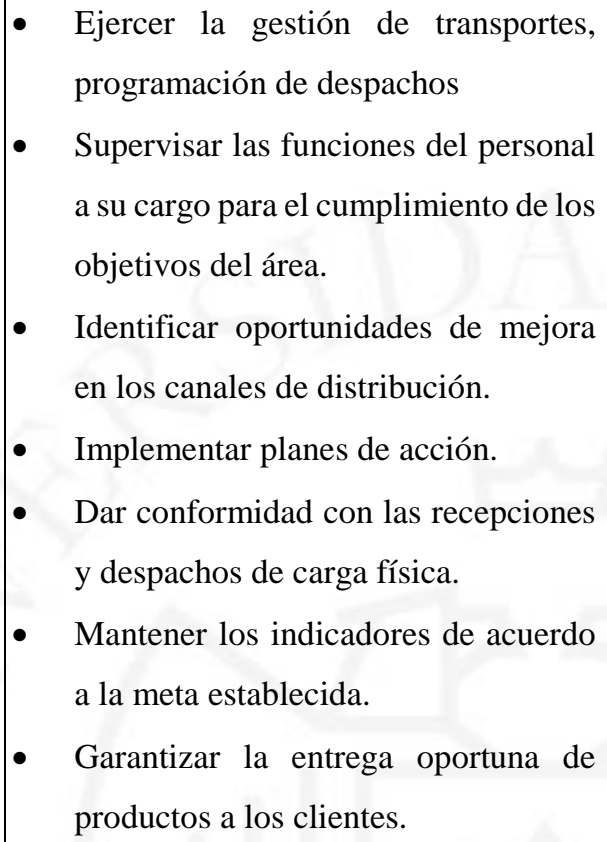 & 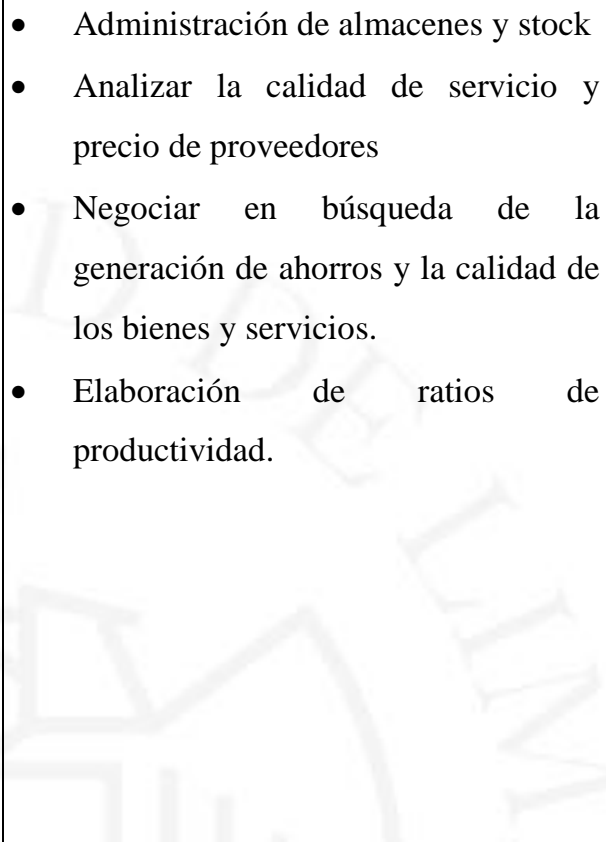 \\
\hline Requisitos & 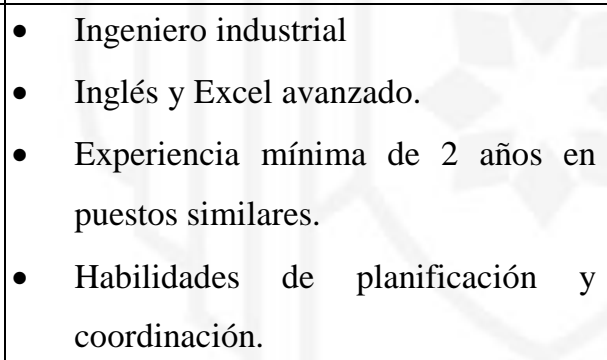 & $\begin{array}{l}\text { - } \quad \text { Bachiller de las carreras de ingeniería } \\
\text { industrial, sistemas o administración. } \\
\text { - } \quad \text { Excel avanzado e inglés intermedio. } \\
\text { - Experiencia mínima de } 1 \text { años en } \\
\text { puestos similares. }\end{array}$ \\
\hline Sueldo estimado & 5,000 soles mensuales. & 3,000 soles mensuales. \\
\hline
\end{tabular}

Elaboración propia 
Tabla 6.3

Almacén

\begin{tabular}{|l|l|}
\hline Cargo & Auxiliar de almacén \\
\hline Funciones & $\bullet \quad$ Ejercer la recepción y control de la materia prima e insumos de los proveedores. \\
& - $\quad$ Despachar el producto terminado. \\
& - $\quad$ Mantener el orden en el almacén \\
& - $\quad$ Realizar el inventario de los almacenes. \\
\hline Requisitos & $-\quad$ Experiencia mínima de un año en puestos similares en empresas afines. \\
& $-\quad$ Excel intermedio. \\
\hline Sueldo estimado & 2000 soles mensuales \\
\hline
\end{tabular}

Elaboración propia

Tabla 6.4

Administración y Finanzas

\begin{tabular}{|c|c|c|}
\hline Cargo & Jefe de Administración y Finanzas & Asistente de Administración y Finanzas \\
\hline Funciones & $\begin{array}{l}\text { - } \text { Realizar y analizar los Estados Financieros. } \\
\text { - } \text { Hacer seguimiento a los presupuestos de planta. } \\
\text { Supervisar el cumplimiento de las cuentas por } \\
\text { cobrar y pagar. } \\
\text { - Responsable del cierre contable mensual y de la } \\
\text { elaboración y presentación de los Estados } \\
\text { Financieros de la empresa. }\end{array}$ & $\begin{array}{l}\text { - Cobranza de facturas y letras. } \\
\text { - Emisión de Estados de Cuenta de } \\
\text { clientes. } \\
\text { - Emisión de reporte e informes. } \\
\text { - Control de los registros de las } \\
\text { cobranzas. }\end{array}$ \\
\hline Requisitos & $\begin{array}{l}\text { - Titulado en administración, ingeniería industrial o } \\
\text { economía. } \\
\text { - } \quad \text { Habilidades de análisis y planeamiento. } \\
\text { - } \quad \text { Experiencia mínima de } 2 \text { años en puestos similares. }\end{array}$ & $\begin{array}{l}\text { - Egresado de las carreras de } \\
\text { administración o economía. } \\
\text { - Excel avanzado e inglés intermedio. } \\
\text { - Experiencia mínima de } 1 \text { años en } \\
\text { puestos similares. }\end{array}$ \\
\hline $\begin{array}{l}\text { Sueldo } \\
\text { estimado }\end{array}$ & 5,000 soles mensuales. & 3,000 soles mensuales. \\
\hline
\end{tabular}

Elaboración propia 
Tabla 6.5

Comercial

\begin{tabular}{|c|c|c|}
\hline Cargo & Jefe Comercial & Asistente de Marketing \\
\hline Funciones & $\begin{array}{l}\text { - Liderar y dirigir las ventas. } \\
\text { - Asegurar la fidelización e incrementar la } \\
\text { cartera de clientes con estrategia en } \\
\text { ventas para lograr las metas asignadas. } \\
\text { - Hacer seguimiento a los programas de } \\
\text { clientes. } \\
\text { - Supervisar, controlar y evaluar el } \\
\text { personal a cargo. }\end{array}$ & $\begin{array}{l}\text { - } \text { Realizar proyecciones de las ventas y } \\
\text { campaña junto con el Jefe Comercial. } \\
\text { - Planificar y coordinar las publicaciones } \\
\text { encargadas por el área comercial con } \\
\text { terceros. } \\
\text { - Revisar y analizar la redacción en } \\
\text { publicidades, notas de prensa, web, } \\
\text { artículos, redes sociales, entre otros. }\end{array}$ \\
\hline Requisitos & $\begin{array}{l}\text { - Profesional en administración, ingeniería } \\
\text { o marketing. } \\
\text { - } \quad \text { Experiencia mínima de } 2 \text { años en puestos } \\
\text { similares } \\
\text { - Habilidades de coordinación y liderazgo. }\end{array}$ & 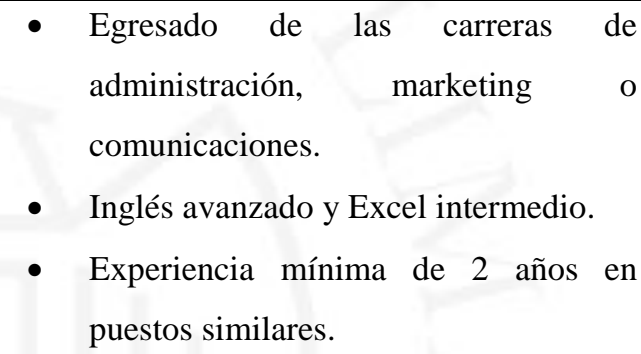 \\
\hline Sueldo estimado & 5,000 soles mensuales. & 3,000 soles mensuales. \\
\hline
\end{tabular}

Elaboración propia

Tabla 6.6

Recursos Humanos

\begin{tabular}{|l|l|}
\hline Cargo & Jefe de Recursos Humanos \\
\hline Funciones & $\bullet \quad$ Supervisar la información del personal de planta, debe controlar los procesos de nómina, \\
& $\begin{array}{l}\text { contratos, procesos administrativos, cumplimiento legal y asegurar que el pago a los } \\
\text { trabajadores sean los correctos y a tiempo. }\end{array}$ \\
& $\bullet \quad$ Debe dirigir los procesos de recursos humanos y de trabajar con base de datos en Excel. \\
\hline Requisitos & $\bullet \quad$ Licenciado o bachiller en administración de empresas, ingeniería industrial o psicología. \\
& $\bullet \quad$ Inglés intermedio y Excel avanzado. \\
& $\bullet \quad$ Experiencia mínima de 2 años en puestos similares. \\
& $\bullet \quad$ El jefe de recursos humanos debe tener experiencia mínima de 2 años en puestos similares. \\
\hline Sueldo estimado & 5,000 soles mensuales. \\
\hline
\end{tabular}

Elaboración propia 
Tabla 6.7

Producción

\begin{tabular}{|c|c|c|}
\hline Cargo & Jefe de Producción & Operarios de Producción \\
\hline Funciones & $\begin{array}{l}\text { - Supervisar todo el proceso de operación, coordinar } \\
\text { labores del personal. } \\
\text { - } \quad \text { Velar por el cumplimiento de los KPI's del área. } \\
\text { - Encargado de tener la producción siempre al día y } \\
\text { sin atrasos. }\end{array}$ & $\begin{array}{l}\text { - } \text { Manejar las máquinas } \\
\text { asignadas, además de } \\
\text { específicos trabajos manuales. }\end{array}$ \\
\hline Requisitos & $\begin{array}{l}\text { - Ingeniero industrial. } \\
\text { - Inglés a nivel intermedio. } \\
\text { - Experiencia mínima de } 5 \text { años en plantas de } \\
\text { consumo alimenticio. } \\
\text { - Habilidades de buena comunicación, planificación y } \\
\text { organización. }\end{array}$ & $\begin{array}{l}\text { - } \text { Secundaria completa. } \\
\text { - Experiencia mínima de } 1 \text { año } \\
\text { como operarios de producción. }\end{array}$ \\
\hline Sueldo estimado & 5,000 soles mensuales. & 900 soles mensuales. \\
\hline
\end{tabular}

Elaboración propia

Tabla 6.8

Calidad

\begin{tabular}{|c|c|c|}
\hline Cargo & Jefe de Control de Calidad & Auxiliar de Control de Calidad \\
\hline Funciones & $\begin{array}{l}\text { - Verificar los parámetros de calidad (peso, } \\
\text { color, características } \\
\text { microbiológicas, entre otros) desde la } \\
\text { materia prima hasta el producto terminado } \\
\text { empaquetado para confirmar si el producto } \\
\text { es apto para consumo o no. }\end{array}$ & $\begin{array}{l}\text { - Elaborar y actualizar la información del } \\
\text { estatus de las materias primas, materiales } \\
\text { de envase y empaque y producto } \\
\text { terminado. } \\
\text { - Generación de los reportes de análisis de } \\
\text { las materias primas, materiales de envase y } \\
\text { empaque, producto terminado y } \\
\text { microbiológicos. }\end{array}$ \\
\hline Requisitos & $\begin{array}{l}\text { - Ingeniero químico } \\
\text { - Inglés a nivel intermedio. } \\
\text { - Experiencia mínima de } 3 \text { años en puestos } \\
\text { similares. } \\
\text { - Conocimientos técnicos para evaluar la } \\
\text { calidad del producto en cualquier parte del } \\
\text { proceso. }\end{array}$ & $\begin{array}{l}\text { - Egresado en ingeniería química } \\
\text { - Inglés y Excel a nivel intermedio. } \\
\text { - Experiencia mínima de } 2 \text { años en puestos } \\
\text { similares. } \\
\text { - Conocimientos técnicos para evaluar la } \\
\text { calidad del producto en cualquier parte del } \\
\text { proceso. }\end{array}$ \\
\hline Sueldo estimado & 4,000 soles mensuales. & 2,000 soles mensuales. \\
\hline
\end{tabular}

Elaboración propia 
Tabla 6.9

Mantenimiento

\begin{tabular}{|c|c|c|}
\hline Cargo & Jefe de Mantenimiento & Auxiliar de Mantenimiento \\
\hline Funciones & $\begin{array}{l}\text { - Asignar al auxiliar para revisar las máquinas } \\
\text { durante los mantenimientos preventivos y } \\
\text { correctivos para asegurar la eficiencia y } \\
\text { eficacia de ellas. } \\
\text { Cumplir el programa de mantenimiento y } \\
\text { mantenerlo actualizado }\end{array}$ & $\begin{array}{l}\text { - Reparación y mantenimiento de } \\
\text { maquinaria. }\end{array}$ \\
\hline Requisitos & $\begin{array}{l}\text { - } \\
\text { - } \quad \text { Ingeniero industrial. } \\
\text { Expécnico a nivel avanzado. } \\
\text { similares. } \\
\text { Conocimientos técnicos en el desarrollo del } \\
\text { plan de mantenimiento. }\end{array}$ & $\begin{array}{l}\text { - } \quad \text { Carrera técnica. } \\
\text { - } \text { Inglés técnico a nivel intermedio. } \\
\text { Experiencia mínima de } 2 \text { años con } \\
\text { maquinaria similar. } \\
\text { Conocimientos técnicos en el } \\
\text { desarrollo del plan de } \\
\text { mantenimiento. }\end{array}$ \\
\hline Sueldo estimado & 4,000 soles mensuales. & 2,000 soles mensuales. \\
\hline
\end{tabular}

Elaboración propia

\subsection{Estructura organizacional.}

Figura 6. 1

Organigrama

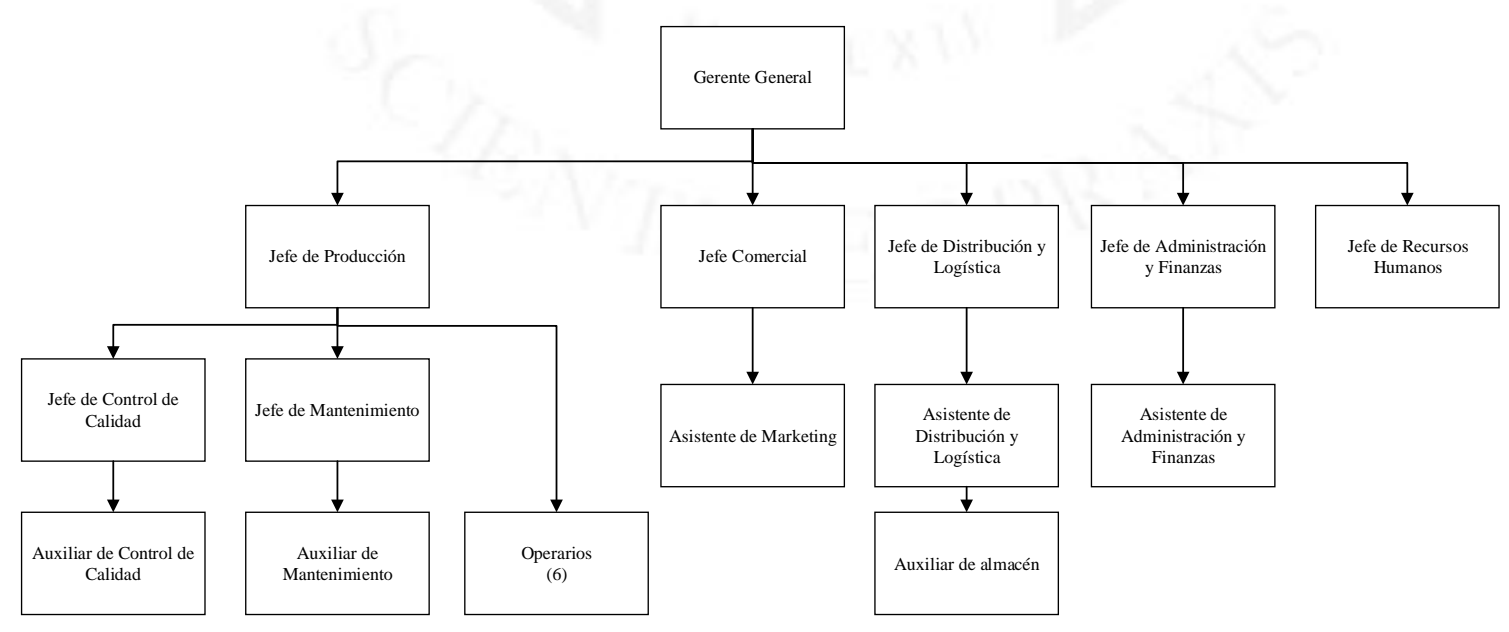

Elaboración propia 


\section{CAPÍTULO VII. ASPECTOS ECONÓMICOS Y FINANCIEROS}

Para efectos de cálculo todos los precios y costos en el presente trabajo están considerados sin IGV ni comisiones de ventas.

\subsection{Inversiones}

\subsubsection{Estimación de las inversiones de largo plazo (tangibles e intangibles)}

\section{Activo fijo tangible}

Para los cálculos se consideró un tipo de cambio de 3.30 soles por dólar.

- Terreno

\section{Tabla 7. 1}

Costo total por terreno

\begin{tabular}{|c|c|c|c|}
\hline Precio $\left(\$ / \mathrm{m}^{2}\right)$ & Precio $\left(\mathrm{S} / . / \mathrm{m}^{2}\right)$ & Terreno $\left(\mathrm{m}^{2}\right)$ & Costo total $(\mathrm{S} /)$ \\
\hline 200.00 & 670.00 & 436.00 & $292,120.00$ \\
\hline
\end{tabular}

Elaboración propia

- Construcción

Tabla 7.2

Costo total por construcción

\begin{tabular}{|c|c|c|c|}
\hline Precio $\left(\$ / \mathrm{m}^{2}\right)$ & Precio $\left(\mathrm{S} / . / \mathrm{m}^{2}\right)$ & Construcción $\left(\mathrm{m}^{2}\right)$ & Costo total $(\mathrm{S} /)$ \\
\hline 350.00 & $1,172.50$ & 497.77 & $583,640.40$ \\
\hline
\end{tabular}

Elaboración propia 
- Maquinaria y equipo

Tabla 7.3

Costo total por maquinaria y equipos puestos en planta

\begin{tabular}{|l|c|}
\hline \multicolumn{1}{|c|}{ Máquinas } & Costo (\$) \\
\hline Báscula industrial & 30.00 \\
\hline Deshidratador & $1,800.00$ \\
\hline Molino & $1,100.00$ \\
\hline Prensa & 500.00 \\
\hline Filtro prensa & $3,000.00$ \\
\hline Envasadora tapadora & $2,000.00$ \\
\hline Balanza de humedad & 840.00 \\
\hline Medidor de PH & 250.00 \\
\hline Medidor de acidez & 222.80 \\
\hline Tornillo sinfín & 500.00 \\
\hline Carretilla hidráulica & 118.00 \\
\hline Faja transportadora (2) & $2,500.00$ \\
\hline Faja transportadora & $2,500.00$ \\
\hline Total (\$) & $20,860.80$ \\
\hline Total (S/.) & $69,883.68$ \\
\hline Bomba & 199.90 \\
\hline Tanque & 209.90 \\
\hline
\end{tabular}

Elaboración propia

- Muebles y enseres

Tabla 7.4

Muebles y enseres fabriles

\begin{tabular}{|c|c|c|c|}
\hline Muebles y enseres & Cantidad & Precio unitario (S/) & Costo total (S/) \\
\hline Escritorio para jefes & 3.00 & 99.90 & 299.70 \\
\hline Escritorio para auxiliares & 3.00 & 84.90 & 254.70 \\
\hline Sillas & 12.00 & 99.00 & $1,188.00$ \\
\hline Laptops para jefes & 3.00 & $1,199.00$ & $3,597.00$ \\
\hline Laptops para auxiliares & 3.00 & $1,099.00$ & $3,297.00$ \\
\hline Impresora & 1.00 & 179.00 & 179.00 \\
\hline \multicolumn{2}{|r}{} & & (continúa)
\end{tabular}


(continuación)

\begin{tabular}{|l|r|r|r|}
\hline Microondas & 1.00 & 219.00 & 219.00 \\
\hline Mesa de corte & 1.00 & 590.00 & 590.00 \\
\hline Pallets & 41.00 & 90.00 & $3,690.00$ \\
\hline Jabas & 937.00 & 10.00 & $9,370.00$ \\
\hline Fluorescente & 30.00 & 5.90 & 177.00 \\
\hline Equipo fluorescente & 15.00 & 91.90 & $1,378.50$ \\
\cline { 3 - 4 } & & & $24,239.90$ \\
\cline { 3 - 4 }
\end{tabular}

Elaboración propia

Tabla 7.5

Muebles y enseres no fabriles

\begin{tabular}{|l|r|r|r|}
\hline Muebles y enseres & Cantidad & Precio unitario (S/) & \multicolumn{2}{l|}{ Costo total } \\
\hline Escritorios para gerente & 1.00 & 249.00 & 249.00 \\
\hline Escritorio para jefes & 4.00 & 99.90 & 399.60 \\
\hline Escritorio para asistentes & 3.00 & 84.90 & 254.70 \\
\hline Sillas & 8.00 & 99.00 & 792.00 \\
\hline Laptops gerencia & 1.00 & $1,399.00$ & $4,399.00$ \\
\hline Laptops para jefes & 4.00 & $1,199.00$ & $3,297.00$ \\
\hline Laptops para asistentes & 3.00 & $1,099.00$ & 750.00 \\
\hline Teléfonos fijos & 5.00 & 150.00 & 358.00 \\
\hline Impresora & 2.00 & 179.00 & 899.00 \\
\hline Refrigeradora & 1.00 & 899.00 & 219.00 \\
\hline Microondas & 1.00 & 219.00 & 401.20 \\
\hline Fluorescente & 68.00 & 5.90 & $3,124.60$ \\
\hline Equipo fluorescente & 34.00 & 91.90 & $16,939.10$ \\
\hline
\end{tabular}

Elaboración propia

Tabla 7.6

Activo fijos tangibles

\begin{tabular}{|l|r|}
\hline Activo fijo tangible & Costo (S/) \\
\hline Terreno & $292,120.00$ \\
\hline Construcción fabril & $248,768.40$ \\
\hline Construcción no fabril & $334,872.00$ \\
\hline Maquinaria y equipo & $70,293.48$ \\
\hline
\end{tabular}

(continúa) 
(continuación)

\begin{tabular}{|l|r|}
\hline Muebles y enseres fabriles & $24,239.90$ \\
\hline Muebles y enseres de oficina & $16,939.10$ \\
\hline Total & $987,232.88$ \\
\hline
\end{tabular}

Elaboración propia

\section{Activo fijo intangible}

Tabla 7.7

Activo fijo intangible

\begin{tabular}{|l|r|}
\hline Activo intangible & Costo (S/) \\
\hline Estudio previo & $5,000.00$ \\
\hline Estudios definitivos & $10,000.00$ \\
\hline Imprevistos & $1,321.76$ \\
\hline Puesto en marcha & $7,029.35$ \\
\hline Total & $23,351.11$ \\
\hline
\end{tabular}

Elaboración propia

\subsubsection{Estimación de las inversiones de corto plazo (Capital de trabajo)}

El capital de trabajo es considerado un ratio de liquidez y es el dinero que se necesita para el desarrollo de la actividad económica de la empresa durante un pequeño periodo de tiempo. Para hallar el capital de trabajo se considera el ciclo de caja con la siguiente formula:

$$
\text { Ciclo de caja }=P P C+P P I-P P P
$$

Periodo promedio de cobro $(\mathrm{PPC})=60$ días

Periodo promedio de conversión de inventario $(\mathrm{PPI})=0$ días

Periodo promedio de pago $(\mathrm{PPP})=0$ días

Con la formula se estimó el ciclo de caja de 60 días, plazo máximo en el que se cobra a los clientes. Para hallar el capital de trabajo, también se considerarán los costos y gastos de materia prima e insumos y sueldos para 60 días. 
Tabla 7.8

Capital de trabajo

\begin{tabular}{|l|c|}
\hline \multicolumn{1}{|c|}{ Capital de trabajo } & Monto (S/./mes) \\
\hline Sueldos & $165,854.58$ \\
\hline Compra de MP e Insumos & $57,921.99$ \\
\hline Servicios básicos & $1,750.37$ \\
\hline Servicios de terceros & $26,066.67$ \\
\hline \multicolumn{1}{|c|}{ Total } & $251,593.61$ \\
\hline
\end{tabular}

Elaboración propia

\subsection{Costos de producción}

\subsubsection{Costos de las materias primas}

Tabla 7.9

Precio unitario de materia prima e insumos sin IGV

\begin{tabular}{|c|c|c|}
\hline Insumo o Material & Precio & Unidades \\
\hline Coco & 1.20 & $\mathrm{~S} / . / \mathrm{kg}$ \\
\hline Envases con tapas & 0.89 & $\mathrm{~S} / . / \mathrm{unidad}$ \\
\hline Etiquetas & 0.21 & $\mathrm{~S} / . / \mathrm{unidad}$ \\
\hline
\end{tabular}

Elaboración propia

Tabla 7. 10

Costos anualizados de materia prima e insumos

\begin{tabular}{|c|c|c|c|c|}
\hline Año & Coco (S/.) & $\begin{array}{c}\text { Envases con tapas } \\
(\mathrm{S} / .)\end{array}$ & Etiquetas (S/.) & Costos totales (S/.) \\
\hline 2018 & $55,574.40$ & $70,818.19$ & $16,709.91$ & $143,102.50$ \\
\hline 2019 & $97,086.43$ & $123,717.12$ & $29,191.68$ & $249,995.23$ \\
\hline 2020 & $132,323.83$ & $168,619.40$ & $39,786.60$ & $340,729.83$ \\
\hline 2021 & $180,918.89$ & $230,543.82$ & $54,397.98$ & $465,860.69$ \\
\hline 2022 & $242,628.26$ & $309,179.77$ & $72,952.53$ & $624,760.56$ \\
\hline
\end{tabular}

Elaboración propia 


\subsubsection{Costo de la mano de obra directa}

En este punto, se analizará el costo por la mano de obra a utilizar. Los operarios serán remunerados con un sueldo de 930 soles mensuales.

De la misma manera, se calculan los beneficios sociales y obligaciones del empleador, esto incluye dos sueldos adicionales por gratificaciones (uno en julio y otro en diciembre), CTS y un seguro social. Se considera que el número de operarios no varían durante la vida útil del proyecto.

Tabla 7.11

Pago anual de la mano de obra directa

\begin{tabular}{|c|c|c|c|c|c|c|c|}
\hline Cargo & $\begin{array}{c}\mathrm{N}^{\mathrm{o}} \mathrm{de} \\
\text { personas }\end{array}$ & Sueldo & $\begin{array}{c}\text { Pago anual } \\
\text { total }\end{array}$ & $\begin{array}{c}\text { Gratificación } \\
\text { anual total }\end{array}$ & $\begin{array}{c}\text { CTS } \\
\text { anual } \\
\text { total }\end{array}$ & $\begin{array}{c}\text { EsSalud } \\
\text { anual total }\end{array}$ & Total (S/) \\
\hline Operarios & 6 & 930.00 & $66,960.00$ & $12,164.40$ & $6,510.00$ & $6,026.40$ & $91,660.80$ \\
\hline
\end{tabular}

Elaboración propia

\subsubsection{Costo Indirecto de Fabricación (materiales indirectos, mano de obra indirecta y costos generales de planta)}

A continuación se presentan todos costos indirectos de fabricación.

\section{Energía eléctrica}

Tabla 7. 12

Tarifa Luz del Sur

\begin{tabular}{|l|r|r|l|}
\hline \multicolumn{2}{|l|}{ Cargo fijo } & 4.85 & Soles \\
\hline \multicolumn{1}{|l|}{ Tarifa } & 0.48 & $\mathrm{~S} / . / \mathrm{kW}$ \\
\hline \multirow{4}{*}{ Alumbrado público } & mayor a 300 hasta $500 \mathrm{~kW}$ & 13.26 & $\mathrm{~S} / . / \mathrm{kW}$ \\
\cline { 2 - 4 } & mayor a 500 hasta $750 \mathrm{~kW}$ & 26.51 & $\mathrm{~S} / . / \mathrm{kW}$ \\
\cline { 2 - 5 } & mayor a 750 hasta $1000 \mathrm{~kW}$ & 30.30 & $\mathrm{~S} / . / \mathrm{kW}$ \\
\cline { 2 - 5 } & mayor a 1000 hasta $1500 \mathrm{~kW} . \mathrm{h}$ & 45.45 & S/./kW.h \\
\cline { 2 - 5 } & mayor a 1500 hasta $3000 \mathrm{~kW} . \mathrm{h}$ & 53.03 & S/./kW.h \\
\hline Mantenimiento y reposición & 1.63 & Soles \\
\hline
\end{tabular}

Fuente: Luz del Sur (2018) 
Tabla 7. 13

Costo anualizado de energía eléctrica fabril

\begin{tabular}{|c|c|c|}
\cline { 2 - 3 } \multicolumn{1}{c|}{} & $\begin{array}{c}\text { Requerimiento fabril } \\
\text { anual total (kW/año) }\end{array}$ & $\begin{array}{c}\text { Costo total Anual } \\
(\mathrm{S} / \text {.) }\end{array}$ \\
\hline 2018 & $8,034.05$ & $4,249.01$ \\
\hline 2019 & $12,022.62$ & $6,207.41$ \\
\hline 2020 & $15,408.31$ & $8,012.99$ \\
\hline 2021 & $20,077.43$ & $10,343.26$ \\
\hline 2022 & $26,006.61$ & $13,186.89$ \\
\hline
\end{tabular}

Elaboración propia

Tabla 7. 14

Costo anualizado de energía eléctrica no fabril

\begin{tabular}{|c|c|r|}
\cline { 2 - 3 } \multicolumn{1}{c|}{} & $\begin{array}{c}\text { Requerimiento anual no } \\
\text { fabril (kW/año) }\end{array}$ & $\begin{array}{c}\text { Costo total Anual } \\
(\mathrm{S} / .)\end{array}$ \\
\hline 2018 & $4,897.92$ & $2,585.92$ \\
\hline 2019 & $4,897.92$ & $2,585.92$ \\
\hline 2020 & $4,897.92$ & $2,585.92$ \\
\hline 2021 & $4,897.92$ & $2,585.92$ \\
\hline 2022 & $4,897.92$ & $2,585.92$ \\
\hline
\end{tabular}

Elaboración propia

Servicio de agua potable y alcantarillado

Tabla 7. 15

Tarifa Sedapal

\begin{tabular}{|c|c|c|}
\hline Cargo fijo & 4.89 & Soles \\
\hline Tarifa & 4.86 & S/./m3 \\
\hline Alcantarillado & 2.19 & S/./m3 \\
\hline
\end{tabular}

Fuente: Sedapal (2018)

Tabla 7. 16

Costo fabril anualizado de agua

\begin{tabular}{|c|c|c|c|}
\cline { 2 - 4 } \multicolumn{1}{c|}{} & $\begin{array}{c}\text { Consumo Fabril Total } \\
\text { (L/Año) }\end{array}$ & $\begin{array}{c}\text { Consumo Total } \\
\text { (m3/Año) }\end{array}$ & $\begin{array}{c}\text { Costo total fabril } \\
\text { Anual (S/) }\end{array}$ \\
\hline 2018 & $161,050.30$ & 161.05 & $1,194.20$ \\
\hline 2019 & $183,513.50$ & 183.51 & $1,352.59$ \\
\hline 2020 & $202,581.33$ & 202.58 & $1,487.03$ \\
\hline 2021 & $228,877.34$ & 228.88 & $1,672.45$ \\
\hline 2022 & $262,269.81$ & 262.27 & $1,907.90$ \\
\hline
\end{tabular}

Elaboración propia 
Tabla 7. 17

Costo no fabril anualizado de agua

\begin{tabular}{|c|c|c|c|}
\cline { 2 - 4 } \multicolumn{1}{c|}{} & $\begin{array}{c}\text { Consumo no Fabril } \\
\text { Total (L/Año) }\end{array}$ & $\begin{array}{c}\text { Consumo Total } \\
\text { (m3/Año) }\end{array}$ & $\begin{array}{c}\text { Costo total no } \\
\text { fabril Anual (S/.) }\end{array}$ \\
\hline 2018 & $87,318.40$ & 87.32 & 674.31 \\
\hline 2019 & $87,318.40$ & 87.32 & 674.31 \\
\hline 2020 & $87,318.40$ & 87.32 & 674.31 \\
\hline 2021 & $87,318.40$ & 87.32 & 674.31 \\
\hline 2022 & $87,318.40$ & 87.32 & 674.31 \\
\hline
\end{tabular}

Elaboración propia 
Tabla 7. 18

Mano de obra indirecta

\begin{tabular}{|c|c|c|c|c|c|c|c|}
\hline Cargo & $\begin{array}{c}\mathrm{N}^{\mathrm{o}} \text { de } \\
\text { personas }\end{array}$ & Sueldo & Pago anual total & $\begin{array}{c}\text { Gratificación } \\
\text { anual total }\end{array}$ & $\begin{array}{c}\text { CTS anual } \\
\text { tota }\end{array}$ & $\begin{array}{c}\text { EsSalud anual } \\
\text { total }\end{array}$ & Total (S/.) \\
\hline Jefe de Producción & 1 & $5,000.00$ & $60,000.00$ & $10,900.00$ & $5,833.33$ & $5,400.00$ & $82,133.33$ \\
\hline Jefe Control de Calidad & 1 & $4,000.00$ & $48,000.00$ & $8,720.00$ & $4,666.67$ & $4,320.00$ & $65,706.67$ \\
\hline Auxiliar de Control de Calidad & 1 & $2,000.00$ & $24,000.00$ & $4,360.00$ & $2,333.33$ & $2,160.00$ & $32,853.33$ \\
\hline Jefe de Mantenimiento & 1 & $4,000.00$ & $48,000.00$ & $8,720.00$ & $4,666.67$ & $4,320.00$ & $65,706.67$ \\
\hline Auxiliar de Almacén & 1 & $2,000.00$ & $24,000.00$ & $4,360.00$ & $2,333.33$ & $2,160.00$ & $32,853.33$ \\
\hline Auxiliar de Mantenimiento & 1 & $2,000.00$ & $24,000.00$ & $4,360.00$ & $2,333.33$ & $2,160.00$ & $32,853.33$ \\
\hline & & & & & & Total & $312,106.67$ \\
\hline
\end{tabular}

Elaboración propia

Tabla 7. 19

Administrativo

\begin{tabular}{|c|c|c|c|c|c|c|c|}
\hline Cargo & $\begin{array}{c}\mathrm{N}^{\mathrm{o}} \text { de } \\
\text { personas }\end{array}$ & Sueldo & $\begin{array}{l}\text { Pago anual } \\
\text { total }\end{array}$ & $\begin{array}{l}\text { Gratificación } \\
\text { anual total }\end{array}$ & $\begin{array}{l}\text { CTS anual } \\
\text { tota }\end{array}$ & $\begin{array}{l}\text { EsSalud anual } \\
\text { total }\end{array}$ & Total (S/.) \\
\hline Gerente General & 1 & $7,000.00$ & $84,000.00$ & $15,260.00$ & $8,166.67$ & $7,560.00$ & $114,986.67$ \\
\hline Jefe de Administración y Finanzas & 1 & $5,000.00$ & $60,000.00$ & $10,900.00$ & $5,833.33$ & $5,400.00$ & $82,133.33$ \\
\hline $\begin{array}{l}\text { Asistente de Administración y } \\
\text { Finanzas }\end{array}$ & 1 & $3,000.00$ & $36,000.00$ & $6,540.00$ & $3,500.00$ & $3,240.00$ & $49,280.00$ \\
\hline Jefe Comercial & 1 & $5,000.00$ & $60,000.00$ & $10,900.00$ & $5,833.33$ & $5,400.00$ & $82,133.33$ \\
\hline Asistente de Marketing & 1 & $3,000.00$ & $36,000.00$ & $6,540.00$ & $3,500.00$ & $3,240.00$ & $49,280.00$ \\
\hline Jefe de Recursos Humanos & 1 & $5,000.00$ & $60,000.00$ & $10,900.00$ & $5,833.33$ & $5,400.00$ & $82,133.33$ \\
\hline Jefe de Distribución y Logística & 1 & $5,000.00$ & $60,000.00$ & $10,900.00$ & $5,833.33$ & $5,400.00$ & $82,133.33$ \\
\hline Asistente de Distribución y Logística & 1 & $3,000.00$ & $36,000.00$ & $6,540.00$ & $3,500.00$ & $3,240.00$ & $49,280.00$ \\
\hline & & & & & & Total & $591,360.00$ \\
\hline
\end{tabular}

Elaboración propia 
Tabla 7.20

Costos indirectos de fabricación

\begin{tabular}{|c|c|c|c|c|c|}
\hline CIF (luz, agua y MOI)(S/.) & 2018 & 2019 & 2020 & 2021 & 2022 \\
\hline Luz fabril & $4,249.01$ & $6,207.41$ & $8,012.99$ & $10,343.26$ & $13,186.89$ \\
\hline Agua & $1,194.20$ & $1,352.59$ & $1,487.03$ & $1,672.45$ & $1,907.90$ \\
\hline MOI & $312,106.67$ & $312,106.67$ & $312,106.67$ & $312,106.67$ & $312,106.67$ \\
\hline Depreciación fabril & $29,982.06$ & $29,982.06$ & $29,982.06$ & $29,982.06$ & $29,982.06$ \\
\hline Total & $347,531.93$ & $349,648.72$ & $351,588.74$ & $354,104.43$ & $357,183.51$ \\
\hline
\end{tabular}

Elaboración propia

\subsection{Presupuestos Operativos}

\subsubsection{Presupuesto de ingreso por ventas}

Se estableció un precio de venta antes de comisión y sin IGV de 16.95 soles por el producto presentado en un envase de 200 gr. El precio de venta al consumidor final será de 23 soles, cabe mencionar que se consideraron los precio del mercado que oscilan entre 17.50 y 24.80 soles con IGV.

Tabla 7. 21

Presupuesto de ingreso por ventas

\begin{tabular}{|c|c|c|c|c|}
\hline Año & Ventas (kg.) & $\begin{array}{c}\text { Ventas } \\
\text { (unidades) }\end{array}$ & $\begin{array}{c}\text { Precio unitario } \\
(\mathrm{S} /)\end{array}$ & Ventas (S/.) \\
\hline 2018 & $15,459.17$ & $77,295.00$ & 16.95 & $1,310,084.75$ \\
\hline 2019 & $27,298.53$ & $136,492.00$ & 16.95 & $2,313,423.73$ \\
\hline 2020 & $37,323.86$ & $186,619.00$ & 16.95 & $3,163,033.90$ \\
\hline 2021 & $51,030.97$ & $255,154.00$ & 16.95 & $4,324,644.07$ \\
\hline 2022 & $69,772.00$ & $348,859.00$ & 16.95 & $5,912,864.41$ \\
\hline
\end{tabular}

Elaboración propia

La cáscara del coco obtenida luego del descascarado será vendida a 0.50 S/ por kilo más IGV. 
Tabla 7.22

Venta de cáscaras

\begin{tabular}{|c|r|r|r|r|r|}
\cline { 2 - 6 } \multicolumn{1}{c|}{} & \multicolumn{1}{c|}{2018} & \multicolumn{1}{c|}{2019} & \multicolumn{1}{c|}{2020} & \multicolumn{1}{c|}{2021} & \multicolumn{1}{c|}{2022} \\
\hline Cáscara kg & $16,192.99$ & $28,288.56$ & $38,555.86$ & $52,715.24$ & $70,695.81$ \\
\hline PV SIN IGV & 0.50 & 0.50 & 0.50 & 0.50 & 0.50 \\
\hline TOTAL INGRESO & $\mathbf{8 , 0 9 6 . 5 0}$ & $\mathbf{1 4 , 1 4 4 . 2 8}$ & $\mathbf{1 9 , 2 7 7 . 9 3}$ & $\mathbf{2 6 , 3 5 7 . 6 2}$ & $\mathbf{3 5 , 3 4 7 . 9 0}$ \\
\hline
\end{tabular}

Elaboración propia

\subsubsection{Presupuesto operativo de costos}

Tabla 7.23

Presupuesto de costo de producción

\begin{tabular}{|l|r|r|r|r|}
\cline { 2 - 5 } \multicolumn{1}{c|}{} & \multicolumn{1}{c|}{$\begin{array}{c}\text { Materia Prima e } \\
\text { Insumos (S/.) }\end{array}$} & $\begin{array}{c}\text { CIF (luz, agua y } \\
\text { MOI)(S/.) (incluye } \\
\text { depreciación fabril) }\end{array}$ & Mano de Obra & \multicolumn{1}{c|}{$\begin{array}{c}\text { Costo de } \\
\text { producción (S/) }\end{array}$} \\
\hline 2018 & $143,102.50$ & $347,531.93$ & $91,660.80$ & $582,295.23$ \\
\hline 2019 & $249,995.23$ & $349,648.72$ & $91,660.80$ & $691,304.75$ \\
\hline 2020 & $340,729.83$ & $351,588.74$ & $91,660.80$ & $783,979.37$ \\
\hline 2021 & $465,860.69$ & $354,104.43$ & $91,660.80$ & $911,625.92$ \\
\hline 2022 & $624,760.56$ & $357,183.51$ & $91,660.80$ & $1,073,604.86$ \\
\hline
\end{tabular}

Elaboración propia

\subsubsection{Presupuesto operativo de gastos}

Tabla 7.24

Gastos administrativos y ventas

\begin{tabular}{|c|c|c|c|c|c|}
\hline Gastos Adm. Y Ventas & 2018 & 2019 & 2020 & 2021 & 2022 \\
\hline Sueldos administrativos & $591,360.00$ & $591,360.00$ & $591,360.00$ & $591,360.00$ & $591,360.00$ \\
\hline Agua no fabril & 674.31 & 674.31 & 674.31 & 674.31 & 674.31 \\
\hline Luz no fabril & $2,585.92$ & $2,585.92$ & $2,585.92$ & $2,585.92$ & $2,585.92$ \\
\hline Servicio de comunicaciones & $1,798.80$ & $1,798.80$ & $1,798.80$ & $1,798.80$ & $1,798.80$ \\
\hline Servicio de vigilancia & $60,000.00$ & $60,000.00$ & $60,000.00$ & $60,000.00$ & $60,000.00$ \\
\hline Servicio de transporte & $36,400.00$ & $36,400.00$ & $36,400.00$ & $36,400.00$ & $36,400.00$ \\
\hline Enfermera & $24,000.00$ & $24,000.00$ & $24,000.00$ & $24,000.00$ & $24,000.00$ \\
\hline Limpieza & $12,000.00$ & $12,000.00$ & $12,000.00$ & $12,000.00$ & $12,000.00$ \\
\hline Soporte técnico (no fabril) & $24,000.00$ & $24,000.00$ & $24,000.00$ & $24,000.00$ & $24,000.00$ \\
\hline Total (S/) & $752,819.04$ & $752,819.04$ & $752,819.04$ & $752,819.04$ & $752,819.04$ \\
\hline
\end{tabular}

Elaboración propia 
Tabla 7.25

Presupuesto operativo de gastos

\begin{tabular}{|l|c|c|c|c|c|}
\cline { 2 - 6 } \multicolumn{1}{c|}{} & 2018 & 2019 & 2020 & 2021 & 2022 \\
\hline Gastos Adm. Y Ventas & 752,819 & 752,819 & 752,819 & 752,819 & 752,819 \\
\hline Depreciación No Fabril & 20,028 & 20,028 & 20,028 & 20,028 & 20,028 \\
\hline Amortización Intangibles & 4,670 & 4,670 & 4,670 & 4,670 & 4,670 \\
\hline Total Gastos Generales & 777,517 & 777,517 & 777,517 & 777,517 & 777,517 \\
\hline
\end{tabular}

Elaboración propia

\subsection{Presupuestos Financieros}

\subsubsection{Presupuesto de Servicio de Deuda}

Tabla 7. 26

Inversión total

\begin{tabular}{|c|c|c|}
\hline & Porcentaje & Total (S/.) \\
\hline Capital propio & $50 \%$ & $631,088.80$ \\
\hline Financiamiento & $50 \%$ & $631,088.80$ \\
\hline & & $1,262,177.60$ \\
\hline
\end{tabular}

Elaboración propia

Tabla 7. 27

Condiciones de financiamiento

\begin{tabular}{|c|c|c|}
\hline TES & Cuotas & Plazo (años) \\
\hline $7.2 \%$ & Creciente & 5 \\
\hline
\end{tabular}

Elaboración propia

Tabla 7.28

Cuadro de servicio a la deuda

\begin{tabular}{|l|l|r|r|r|r|r|r|}
\cline { 2 - 8 } \multicolumn{1}{c|}{ Mes } & Factor & \multicolumn{1}{c|}{ Monto } & \multicolumn{1}{c|}{ Interés } & \multicolumn{1}{c|}{ Amortización } & \multicolumn{1}{c|}{ Cuota } & \multicolumn{1}{c|}{ Saldo } \\
\hline 2018 & Enero & 0.02 & $631,088.80$ & $45,678.54$ & $11,474.34$ & $57,152.88$ & $619,614.46$ \\
\hline & Julio & 0.04 & $619,614.46$ & $44,848.02$ & $22,948.68$ & $67,796.71$ & $596,665.77$ \\
\hline 2019 & Enero & 0.05 & $596,665.77$ & $43,186.98$ & $34,423.03$ & $77,610.01$ & $562,242.75$ \\
\hline & Julio & 0.07 & $562,242.75$ & $40,695.43$ & $45,897.37$ & $86,592.80$ & $516,345.38$ \\
\hline 2020 & Enero & 0.09 & $516,345.38$ & $37,373.35$ & $57,371.71$ & $94,745.06$ & $458,973.67$ \\
\hline & Julio & 0.11 & $458,973.67$ & $33,220.76$ & $68,846.05$ & $102,066.81$ & $390,127.62$ \\
\hline 2021 & Enero & 0.13 & $390,127.62$ & $28,237.64$ & $80,320.39$ & $108,558.04$ & $309,807.23$ \\
\hline & Julio & 0.15 & $309,807.23$ & $22,424.01$ & $91,794.73$ & $114,218.75$ & $218,012.49$ \\
\hline 2022 & Enero & 0.16 & $218,012.49$ & $15,779.86$ & $103,269.08$ & $119,048.94$ & $114,743.42$ \\
\hline & Julio & 0.18 & $114,743.42$ & $8,305.19$ & $114,743.42$ & $123,048.61$ & \\
\hline
\end{tabular}

Elaboración propia 


\subsubsection{Presupuesto de Estado Resultados}

Tabla 7. 29

Depreciación de activos tangibles

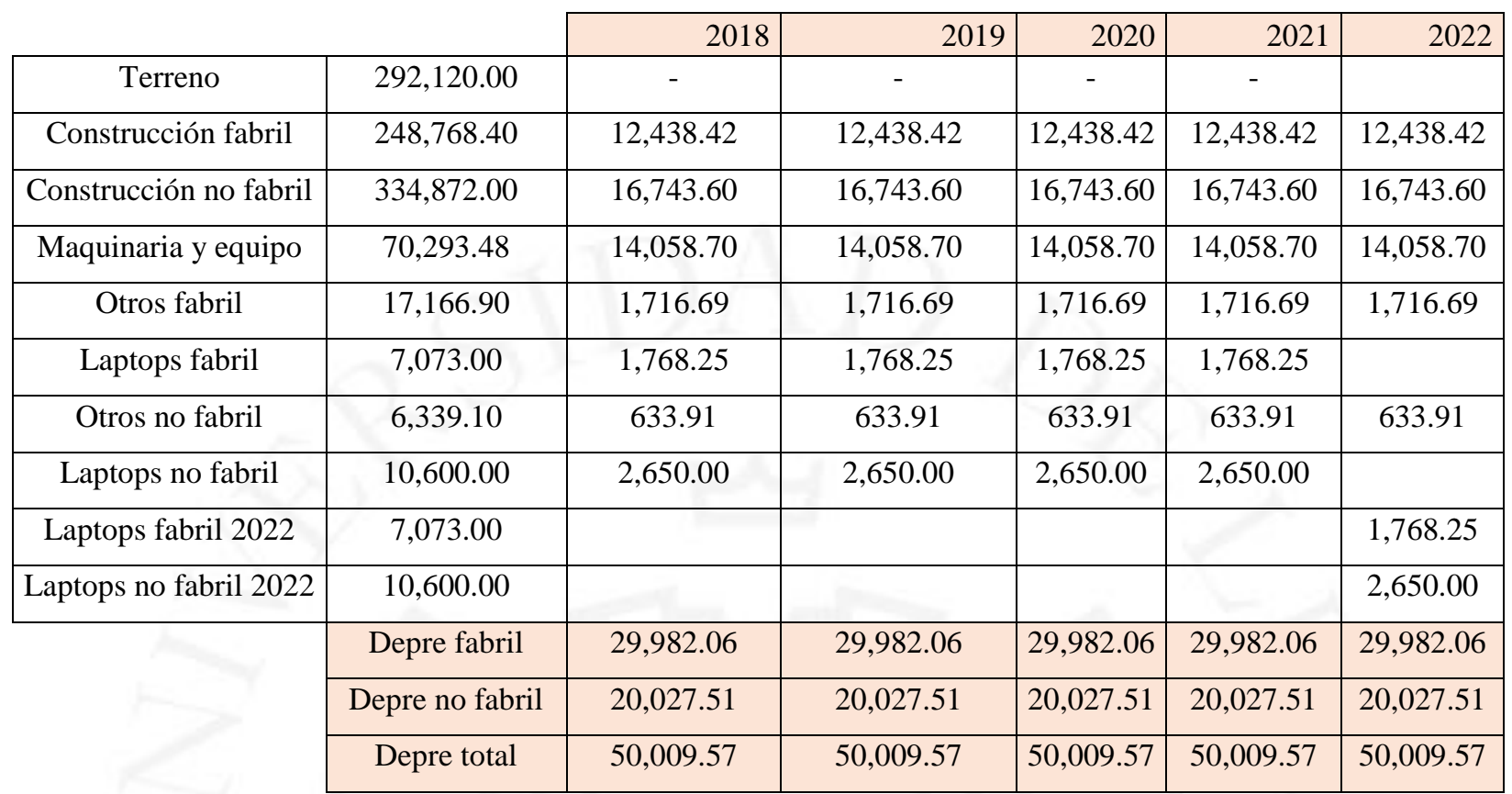

Elaboración propia

Tabla 7.30

Amortización de intangibles

\begin{tabular}{|c|c|c|c|c|c|c|}
\cline { 2 - 7 } \multicolumn{1}{c|}{} & 2018 & 2019 & 2020 & 2021 & 2022 & Amortización \\
\hline Estudio previo & $1,000.00$ & $1,000.00$ & $1,000.00$ & $1,000.00$ & $1,000.00$ & $5,000.00$ \\
\hline Estudios definitivos & $2,000.00$ & $2,000.00$ & $2,000.00$ & $2,000.00$ & $2,000.00$ & $10,000.00$ \\
\hline Imprevistos & 264.35 & 264.35 & 264.35 & 264.35 & 264.35 & $1,321.76$ \\
\hline Puesto en marcha & $1,405.87$ & $1,405.87$ & $1,405.87$ & $1,405.87$ & $1,405.87$ & $7,029.35$ \\
\hline Amortización & $4,670.22$ & $4,670.22$ & $4,670.22$ & $4,670.22$ & $4,670.22$ & \\
\hline
\end{tabular}

Elaboración propia 
Tabla 7.31

Estado de resultados

\begin{tabular}{|c|c|c|c|c|c|}
\hline & 2018 & 2019 & 2020 & 2021 & 2022 \\
\hline Ingreso por ventas & $1,310,084.75$ & $2,313,423.73$ & $3,163,033.90$ & $4,324,644.07$ & $5,912,864.41$ \\
\hline (-) Costo de producción & $582,295.23$ & $691,304.75$ & $783,979.37$ & $911,625.92$ & $1,073,604.86$ \\
\hline Utilidad bruta & $727,789.51$ & $1,622,118.98$ & $2,379,054.53$ & $3,413,018.15$ & $4,839,259.54$ \\
\hline$(+)$ Otros ingresos & $8,096.50$ & $14,144.28$ & $19,277.93$ & $26,357.62$ & $35,347.90$ \\
\hline (-)Otros gastos & 32.39 & 56.58 & 77.11 & 105.43 & 141.39 \\
\hline (-) Gastos Generales & $777,516.77$ & $777,516.77$ & $777,516.77$ & $777,516.77$ & $777,516.77$ \\
\hline Utilidad Operativa & $-41,663.14$ & $858,689.91$ & $1,620,738.57$ & $2,661,753.57$ & $4,096,949.29$ \\
\hline (-) Gastos Financieros & $90,526.56$ & $83,882.41$ & $70,594.11$ & $50,661.66$ & $24,085.05$ \\
\hline (-)Valor en libros & & & & & $462,738.05$ \\
\hline$(+)$ Valor de mercado & & & & & $231,369.03$ \\
\hline Utilidad Antes de Impuestos & $-132,189.71$ & $774,807.50$ & $1,550,144.46$ & $2,611,091.91$ & $3,841,495.21$ \\
\hline (-)Impuesto a la renta $(29.5 \%)$ & - & $228,568.21$ & $457,292.62$ & $770,272.11$ & $1,133,241.09$ \\
\hline Utilidad Neta & $132,189.71$ & $546,239.29$ & $1,092,851.85$ & $1,840,819.80$ & $2,708,254.12$ \\
\hline$(-)$ Reserva legal & & $54,623.93$ & $71,593.83$ & & \\
\hline Utilidad de libre disposición & $132,189.71$ & $491,615.36$ & $1,021,258.02$ & $1,840,819.80$ & $2,708,254.12$ \\
\hline
\end{tabular}

Elaboración propia 


\subsubsection{Presupuesto de Estado de Situación Financiera}

Tabla 7.32

Estado de situación financiera

\begin{tabular}{|c|c|c|c|}
\hline \multicolumn{4}{|c|}{$\begin{array}{c}\text { ESTADO DE SITUACIÓN FINANCIERA } \\
\text { AL 31.12.2018 } \\
\text { (Expresado en soles) }\end{array}$} \\
\hline$\underline{\text { Activo }}$ & & $\underline{\text { Pasivo }}$ & \\
\hline Activo Corriente & & Pasivo Corriente & \\
\hline Efectivo y equivalente de efectivo & $4,068.69$ & Servicios por pagar & 875.19 \\
\hline Cuentas por cobrar a corto plazo & $136,467.16$ & Impuesto a la renta por pagar & - \\
\hline & & Cuentas por pagar corto plazo & $34,423.03$ \\
\hline Total activo corriente & $140,535.85$ & Total pasivo corriente & $35,298.21$ \\
\hline & & & \\
\hline \multicolumn{4}{|l|}{ Activo no Corriente } \\
\hline Terreno & $292,120.00$ & Pasivo no Corriente & \\
\hline Infraestructura & $583,640.40$ & Cuenta por pagar a largo plazo & $562,242.75$ \\
\hline Muebles y enseres & $41,179.00$ & Total pasivo no corriente & $562,242.75$ \\
\hline Maquinaria y equipos & $70,293.48$ & Total Pasivo & $597,540.96$ \\
\hline Depreciación tangibles & $-50,009.57$ & & \\
\hline Intangibles & $23,351.11$ & & \\
\hline Amortización de intangibles & $-4,670.22$ & $\underline{\text { Patrimonio }}$ & \\
\hline Total activo no corriente & $955,904.20$ & Capital social & $631,088.80$ \\
\hline \multirow[t]{2}{*}{ 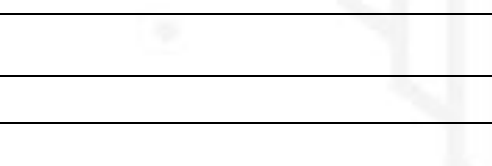 } & & Utilidad neta & $-132,189.71$ \\
\hline & & Total Patrimonio & 498,899.09 \\
\hline Total Activo & $1,096,440.05$ & Total Pasivo y Patrimonio & $1,096,440.05$ \\
\hline
\end{tabular}

Elaboración propia

\subsubsection{Flujo de caja de corto plazo}

La política de cobranza de Cocoil se maneja de la siguiente manera: $25 \%$ al contado, $25 \%$ a 30 días y el 50\% restante a 60 días. El flujo de caja de corto plazo se refleja en el siguiente cuadro. 
Tabla 7. 33 Cobranzas enero 2018 - Febrero 2019

\begin{tabular}{|c|c|c|c|c|c|c|c|c|c|c|c|c|c|}
\hline Ene. & Feb. & Mar. & Abr. & Ma. & Jun. & Jul. & Ago. & Sept. & Oct. & Nov. & Dic. & Ene. & Feb. \\
\hline $27,293$. & $27,293.4$ & $27,293.4$ & $27,293.4$ & $27,293.4$ & $27,293.4$ & $27,293.4$ & $27,293.4$ & $27,293.4$ & $27,293.4$ & $27,293.4$ & $27,293.4$ & & \\
\hline & & & & & & & & & & .4 & & .4 & \\
\hline & & & & & & & & & & & & & \\
\hline $27,293.4$ & 1,586.9 & $109,173.7$ & $109,173.7$ & $109,173.7$ & $109,173.7$ & $109,173.7$ & $109,173.7$ & $109,173.7$ & \begin{tabular}{|l|}
$109,173.7$ \\
\end{tabular} & $109,173.7$ & $109,173.7$ & $81,880.3$ & $54,586.9$ \\
\hline
\end{tabular}

Elaboración propia

Tabla 7. 34

Flujo de caja a corto plazo

\begin{tabular}{|c|c|c|c|c|c|c|c|c|c|c|c|c|}
\hline & Ene. & Feb. & Mar. & Abr. & Ma. & Jun. & Jul. & Ago. & Sept. & Oct. & Nov. & Dic. \\
\hline Efectivo & $251,593.6$ & $131,415.4$ & $94,808.4$ & $112,788.2$ & $130,768.0$ & $113,409.5$ & $131,389.3$ & $15,540.2$ & $33,520.0$ & $51,499.8$ & $69,479.6$ & $52,121.1$ \\
\hline Otros ingresos & 674.7 & 674.7 & 674.7 & 674.7 & 674.7 & 674.7 & 674.7 & 674.7 & 674.7 & 674.7 & 674.7 & 674.7 \\
\hline Ventas & $27,293.4$ & $54,586.9$ & $109,173.7$ & $109,173.7$ & $109,173.7$ & $109,173.7$ & $109,173.7$ & $109,173.7$ & $109,173.7$ & $109,173.7$ & $109,173.7$ & $109,173.7$ \\
\hline Total de ingreso & $279,561.7$ & $186,677.0$ & $204,656.8$ & $222,636.6$ & $240,616.4$ & $223,257.9$ & $241,237.7$ & $125,388.6$ & $143,368.4$ & $161,348.2$ & $179,328.0$ & $161,969.5$ \\
\hline
\end{tabular}

\begin{tabular}{|c|c|c|c|c|c|c|c|c|c|c|c|c|}
\hline MO directa & $6,082.2$ & $6,082.2$ & $6,082.2$ & $6,082.2$ & $9,337.2$ & $6,082.2$ & $12,164.4$ & $6,082.2$ & $6,082.2$ & $6,082.2$ & $9,337.2$ & $12,164.4$ \\
\hline MO indirecta & $20,710.0$ & $20,710.0$ & $20,710.0$ & $20,710.0$ & $31,793.3$ & $20,710.0$ & $41,420.0$ & $20,710.0$ & $20,710.0$ & $20,710.0$ & $31,793.3$ & $41,420.0$ \\
\hline Administrativo & $39,240.0$ & $39,240.0$ & $39,240.0$ & $39,240.0$ & $60,240.0$ & $39,240.0$ & $78,480.0$ & $39,240.0$ & $39,240.0$ & $39,240.0$ & $60,240.0$ & $78,480.0$ \\
\hline MMPP e insumos & $11,925.2$ & $11,925.2$ & $11,925.2$ & $11,925.2$ & $11,925.2$ & $11,925.2$ & $11,925.2$ & $11,925.2$ & $11,925.2$ & $11,925.2$ & $11,925.2$ & $11,925.2$ \\
\hline Servicios & & 875.2 & 875.2 & 875.2 & 875.2 & 875.2 & 875.2 & 875.2 & 875.2 & 875.2 & 875.2 & 875.2 \\
\hline Gastos terceros & $13,033.3$ & $13,033.3$ & $13,033.3$ & $13,033.3$ & $13,033.3$ & $13,033.3$ & $13,033.3$ & $13,033.3$ & $13,033.3$ & $13,033.3$ & $13,033.3$ & $13,033.3$ \\
\hline Gastos financieros & $45,678.5$ & & & & & & $44,848.0$ & & & & & \\
\hline Amortización & $11,474.3$ & & & & & & $22,948.7$ & & & & & \\
\hline Otros gastos & 2.7 & 2.7 & 2.7 & 2.7 & 2.7 & 2.7 & 2.7 & 2.7 & 2.7 & 2.7 & 2.7 & 2.7 \\
\hline \multicolumn{13}{|l|}{ Impuestos a la renta } \\
\hline Total de egresos & $148,146.3$ & $91,868.6$ & $91,868.6$ & $91,868.6$ & $127,207.0$ & $91,868.6$ & $225,697.5$ & $91,868.6$ & $91,868.6$ & $91,868.6$ & $127,207.0$ & $157,900.8$ \\
\hline
\end{tabular}

\begin{tabular}{|c|c|c|c|c|c|c|c|c|c|c|c|c|}
\hline \begin{tabular}{|l} 
Saldo \\
\end{tabular} & $131,415.4$ & $94,808.4$ & $112,788.2$ & \begin{tabular}{|l}
$130,768.0$ \\
\end{tabular} & $113,409.5$ & $131,389.3$ & $15,540.2$ & $33,520.0$ & $51,499.8$ & $69,479.6$ & $52,121.1$ & $4,068.7$ \\
\hline
\end{tabular}

Elaboración propia 


\subsection{Flujo de fondos netos}

\subsubsection{Flujo de fondos económicos}

Tabla 7. 35

Flujo de fondos económicos

\begin{tabular}{|c|c|c|c|c|c|c|}
\cline { 2 - 6 } \multicolumn{1}{c|}{} & 0 & 2018 & 2019 & 2020 & 2021 & 2022 \\
\hline Utilidad Neta & & $-132,189.71$ & $546,239.29$ & $1,092,851.85$ & $1,840,819.80$ & $2,708,254.12$ \\
\hline (-)Inversión & $-1,262,177.60$ & & & & & $-17,673.00$ \\
\hline Depreciación tangible & & $50,009.57$ & $50,009.57$ & $50,009.57$ & $50,009.57$ & $50,009.57$ \\
\hline Amortización intangibles & & $4,670.22$ & $4,670.22$ & $4,670.22$ & $4,670.22$ & $4,670.22$ \\
\hline Valor en libros & & & & & & $462,738.05$ \\
\hline Capital de Trabajo & & & & & & $251,593.61$ \\
\hline FFE & $-1,262,177.60$ & $-77,509.92$ & $600,919.08$ & $1,147,531.64$ & $1,895,499.59$ & $3,459,592.57$ \\
\hline
\end{tabular}

Elaboración propia

\subsubsection{Flujo de fondos financieros}

Tabla 7.36

Flujo de fondos financieros

\begin{tabular}{|c|c|c|c|c|c|c|}
\hline & & & & & & \\
\hline & 0 & 2018 & 2019 & 2020 & 2021 & 2022 \\
\hline Utilidad Neta & & $-132,189.71$ & $546,239.29$ & $1,092,851.85$ & $1,840,819.80$ & $2,708,254.12$ \\
\hline (-)Inversión & $\stackrel{-}{1,262,177.60}$ & & & & & $-17,673.00$ \\
\hline Financiamiento & $631,088.80$ & & & & & \\
\hline $\begin{array}{c}\text { (-) Amortización del } \\
\text { préstamo }\end{array}$ & & $-34,423.03$ & $-80,320.39$ & $-126,217.76$ & $-172,115.13$ & $-218,012.49$ \\
\hline Depreciación tangible & & $50,009.57$ & $50,009.57$ & $50,009.57$ & $50,009.57$ & $50,009.57$ \\
\hline $\begin{array}{l}\text { Amortización } \\
\text { intangibles }\end{array}$ & & $4,670.22$ & $4,670.22$ & $4,670.22$ & $4,670.22$ & $4,670.22$ \\
\hline Valor en libros & & & . & & & $462,738.05$ \\
\hline Capital de trabajo & & & & & & $251,593.61$ \\
\hline FFF & $-631,088.80$ & $-111,932.95$ & $520,598.68$ & $1,021,313.88$ & $1,723,384.46$ & $3,241,580.08$ \\
\hline
\end{tabular}

Elaboración propia 


\section{CAPÍTULO VIII. EVALUACIÓN ECONÓMICA Y FINANCIERA DEL PROYECTO}

\subsection{Evaluación económica: VAN, TIR, B/C, PR}

Para determinar el COK del proyecto se utilizó el modelo de CAPM.

$$
R s=R f+\beta(R m-R f)+\text { riesgo país }
$$

El rendimiento del mercado $(\mathrm{Rm})$ se obtuvo mediante el promedio de los valores mensuales de la bolsa de Lima de los último 10 años, que dio como resultado un rendimiento mensual de 0.025\%, este valor se convirtió en un rendimiento anual de 9.53\% (Bloomberg, 2018).

La tasa libre de riesgo (Rf) se obtuvo a través de la curva de rendimiento de los bonos del tesoro de EEUU a 10 años, la cual asciende a 3.09\% (Pulso Bursátil, 2018) y el riesgo país asciende a 1.50\% (Banco Central de Reserva del Perú, 2018), se obtuvo de la información del spread EMBIG Perú.

Se tomó como referencia el valor del beta no apalancado de la industria alimenticia equivalente a 0.55 (Damodaran, 2018), dicho dato se triplicó para representar un escenario conservador. Para obtener el beta apalancado se usó la siguiente fórmula.

$$
\beta \text { apalancado }=\beta \text { no apalancado } * 1+\left[(1-T) *\left(\frac{D}{E}\right)\right]
$$

El impuesto a la renta (T) considerado equivale a 29.5\%. El porcentaje de la inversión total financiado por terceros (D) y el porcentaje con capital propio (E) ascienden a 50\% y 50\% respectivamente. Con dichos datos se obtuvo un beta apalancado de 2.8.

Finalmente, con los datos hallados, se logró un COK de 22.61\%. 
Tabla 8.1

Evaluación económica

\begin{tabular}{|l|c|}
\hline VNA económico & $3,046,060.45$ \\
\hline VAN económico & $1,783,882.85$ \\
\hline TIR económico & $54 \%$ \\
\hline B/C económico & 2.41 \\
\hline PR económico & 3 años, 4 meses y 11 días \\
\hline
\end{tabular}

Elaboración propia

\subsection{Evaluación financiera: VAN, TIR, B/C, PR.}

Tabla 8.2

Evaluación financiera

\begin{tabular}{|c|c|}
\hline VNA financiero & $2,741,266.71$ \\
\hline VAN financiero & $2,110,177.91$ \\
\hline TIR financiero & $78 \%$ \\
\hline B/C financiero & 4.34 \\
\hline PR financiero & 2 años, 8 meses y 5 días \\
\hline
\end{tabular}

\subsubsection{Análisis de ratios (liquidez, solvencia, rentabilidad) e indicadores económicos y financieros del proyecto.}

Tabla 8.3

Indicadores económicos

\begin{tabular}{|l|l|}
\hline \multicolumn{1}{|c|}{ Nombre } & \multicolumn{1}{c|}{ Interpretación } \\
\hline VAN económico & $\begin{array}{l}\text { Desde el punto de vista económico, el proyecto conviene ya que su valor actual neto es mayor } \\
\text { a cero. }\end{array}$ \\
\hline TIR económico & $\begin{array}{l}\text { La tasa interna de retorno es mayor al costo de oportunidad (22.61\%) por lo tanto conviene } \\
\text { realizar el proyecto. }\end{array}$ \\
\hline B/C económico & $\begin{array}{l}\text { La capacidad de generación de ingresos del proyecto es 2.41 veces por cada unidad de inversión } \\
\text { realizada. }\end{array}$ \\
\hline PR económico & La inversión se recuperará en el tiempo indicado: 3 años, 4 meses y 11 días. \\
\hline
\end{tabular}

Elaboración propia 
Tabla 8.4

Indicadores financieros

\begin{tabular}{|l|l|}
\hline \multicolumn{1}{|c|}{ Nombre } & \multicolumn{1}{|c|}{ Interpretación } \\
\hline VAN financiero & $\begin{array}{l}\text { El proyecto conviene, desde un punto de vista financiero, por tener un valor actual neto mayor } \\
\text { a cero. }\end{array}$ \\
\hline TIR financiero & El TIR es mayor al Cok $(22.61 \%)$ por lo tanto conviene realizar el proyecto. \\
\hline B/C financiero & $\begin{array}{l}\text { En este proyecto, la capacidad de generación de ingresos es } 4.34 \text { veces por cada unidad de } \\
\text { inversión realizada. }\end{array}$ \\
\hline PR financiero & La inversión se recuperará en el tiempo indicado: 2 años, 8 meses y 5 días. \\
\hline
\end{tabular}

Elaboración propia

Tabla 8. 5

Ratios al 31 de diciembre del 2018

\begin{tabular}{|c|c|c|c|c|}
\hline Tipo & Nombre & Fórmula & Valor & Interpretación \\
\hline Liquidez & $\begin{array}{l}\text { Razón } \\
\text { corriente }\end{array}$ & $\mathrm{AC} / \mathrm{PC}$ & 3.98 & $\begin{array}{c}\text { Se tiene } 3.98 \text { soles de activos para } \\
\text { enfrentar a las obligaciones de corto } \\
\text { plazo por cada sol de pasivos. }\end{array}$ \\
\hline \multirow[b]{2}{*}{ Solvencia } & $\begin{array}{l}\text { Razón deuda / } \\
\text { patrimonio }\end{array}$ & $\begin{array}{c}\text { Pasivo / } \\
\text { Patrimonio }\end{array}$ & $119.77 \%$ & $\begin{array}{l}\text { El } 119.77 \% \text { refleja la deuda a terceros, } \\
\text { en relación a cada solo de } \\
\text { financiamiento propio de la empresa. }\end{array}$ \\
\hline & $\begin{array}{c}\text { Razón de } \\
\text { endeudamiento }\end{array}$ & $\begin{array}{l}\text { Pasivo / } \\
\text { Activo }\end{array}$ & $54.50 \%$ & $\begin{array}{l}\text { El } 0.54 \text { ha sido financiado por } \\
\text { personas ajenas a la entidad. }\end{array}$ \\
\hline Gestión & $\begin{array}{l}\text { Rotación de } \\
\text { activos totales }\end{array}$ & $\begin{array}{l}\text { ventas / } \\
\text { activo }\end{array}$ & 1.19 & $\begin{array}{l}\text { Por cada sol invertido en activos se } \\
\text { genera } 1.19 \text { de ingresos por ventas. }\end{array}$ \\
\hline \multirow[t]{2}{*}{ Rentabilidad } & Margen Neto & $\begin{array}{l}\text { Ut neta / } \\
\text { ventas }\end{array}$ & $-10.09 \%$ & $\begin{array}{l}\mathrm{El}-10.09 \% \text { de la ventas es utilidad } \\
\text { disponible que será distribuido entre } \\
\text { los accionistas. }\end{array}$ \\
\hline & Margen bruto & $\begin{array}{l}\text { Ut bruta / } \\
\text { ventas }\end{array}$ & $55.55 \%$ & $\begin{array}{l}\text { El } 55.55 \% \text { de las ventas logra } \\
\text { convertirse en utilidad bruta. }\end{array}$ \\
\hline
\end{tabular}

Elaboración propia

\subsection{Análisis de sensibilidad del proyecto.}

Se analizará la sensibilidad del proyecto para evaluar posibles reacciones de los indicadores financieros frente a cambios en dos factores importantes: precio de venta e incremento salarial. Se considera un escenario optimista, pesimista y el mínimo posible en escenario precio y el máximo posible en el escenario salarios para no generar pérdidas. 
Tabla 8. 6

Cambios en el precio de venta

\begin{tabular}{|c|c|c|c|c|c|c|c|c|c|}
\hline $\begin{array}{l}\text { Precio } \\
(\mathrm{S} /)\end{array}$ & Variación & VAN & Var VAN & TIR & Var TIR & $\mathrm{B} / \mathrm{C}$ & $\operatorname{Var} B / C$ & PR & Var PR \\
\hline 19.49 & $15.00 \%$ & $3,027,137$ & $43.45 \%$ & $101.9 \%$ & $30.13 \%$ & 5.80 & $33.45 \%$ & $\begin{array}{c}2 \text { años } 1 \text { mes } 4 \\
\text { días }\end{array}$ & $-21.87 \%$ \\
\hline 16.95 & $0.00 \%$ & $2,110,178$ & $0.00 \%$ & $78.3 \%$ & $0.00 \%$ & 4.34 & $0.00 \%$ & $\begin{array}{c}2 \text { años } 8 \text { meses } 5 \\
\text { días } \\
\end{array}$ & $0.00 \%$ \\
\hline 14.41 & $-15.00 \%$ & $1,177,743$ & $-44.19 \%$ & $54.0 \%$ & $-31.05 \%$ & 2.87 & $-34.01 \%$ & $\begin{array}{c}3 \text { años } 6 \text { meses } \\
30 \text { días }\end{array}$ & $33.68 \%$ \\
\hline 11.20 & $-33.92 \%$ & 0 & $-100.00 \%$ & $22.6 \%$ & $-71.13 \%$ & 1.00 & $-76.98 \%$ & 5 años & $-100.00 \%$ \\
\hline
\end{tabular}

Elaboración propia

Tabla 8.7

Variación en los salarios

\begin{tabular}{|c|c|c|c|c|c|c|c|c|c|}
\hline $\begin{array}{c}\text { Total } \\
\text { Salarios }\end{array}$ & Variacion & VAN & $\begin{array}{c}\text { Var } \\
\text { VAN }\end{array}$ & TIR & Var TIR & B/C & Var B/C & PR & Var PR \\
\hline $\begin{array}{c}144,396.5 \\
9\end{array}$ & $15.00 \%$ & $1,760,179$ & $-16.59 \%$ & $66.31 \%$ & $-15.35 \%$ & 3.72 & $-14.39 \%$ & $\begin{array}{c}3 \text { años } 1 \text { mes } \\
18 \text { días }\end{array}$ & $16.89 \%$ \\
\hline $995,127.47$ & $0.00 \%$ & $2,110,178$ & $0.00 \%$ & $78.34 \%$ & $0.00 \%$ & 4.34 & $0.00 \%$ & $\begin{array}{c}2 \text { años } 8 \\
\text { meses } 5 \text { días }\end{array}$ & $0.00 \%$ \\
\hline $845,858.35$ & $-15.00 \%$ & $2,455,503$ & $16.36 \%$ & $91.64 \%$ & $16.98 \%$ & 4.99 & $14.98 \%$ & $\begin{array}{c}2 \text { años } 3 \\
\text { meses } 9 \text { días }\end{array}$ & $-15.13 \%$ \\
\hline $\begin{array}{c}1,884,273.8 \\
6\end{array}$ & $89.35 \%$ & 0 & $100.00 \%$ & $22.61 \%$ & $-71.13 \%$ & 1.00 & $-76.98 \%$ & 5 años & $86.53 \%$ \\
\hline
\end{tabular}

Elaboración propia 


\section{CAPÍTULO IX. EVALUACIÓN SOCIAL DEL PROYECTO}

\subsection{Identificación de las zonas y comunidades de influencia del proyecto}

En este punto se estudiaran las zonas que se verán impactadas por la puesta en marcha de la empresa Cocoil. La primera zona es Lurín, pues es el distrito en donde se ubicará la planta físicamente, lo que conlleva a una inversión en construcción, infraestructura, estudios de terrenos, entre otros, lo que le dará al distrito la posibilidad de mejorar su valor. De una manera en general se verá impactada, también la ciudad de Lima, ya que este proyecto genera diversos puestos de trabajos que se presentan como oportunidades laborales para la población económicamente activa desempleada, la cual asciende en Lima a 234.3 miles de habitantes (INEI, 2016). Finalmente, de una vista macroeconómica, este proyecto puede generar oportunidad de crecimiento a los proveedores de la materia prima.

\subsection{Análisis de indicadores sociales (valor agregado, densidad de capital, intensidad de capital, generación de divisas)}

Para analizar el proyecto es necesario aplicar indicadores macroeconómicos de interés social. En esta evaluación se considera una tasa social igual al COK (22.61\%).

\section{Valor agregado}

Es el aporte que se usa para la transformación de materia prima e insumos. Incluye sueldos, intereses, depreciación, utilidades, impuestos, etc. El valor actualizado del valor agregado brinda una idea de los probables beneficios del estudio. 
Tabla 9.1

Valor agregado

\begin{tabular}{|c|c|c|c|c|c|}
\hline & 1 & 2 & 3 & 4 & 5 \\
\hline Ingresos & $1,310,084.75$ & $2,313,423.73$ & $3,163,033.90$ & $4,324,644.07$ & $5,912,864.41$ \\
\hline (-)MMPP & $143,102.50$ & $249,995.23$ & $340,729.83$ & $465,860.69$ & $624,760.56$ \\
\hline Total & $1,166,982.25$ & $2,063,428.50$ & $2,822,304.07$ & $3,858,783.37$ & $5,288,103.85$ \\
\hline VNA & $7,470,858.29$ & & & & \\
\hline $\begin{array}{c}\text { Valor } \\
\text { Agregado }\end{array}$ & $7,470,858.29$ & & & & \\
\hline
\end{tabular}

Elaboración propia

\section{Densidad de capital}

Representa la relación de la inversión del capital y el empleo generado

Tabla 9.2

Densidad de capital

\begin{tabular}{|l|l|l|}
\hline Fórmula & Datos & Resultado \\
\hline$\frac{\text { Inversión total }}{\# \text { de empleos }}$ & $\frac{1^{\prime} 262,177.60}{20}$ & $63,108.88$ soles/empleo \\
\hline
\end{tabular}

Elaboración propia

\section{Intensidad de capital}

Representa la relación del total invertido y el valor agregado del proyecto. Mide el grado de inversión para crear valor agregado sobre los insumos.

Tabla 9.3

Intensidad de capital

\begin{tabular}{|l|l|l|}
\hline Fórmula & Datos & Resultado \\
\hline$\frac{\text { Inversión total }}{\text { Valor agregado }}$ & $\frac{1^{\prime} 262,177.60}{7^{\prime} 470,858.29}$ & 0.17 \\
\hline
\end{tabular}

Elaboración propia 


\section{Generación de divisas}

Debido a que este proyecto no tiene exportaciones ni importaciones la generación de divisas no es

un indicador con el que se puede evaluar el proyecto, ya que el balance neto de divisas (exportaciones - importaciones) es igual a cero. 


\section{CONCLUSIONES}

- Se concluye que la hipótesis del proyecto se cumple, es decir, la instalación de una planta productora de aceite de coco es viable técnicamente, económicamente, socialmente y financieramente.

- Se consideró la demanda interna aparente del aceite de oliva para obtener la demanda del proyecto. Dicha DIA fue segmentada por los porcentajes de intensidad e intención de compra, el porcentaje de personas en Lima Metropolitana y según el estilo de vida sofisticado o afortunado.

- Para determinar la localización de la planta se basó en diferentes factores que mediante un análisis de ranking de factores se determinó que la mejor localización de la planta es Lurín.

- Luego de analizar los diferentes tamaños, se obtuvo que el factor limitante es el tamaño Mercado que asciende $67,772.00 \mathrm{Kg}$.

- Se hizo un análisis del personal requerido para el buen funcionamiento de la planta. Se necesita de 6 operarios y 14 personas distribuidas por áreas.

- Se obtuvo una inversión total de S/ 1’262,177.60 de los cuales, el 50\% se financiará con el Banco de Crédito del Perú con una TES de $7.2 \%$ y en cuotas crecientes, mientras que el otro 50\% de la inversión será capital propio.

- Los indicadores que muestran la viabilidad financiera del proyecto son el VANF de S/2,110,177.91, TIRF de 78\%, el periodo de recupero financiero de 2 años, 8 meses y 5 días y el beneficio costo financiero de 4.34 .

- Los indicadores que muestran la viabilidad económica del proyecto son el VANE de S/1,783,882.85, TIRE de 54\%, el periodo de recupero económico de 3 años, 4 meses y 11 días y el beneficio costo económico de 2.41 .

- Los indicadores muestran que el proyecto es viable por tener un VAN mayor a 0 , un TIR mayor al Cok y una relación de beneficio costo mayor a 1 .

- La evaluación social del proyecto nos muestra que generará impactos positivos como desarrollo de nueva infraestructura, generación de nuevos puestos de trabajo, así como crecimiento de los proveedores de la empresa. 


\section{RECOMENDACIONES}

- Es recomendable establecer objetivos cuantitativos y cualitativos para tener siempre un enfoque del proyecto.

- Es importante obtener datos de fuentes primarias y secundarias que sean confiables para que estos sean exactos y muestren información verídica.

- Es necesario escoger correctamente el o los productos sustitutos para tener una mayor aproximación a los datos verdaderos si es que no se tiene información de la demanda histórica, consumos u otro dato necesario del producto a estudiar.

- Es importante mantener el enfoque del mercado meta durante toda la investigación de del proyecto para tener un proyecto confiable. 


\section{REFERENCIAS}

Aceite de Coco. (14 de Junio de 2015). Aceite de Coco. Recuperado en Junio de 2016, de Aceite de Coco Toda la Verdad y Hechos Científicos: http://www.aceitedecoco.org/

Actualidad Empresarial. (2014). Registro de activos fijos: ¿debe consignarse la depreciación. Área Tributaria, 11-14.

Agricultura Urbana Perú. (25 de Abril de 2013). Recuperado de http://agriculturaurbanaperu.blogspot.com

Alibaba. (2016). Alibaba.com. Recuperado de https://spanish.alibaba.com

Alicorp. (2010). Memoria Anual.

Alimentos Argentinos. (2015). Alimentos Argentinos. Recuperado de http://www.alimentosargentinos.gob.ar

Alimentoscon. (2016). Alimentoscon. Recuperado de http://alimentosxon.com

Altavoz. (2014). Altavoz. Recuperado de altavoz.pe

AMV Ediciones. (1988). Producción, análisis y control de calidad de aceites y grasas comestibles. Madrid.

Ancín, J. M. (2001). La distribución comercial: Opciones estratégicas. Madrid: Esic.

APEIM. (2016). Asociación Peruana de Empresas de Investigación de Mercados. Recuperado el Junio de 2016, de http://apeim.com.pe/

Arellano, R. (2015). Arellano Marketing. Recuperado de http://www.arellanomarketing.com/

Autointegra. (2016). Autointegra. Recuperado de http://www.autointegra.cl

Banco Central de Reserva del Perú. (Agosto de 2018). BCRP Data. Recuperado de https:www.bcrp.gob.pe

Barrios, J., Nunes, M., y Velasquez, T. (2015). Obtención de aceite vegetal de coco y almendra mediante extracción sólido-líquido. Departamento de termodinámica y fenómenos de transporte.

BASA. (2016). BASA. Recuperado de http://www.basa.com.pe 
Bloomberg. (Septiembre de 2018). Bolsa de valores de Lima. Lima, Perú.

Canal 6 tecpan. (11 de Julio de 2014). Proceso de extracción del aceite de coco en Agroindustrias del Sur en San Jerónimo (Aceitera). San Jerónimo, Ciudad de México, México.

CCM Salud. (Marzo de 2015). CCM Salud. Recuperado de http://salud.ccm.net/

Ching. (02 de Febrero de 2016). El comercio. Recuperado de http://elcomercio.pe/

Congerso de la República del Perú. (26 de Junio de 2008). Recuperado de http://www.leyes.congreso.gob.pe/

Damodaran, A. (2018). Betas by sector.

Definiciona. (2016). Definiciona . Recuperado el 15 de Mayo de 2016, de Definición y etimología: http://definiciona.com

Diaz, B., Jarufe, B., y Noriega, M. T. (2007). Disposición de planta. Lima: Universidad de Lima.

El aceite de coco. (21 de Enero de 2015). El aceite de coco. Recuperado de 10 características clave del aceite de coco: www.aceitedecoco.org

El Comercio. (1 de Agosto de 2017). Agua, leche o champú: versatilidad del coco impulsa producción. Diario El Comercio.

Emapa San Martín. (2014).

Escuela de Ingeniería de Antioquia. (2009). Mecánica de fluidos y recursos hidráulicos. Recuperado de http://fluidos.eia.edu.co/

Euromonitor Internacional. (07 de Octubre de 2015). Portal Euromonitor. Recuperado el Junio de 2016, de http://www.portal.euromonitor.com

Expat. (2010). Expat.

Fruticola. (Junio de 2015). Fruticola. Recuperado de http://www.portalfruticola.com

Google Maps. (2016). Google Maps. Recuperado Recuperado de https://www.google.com.pe/maps/

Grasas y Aceites Vegetales. (2014). Grasas y Aceites Vegetales. Recuperado de http://grasas-yaceites-vegetales.webnode.com

Hanna Instruments. (2016). Hanna Instruments. Recuperado de https://www.hannatienda.es/ 
INDECOPI. (Mayo de 2010). Catálodo especializado de normas técnicas peruanas. Lima.

Indutec Perú. (2016). Indutec Perú S.A.C. Recuperado de http://www.indutecperu.com

INEI. (2016). Denuncias de faltas según departamento. Lima.

INEI. (2016). Instituto Nacional de Estadística e Informática. Recuperado de http://proyectos.inei.gob.pe

INEI. (2016). Instituto Nacional de Estadísticas e Informática. Recuperado de http://www.inei.gob.pe

Infotrade. (2018). Estadísticas del Comercio Exterior de Perú. Recuperado de http://infotrade.promperu.gob.pe/prototipo.asp

Kioseka Salud. (Marzo de 2015). Recuperado el Junio de 2016, de Kioseka Net: http://salud.ccm.net/

Konz, S. (1994). Diseño de Sistemas de trabajo. México D.F.: Editorial Limusa S.A.

La Nación. (Julio de 2015). La Nación. Recuperado de http://lanacion.com.ec

Levys Bazar. (2016). Levys Bazar. Recuperado de www.levysbazar.com

Licata, M. (2016). Zonadiet. Recuperado de www.zonadiet.com

Luna, A., Palou, E., y López, A. (2009). Aceites escenciales: métodos de extracción. Unicersidad de las Américas Puebla, Departamento de ingeniería química y alimentos, Cholula.

Luz del Sur. (04 de Agosto de 2018). Recuperado de www.luzdelsur.com.pe

Luz del Sur. (04 de Julio de 2018). Luz del Sur. Recuperado de https://www.luzdelsur.com.pe

Maximixe Consult S. A. (Enero de 2014). Aceites Comestibles. Riesgo de Mercado, 1-19.

Maximixe Consult. S.A. (2016). Aceites comestibles. 11.

Menacho, L. M. (2013). Biblioteca Univesidad del Santo. Recuperado el 15 de Mayo de 2016, de biblioteca.uns.edu.pe

Mercola. (22 de Octubre de 2010). Dr. Mercola. Recuperado de http://espanol.mercola.com/

Mercola. (18 de Noviembre de 2013). Dr. Mercola. Recuperado el Junio de 2016, de http://espanol.mercola.com/ 
Mercola. (23 de Agosto de 2014). Dr. Mercola. Recuperado de http://articulos.mercola.com/ Mercola. (15 de Mayo de 2016). Dr. Mercola. Recuperado de http://espanol.mercola.com/

Mercola, D. J. (18 de Noviembre de 2013). Dr. Mercola. Recuperado el 15 de Mayo de 2016, de espanol.mercola.com

MINAGRI. (2014). Ministerio de Agricultura y Riego . Recuperado de www.minagri.gob.pe

Ministerio de Transporte y Comunicaciones. (2014). MTC. Recuperado de http://www.mtc.gob.pe

Ministro de Trabajo y Promoción del Empleo. (2012). INABIF. Recuperado de http://inabif.gob.pe

Mora, O. (2003). Ácido láurico: componente bioactivo del aceite de palmiste. En Palmas Vol. 24 (págs. 79-83).

Morales, D. (1985). Estudio preliminar para la instalación de una fábrica de aceite de coco. Lima, Peru: Universidad de Lima.

Oficina de Estudios Económicos y Estadísticos. (2016). OEEE. Recuperado el 2016, de http://frenteweb.minagri.gob.pe/sisca/?mod=consulta_cult

Ortega, J., Reyes, J., y Torres, J. (2005). Propuesta de agroindustrialización del coco como una estrategia para la contribución económica al desarrollo rural de la comunidad de la isla el espíritu santo, puerto el triunfo en el departamento de Usulutan. Universidad de el Salvador, San Salvador.

Perú 21. (11 de Julio de 2016). INEI: Población peruana supera los 31 millones habitantes. Perú 21.

Portafolio. (2015 de Setiembre de 2015). Portafolio. Recuperado de Razones para contratar procesos de negocio con terceros: www.portafolio.co

Pulso Bursátil. (24 de Septiembre de 2018). Universidad de Lima. Recuperado de http://fresno.ulima.edu.pe

Rivera, R., Lomeli, J., Roman, L., y Vera, F. (2001). Etracción de aceite de coco a partir de la copra por medio de disolventes químicos. Aguascalientes: Conciencia Tecnológica.

RPP Noticias. (Junio de 2015). RPP Noticias. Recuperado de http://rpp.pe

SEDALORETO S.A. (2016). Recuperado de http://www.sedaloreto.com.pe 
Sedapal. (17 de Junio de 2015). Sedapal. Recuperado de http://www.sedapal.com.pe/

SEDAPAL S.A. (2018). Servicio de Agua Potable y Alcantarillado de Lima. Recuperado de http://www.sedapal.com.pe

SENASA. (2014). Servcio Nacional de Sanidad Agraria. Recuperado de https://www.senasa.gob.pe

SIEA . (2018). Ministerio de Agricultura y Riego.

Sodimac. (2016). Sodimac . Recuperado de http://www.sodimac.com.pe

SUNAT. (2000). OFICIO N $N^{\circ} 022-2000$ - KC 0000. Lima.

SUNAT. (2016). Superintendencia Nacional de Aduanas y de Administración Tributaria. Recuperado de www.sunat.gob.pe

Superintendencia del Mercado de Valores. (11 de Mayo de 2014). Semana Económica. Recuperado de http://www.smv.gob.pe/

Surveyanyplace. (2017). 9 ventajas y desventajas de los cuestionarios.

Tecmaq. (2016). Tecmaq S.R.L. Recuperado de http://www.tecmaqsrl.com/

Testo. (2016). Testo be sure. Recuperado de https://www.testo.com/es-ES/

Thompson, I. (Agosto de 2007). Promonegocios. Recuperado de http://www.promonegocios.net/

Trigoso, M., y Salas, L. (21 de Febrero de 2012). Peruanos pagan más por productos saludables en la región . Gestión.

ULINE. (2016). ULINE. Recuperado de es. uline.mx

Veritrade. (2018). Recuperado de http://business.veritrade.info 


\section{BIBLIOGRAFÍA}

Ancín, J. M. (2001). La distribución comercial: Opciones estratégicas. Madrid: Esic.

Barrios, J., Nunes, M., y Velasquez, T. (2015). Obtención de aceite vegetal de coco y almendra mediante extracción sólido-líquido. Departamento de termodinámica y fenómenos de transporte.

Diaz, B., Jarufe, B., y Noriega, M. T. (2007). Disposición de planta. Lima: Universidad de Lima.

Konz, S. (1994). Diseño de Sistemas de trabajo. México D.F.: Editorial Limusa S.A.

Luna, A., Palou, E., y López, A. (2009). Aceites escenciales: métodos de extracción. Unicersidad de las Américas Puebla, Departamento de ingeniería química y alimentos, Cholula.

Morales, D. (1985). Estudio preliminar para la instalación de una fábrica de aceite de coco. Lima, Peru: Universidad de Lima. 


\section{ANEXOS}




\section{Anexo 1: Modelo de encuesta}

A continuación, se presentan una serie de preguntas con el fin de determinar la demanda del aceite de coco. Su opinión es muy importante, gracias de antemano.

¿Qué tipo de aceite utiliza para cocinar?

- $\quad$ Aceite vegetal

- 1

- 2

- Aceite de oliva

- 3

- Aceite de coco

- 4

- Aceite animal

- Otra:

- 5

- 6

- 7

- 8

¿Sabía usted que el aceite de coco fortalece

- 9

el sistema inmunológico, ayuda a mantener saludable el corazón y favorece el correcto funcionamiento del cerebro y la tiroides?

- $\quad$ Sí

- No

Conociendo los beneficios de este producto ¿Usted compraría aceite de coco en una presentación de 200 gr para cocinar?

- 10

¿Cuánto estaría dispuesto a pagar por un envase de 200 gr de aceite de coco?

- $\quad$ De 20 a 22 soles

- De 23 a 25 soles

- $\quad$ De 26 a más

¿Dónde le gustaría encontrar el producto?

- Sí

- No (Concluya la encuesta)

En la siguiente escala del 1 al 10 ¿Qué tan dispuesto estaría a comprar dicho producto?

- Supermercados

- Tiendas naturistas

- Estación de servicios

- Bodegas 


\section{Anexo 2: Resultados de encuesta}

1. Tipos de aceite

¿Qué tipo de aceite utiliza para cocinar?

384 respuestas

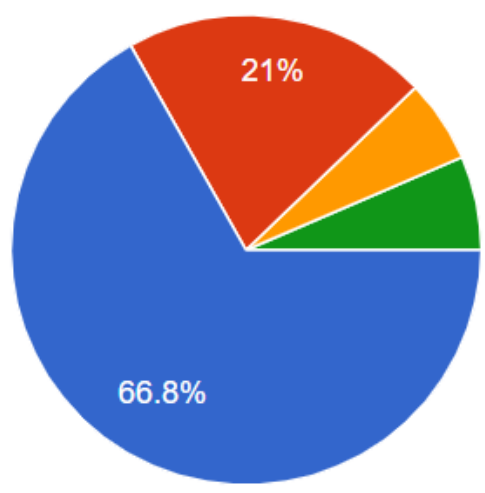

Aceite vegetal

Aceite de oliva

Aceite de coco

Aceite animal

2. ¿Sabía usted que el aceite de coco fortalece el sistema inmunológico, ayuda a mantener saludable el corazón y favorece el funcionamiento del cerebro y tiroides?

¿Sabía usted que el aceite de coco fortalece el sistema inmunológico, ayuda a mantener saludable el corazón, fortalece el correcto funcionamiento del cerebro y la tiroides?

384 respuestas
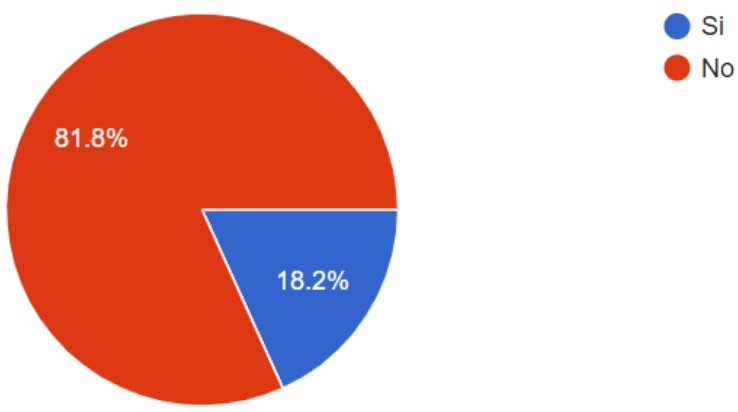

No 
3. Intención de compra

Conociendo los beneficios de este producto ¿Compraría usted aceite de coco en una presentación de 200 gr para cocinar?

384 respuestas

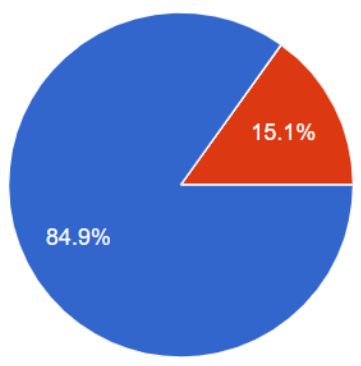

No (Concluya la encuesta)

4. Intensidad de compra

En la siguiente escala del 1 al 10 ¿Qué tan dispuesto estaría a comprar dicho producto? Siendo 10 muy dispuesto y 1 poco dispuesto.

326 respuestas

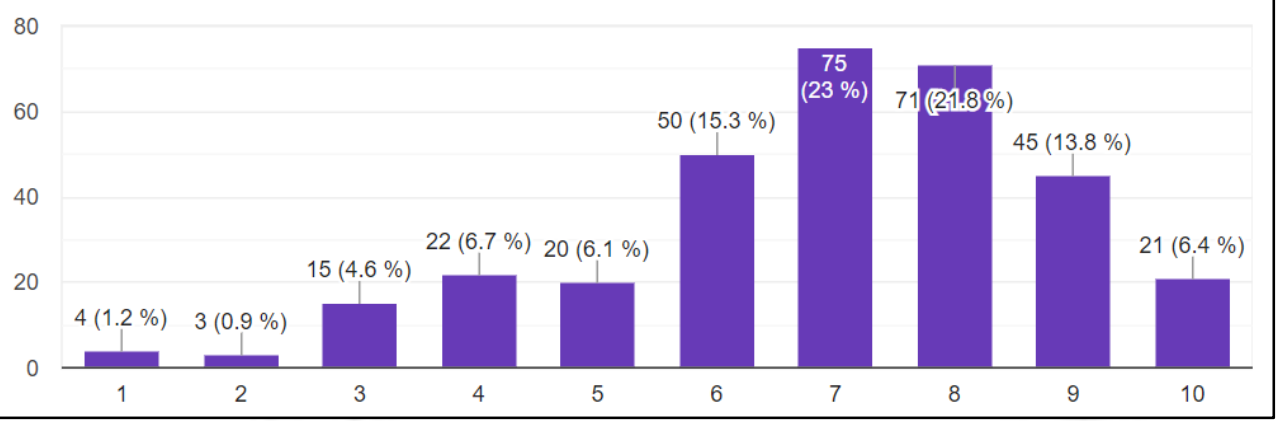


5. Rangos de precios de aceite de coco

¿Cuánto estaría dispuesto a pagar por un envase de $200 \mathrm{gr}$ de aceite de coco?

326 respuestas

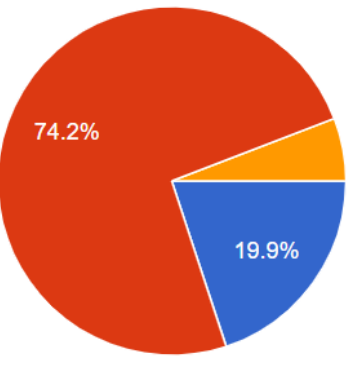

De 20 a 22 soles

De 23 a 25 soles

De 26 a más

6. Preferencia de lugar de compra

¿Dónde le gustaría encontrar el producto?

326 respuestas

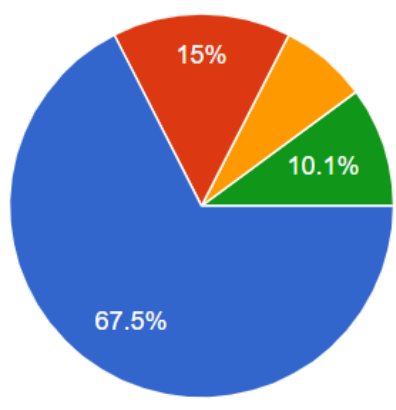

Estación de servicios

Bodegas 


\section{Anexo 3: Cotización de etiquetas}

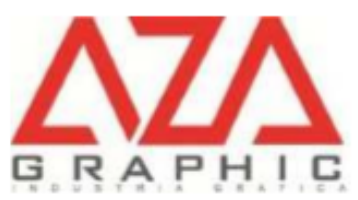

Noviembre 10,2016

Presupuesto Nro. 141989

Señores

CLIENTE NUEVO

Presente.-

Estimados Señores :

Por intermedio de la presente nos es grato someter a vuestra consideración la siguiente cotización:

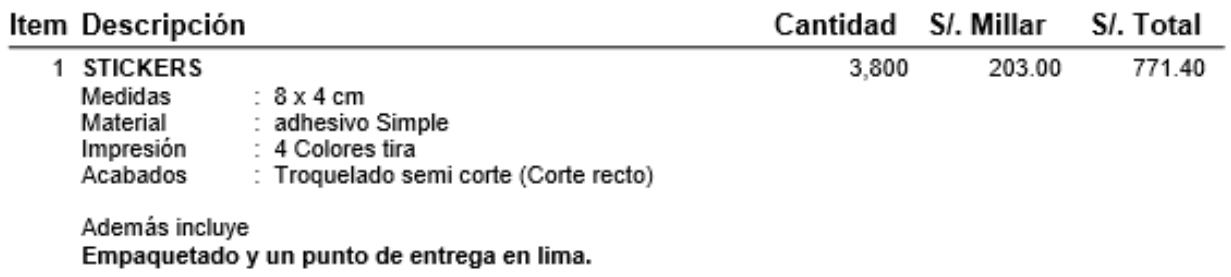

Una vez aprobado el presupuesto enviar la orden por mail a:

ventas@aza.pe, administracion@aza.pe,

El cliente proporciona archivo listo para impresión.

Los precios pueden variar si el cliente entrega archivos que no coincidan con el material presupuestado.

De acuerdo a las Politicas de la Empresa con respecto a las demasias Industriales, la cantidad puede variar en un $+/-3 \%$. La factura se generará por la

cantidad producida al mismo costo unitario. Considerarlo al recibir su material.

Atentamente,

Los precios anteriormente indicados no incluyen el I.G.V.

Condiciones de pago : $50 \%$ adelantado y $50 \%$ contraentresa

Fecha de entrega : A tratar

Asesor Comercial : FERNANDO AZA PICCONE

Validez de presupuesto : 15 días

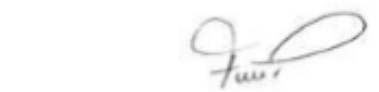

FERNANDO AZA PICCONE

Firma 


\section{Anexo 4: Precio de coco}

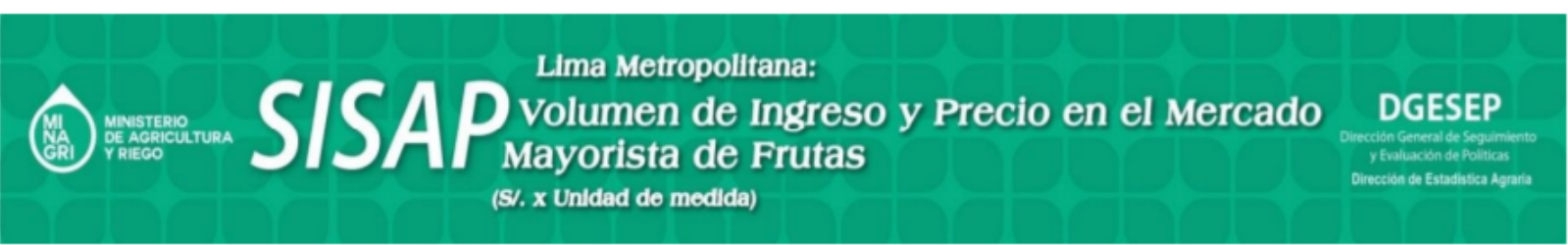

\section{lunes, 31 de octubre de 2016}

\begin{tabular}{|c|c|c|c|c|c|c|c|c|c|}
\hline \multirow{3}{*}{ PRODUCTOS } & \multicolumn{4}{|c|}{ Volumen de ingreso (t) } & \multicolumn{5}{|c|}{ Precios S/ x Unidad de medida } \\
\hline & \multirow[b]{2}{*}{ Ayer } & \multirow[b]{2}{*}{ Hoy } & \multicolumn{2}{|c|}{ Promedio } & \multirow{2}{*}{$\begin{array}{l}\text { Unidad } \\
\text { de } \\
\text { medida }\end{array}$} & \multirow{2}{*}{\begin{tabular}{c|} 
Equiv \\
en \\
Kg.
\end{tabular}} & \multicolumn{3}{|c|}{ Precio promedio } \\
\hline & & & $\begin{array}{l}\text { Ült. } 7 \\
\text { dias }\end{array}$ & $\begin{array}{l}\text { Ült. } 4 \\
\text { lunes }\end{array}$ & & & Ayer & Hoy & $\begin{array}{l}\text { Últimos } \\
7 \text { dias }\end{array}$ \\
\hline Aguaje & & 3 & & & Bandeja & 10.00 & 24.25 & 24.50 & 23.29 \\
\hline Aguaymanto & 2 & - & & & Kilogramo & 1.00 & 5.35 & 5.38 & 5.35 \\
\hline Albaricoque & - & 7 & & & Caja Madera & 10.00 & 48.25 & 48.00 & 47.57 \\
\hline Arándano & 2 & 2 & - & & Kilogramo & 1.00 & 16.25 & 16.00 & 16.36 \\
\hline Camu Camu & 3 & - & - & & Bolsa & 1.00 & 6.43 & 6.40 & 6.49 \\
\hline Carambola & 15 & 12 & - & 9 & Cajon & 10.00 & 14.25 & 14.00 & 14.14 \\
\hline Chirimoya Cumbe & 10 & 13 & 14 & 12 & Kilogramo & 1.00 & 6.93 & 6.93 & 6.68 \\
\hline Ciruela Nectarina (Importada) & & 12 & & - & Cajon & 10.00 & 45.25 & 45.00 & 44.14 \\
\hline Ciruela Santa Rosa/Nacional & 15 & & - & 5 & Cajon & 10.00 & 50.25 & 50.00 & 49.18 \\
\hline Coco & 12 & 18 & & 8 & Unidad & 1.50 & 1.63 & 1.63 & 1.49 \\
\hline Cocona (Selva) & 14 & 8 & - & 9 & Bandeja & 15.00 & 31.25 & 31.50 & 31.82 \\
\hline Fresa Aroma & 113 & 80 & 118 & 72 & Kilogramo & 1.00 & 2.13 & 2.10 & 2.13 \\
\hline Granadilla (Costa) & 10 & -1 & - & - & Ciento & 8.00 & 23.50 & 23.50 & 22.18 \\
\hline Granadilla (Selva) & 33 & 33 & 41 & 33 & Cajon & 13.00 & 44.00 & 43.75 & 44.14 \\
\hline Guanabana De La Selva & 6 & 10 & & & Kilogramo & 1.00 & 5.65 & 5.65 & 5.67 \\
\hline Kiwi Importado Chileno & - & 18 & & & Caja & 12.00 & 62.75 & 64.00 & 60.68 \\
\hline Lima Dulce & 11 & -1 & & & Kilogramo & 1.00 & 2.75 & 2.75 & 2.65 \\
\hline Limon Dulce - Selva & 12 & 10 & & 7 & Jaba & 20.00 & 39.25 & 39.25 & 37.86 \\
\hline Lucuma De Seda & 10 & 5 & & & Kilogramo & 1.00 & 6.73 & 6.73 & 6.33 \\
\hline Mandarina Dorina & 18 & 13 & & & Kilogramo & 1.00 & 1.93 & 1.93 & 1.83 \\
\hline Mandarina Kara & & & & & Kilogramo & 1.00 & 1.85 & 1.85 & 1.79 \\
\hline
\end{tabular}




\section{Anexo 5: Factor de conversión de fluorescente Phillips}

4' SPECIFICATION VAPORLUME

1504-PF

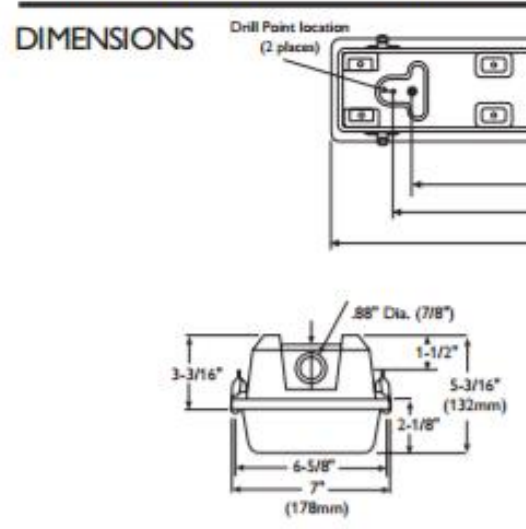

SHALLOW LENS VERSION (STANDARD)
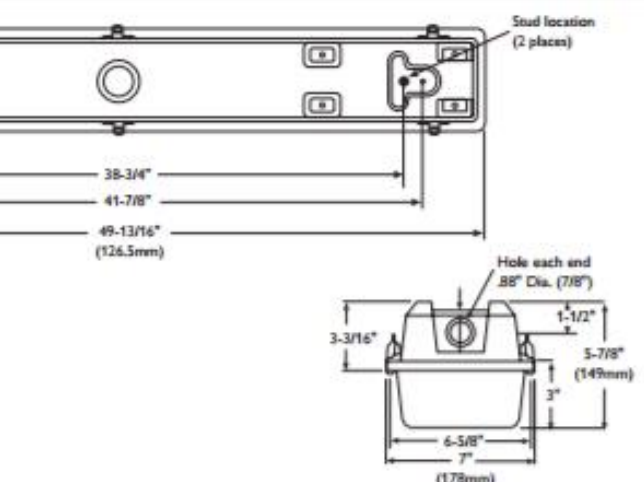

DEEP LENS VERSION FOR HIGH AMEIENT, OR WHEN $800 \mathrm{~mA}$ LAMPS ARE OPERATED ON MAGNETIC BALLASTS.

\section{MOUNTING BRACKETS}

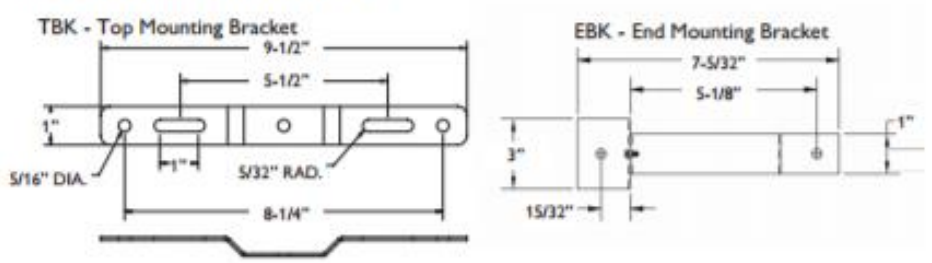

EBK - End Mounting Bracket

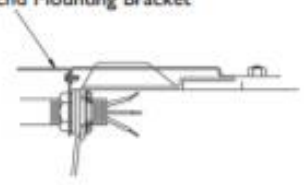

\begin{tabular}{|c|c|c|c|}
\hline \multicolumn{4}{|c|}{$\begin{array}{l}\text { PHOTOMETRIC } \\
\text { COMPARATIVE YEA }\end{array}$} \\
\hline \multicolumn{4}{|c|}{ CANDLEPOWER } \\
\hline Anglo & End & 45 & Crou \\
\hline is & $\begin{array}{l}1408 \\
\text { Mou } \\
\text { stou }\end{array}$ & 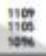 & 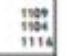 \\
\hline $\begin{array}{l}\text { st } \\
\text { a } \\
\text { a }\end{array}$ & 悹 & $\begin{array}{l}\text { wes } \\
\text { seis } \\
\text { not }\end{array}$ & 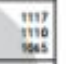 \\
\hline $\begin{array}{l}\text { 岁 } \\
n\end{array}$ & $\begin{array}{l}\text { 染 } \\
\text { it }\end{array}$ & $\begin{array}{l}\text { 湈 } \\
\text { is }\end{array}$ & $\begin{array}{l}n \\
m \\
m\end{array}$ \\
\hline$\underset{n}{n}$ & $\stackrel{3}{\underset{i}{3}}$ & $\underset{m}{m}$ & $\begin{array}{c}\mathrm{n} \\
\mathrm{m} \\
\mathrm{m}\end{array}$ \\
\hline $\begin{array}{l}\text { 翟 } \\
\text { as }\end{array}$ & i & 黛 & $\underset{2}{9}$ \\
\hline $\begin{array}{l}\text { is } \\
\text { is } \\
\text { tis } \\
\text { in }\end{array}$ & i & i & : \\
\hline
\end{tabular}

CATALOG \# V2WAE232,120,1/2-EB LAMPS $=$ F32TB

INPUT WATTS $=54$

LER $=F \cdot 79$

TEST H20017 SMMHE1.5 BALAST = ELECTRONIC BALAST EACTOR =

$T E R=45$
$C Y=85.18$

\section{COMPARATIVE YEARLY LIGHTING ENERGY COST PER 1000 LUMENS $=\$ 3.04$ BASED ON 3000 HRS. AND $\$ .08$ PER KWH.}

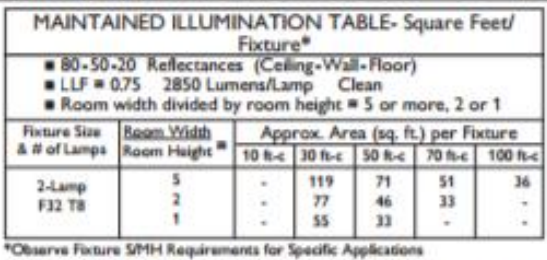

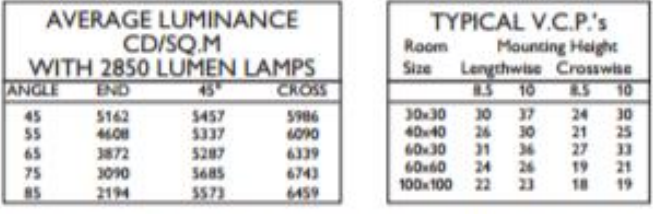

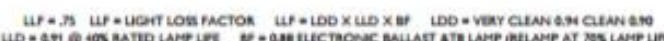
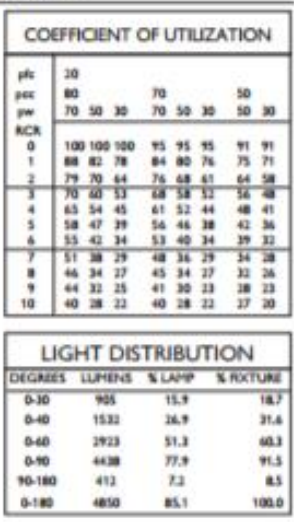

Some luminaires use fluorescent or high intensity davcharge

(HID) lamps that contain small amounts of mereury. Such lamps

Hg are labeled, "Contain Mercury" and/or the symbol "HG", Lamps

that contain mercury must be daposed of in accordance with

diaposal can be found at www.lamprecycle. org 


\section{Anexo 6: Flujo de fondos financieros ante un escenario pesimista con una variación del - $15 \%$ en el precio de venta}

\begin{tabular}{|c|c|c|c|c|c|c|}
\hline & 0 & 2018 & 2019 & 2020 & 2021 & 2022 \\
\hline Utilidad Neta & & $\begin{array}{c}- \\
328,702.42 \\
\end{array}$ & $\begin{array}{c}301,594.7 \\
3 \\
\end{array}$ & $758,361.01$ & $\begin{array}{c}1,383,488.6 \\
9 \\
\end{array}$ & $\begin{array}{c}2,082,968.7 \\
1 \\
\end{array}$ \\
\hline (-)Inversión & $\begin{array}{c}- \\
1,262,177.60 \\
\end{array}$ & & & & & $-17,673.00$ \\
\hline Financiamiento & $631,088.80$ & & & & & \\
\hline $\begin{array}{l}\text { (-) Amortización del } \\
\text { préstamo }\end{array}$ & & $-34,423.03$ & $-80,320.39$ & $\begin{array}{c}- \\
126,217.76 \\
\end{array}$ & $-172,115.13$ & $-218,012.49$ \\
\hline Depreciación tangible & & $50,009.57$ & $50,009.57$ & $50,009.57$ & $50,009.57$ & $50,009.57$ \\
\hline Amortización intangibles & 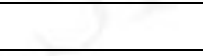 & $4,670.22$ & $4,670.22$ & $4,670.22$ & $4,670.22$ & $4,670.22$ \\
\hline Valor en libros & 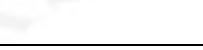 & & & & 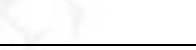 & $462,738.05$ \\
\hline Capital de trabajo & & 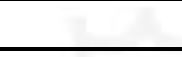 & & & & $251,593.61$ \\
\hline FFF & $-631,088.80$ & $\begin{array}{c}- \\
308,445.66\end{array}$ & $\begin{array}{c}275,954.1 \\
2\end{array}$ & $686,823.04$ & $\begin{array}{c}1,266,053.3 \\
5\end{array}$ & $\begin{array}{c}2,616,294.6 \\
7\end{array}$ \\
\hline
\end{tabular}

\section{Anexo 7: Flujo de fondos financieros ante un escenario optimista con una variación del $+15 \%$ en el precio de venta}

\begin{tabular}{|c|c|c|c|c|c|c|}
\hline & 0 & 2018 & 2019 & 2020 & 2021 & 2022 \\
\hline Utilidad Neta & & $45,347.72$ & $\begin{array}{c}790,883.8 \\
5 \\
\end{array}$ & $\begin{array}{c}1,427,342.6 \\
8 \\
\end{array}$ & $\begin{array}{c}2,298,150.9 \\
1 \\
\end{array}$ & $\begin{array}{c}3,333,539.5 \\
3 \\
\end{array}$ \\
\hline (-)Inversión & $\begin{array}{c}- \\
1,262,177.60\end{array}$ & & & & & $-17,673.00$ \\
\hline Financiamiento & $631,088.80$ & & & & & \\
\hline $\begin{array}{l}\text { (-) Amortización del } \\
\text { préstamo }\end{array}$ & & $\begin{array}{c}- \\
34,423.03 \\
\end{array}$ & $-80,320.39$ & $-126,217.76$ & $-172,115.13$ & $-218,012.49$ \\
\hline Depreciación tangible & & $50,009.57$ & $50,009.57$ & $50,009.57$ & $50,009.57$ & $50,009.57$ \\
\hline Amortización intangibles & 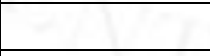 & $4,670.22$ & $4,670.22$ & $4,670.22$ & $4,670.22$ & $4,670.22$ \\
\hline Valor en libros & & & & & & $462,738.05$ \\
\hline Capital de trabajo & & & & & & $251,593.61$ \\
\hline FFF & $-631,088.80$ & $65,604.48$ & $\begin{array}{c}765,243.2 \\
4 \\
\end{array}$ & $\begin{array}{c}1,355,804.7 \\
1 \\
\end{array}$ & $\begin{array}{c}2,180,715.5 \\
7 \\
\end{array}$ & $\begin{array}{c}3,866,865.4 \\
9 \\
\end{array}$ \\
\hline
\end{tabular}




\section{Anexo 8: Flujo de fondos financieros ante un escenario con el mínimo precio de venta}

\begin{tabular}{|c|c|c|c|c|c|c|}
\hline & 0 & 2018 & 2019 & 2020 & 2021 & 2022 \\
\hline Utilidad Neta & & $\begin{array}{c}- \\
660,950.91 \\
\end{array}$ & $\begin{array}{c}- \\
158,909.74 \\
\end{array}$ & $192,829.79$ & $610,268.63$ & $\begin{array}{c}1,025,784.5 \\
2 \\
\end{array}$ \\
\hline (-)Inversión & $1,262,177.60$ & & & & & $-17,673.00$ \\
\hline Financiamiento & $631,088.80$ & & & & . & \\
\hline $\begin{array}{l}\text { (-) Amortización del } \\
\text { préstamo }\end{array}$ & & $-34,423.03$ & $-80,320.39$ & $\begin{array}{c}- \\
126,217.76\end{array}$ & $172,115.13$ & $-218,012.49$ \\
\hline Depreciación tangible & & $50,009.57$ & $50,009.57$ & $50,009.57$ & $50,009.57$ & $50,009.57$ \\
\hline Amortización intangibles & & $4,670.22$ & $4,670.22$ & $4,670.22$ & $4,670.22$ & $4,670.22$ \\
\hline Valor en libros & & 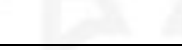 & & 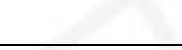 & 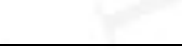 & $462,738.05$ \\
\hline Capital de trabajo & & & & & & $251,593.61$ \\
\hline FFF & $-631,088.80$ & $\begin{array}{c}- \\
640,694.15 \\
\end{array}$ & $\begin{array}{c}- \\
184,550.34\end{array}$ & $121,291.82$ & $492,833.29$ & $\begin{array}{c}1,559,110.4 \\
7 \\
\end{array}$ \\
\hline
\end{tabular}

\section{Anexo 9: Flujo de fondos financieros ante un escenario pesimista con una variación del $+15 \%$ en los salarios}

\begin{tabular}{|c|c|c|c|c|c|c|}
\hline & 0 & 2018 & 2019 & 2020 & 2021 & 2022 \\
\hline Utilidad Neta & & $\begin{array}{c}- \\
283,802.78\end{array}$ & $\begin{array}{c}439,473.3 \\
6\end{array}$ & $986,328.48$ & $\begin{array}{c}1,734,660.2 \\
8\end{array}$ & $\begin{array}{c}2,602,579.7 \\
4\end{array}$ \\
\hline (-)Inversión & $\begin{array}{c}- \\
1,294,858.45\end{array}$ & & & & & $-17,673.00$ \\
\hline Financiamiento & $647,429.23$ & & & & & \\
\hline $\begin{array}{c}\text { (-) Amortización del } \\
\text { préstamo }\end{array}$ & & $-35,314.32$ & $-82,400.08$ & $\begin{array}{c}- \\
129,485.85 \\
\end{array}$ & $-176,571.61$ & $-223,657.37$ \\
\hline Depreciación tangible & & $50,009.57$ & $50,009.57$ & $50,009.57$ & $50,009.57$ & $50,009.57$ \\
\hline Amortización intangibles & & $4,670.22$ & $4,670.22$ & $4,670.22$ & $4,670.22$ & $4,670.22$ \\
\hline Valor en libros & & & & & & $462,738.05$ \\
\hline Capital de trabajo & & & & & & $284,274.46$ \\
\hline FFF & $-647,429.23$ & $\begin{array}{c}- \\
264,437.32 \\
\end{array}$ & $\begin{array}{c}411,753.0 \\
6\end{array}$ & $911,522.42$ & $\begin{array}{c}1,612,768.4 \\
6\end{array}$ & $\begin{array}{c}3,162,941.6 \\
7\end{array}$ \\
\hline
\end{tabular}




\section{Anexo 10: Flujo de fondos financieros ante un escenario optimista con una variación del $\mathbf{- 1 5 \%}$ en los salarios}

\begin{tabular}{|c|c|c|c|c|c|c|}
\cline { 2 - 7 } \multicolumn{1}{c|}{} & 0 & 2018 & 2019 & 2020 & 2021 & 2022 \\
\hline Utilidad Neta & & $13,693.47$ & $653,005.22$ & $1,199,375.21$ & $1,946,979.32$ & $2,813,928.51$ \\
\hline (-)Inversión & $-1,229,496.75$ & & & & & $-17,673.00$ \\
\hline Financiamiento & $614,748.37$ & & & & & \\
\hline (-) Amortización del préstamo & & $-33,531.73$ & $-78,240.70$ & $-122,949.67$ & $-167,658.65$ & $-212,367.62$ \\
\hline Depreciación tangible & & $50,009.57$ & $50,009.57$ & $50,009.57$ & $50,009.57$ & $50,009.57$ \\
\hline Amortización intangibles & & $4,670.22$ & $4,670.22$ & $4,670.22$ & $4,670.22$ & $4,670.22$ \\
\hline Valor en libros & & & & & & $462,738.05$ \\
\hline Capital de trabajo & & & & & & $218,912.75$ \\
\hline FFF & $-614,748.37$ & $34,841.53$ & $629,444.31$ & $1,131,105.33$ & $1,834,000.46$ & $3,320,218.48$ \\
\hline
\end{tabular}

\section{Anexo 11: Flujo de fondos financieros ante un escenario con el máximo salario en total}

\begin{tabular}{|c|c|c|c|c|c|c|}
\cline { 2 - 7 } \multicolumn{1}{c|}{} & 0 & 2018 & 2019 & 2020 & 2021 & 2022 \\
\hline Utilidad Neta & & $-1,309,628.07$ & $-401,294.84$ & $265,583.49$ & $1,016,377.13$ & $1,887,579.04$ \\
\hline (-)Inversión & $-1,515,979.53$ & & & & & $-17,673.00$ \\
\hline Financiamiento & $757,989.76$ & & & & & \\
\hline (-) Amortización del préstamo & & $-41,344.90$ & $-96,471.42$ & $-151,597.95$ & $-206,724.48$ & $-261,851.01$ \\
\hline Depreciación tangible & & $50,009.57$ & $50,009.57$ & $50,009.57$ & $50,009.57$ & $50,009.57$ \\
\hline Amortización intangibles & & $4,670.22$ & $4,670.22$ & $4,670.22$ & $4,670.22$ & $4,670.22$ \\
\hline Valor en libros & & & & & & $462,738.05$ \\
\hline Capital de trabajo & & & & & & $505,395.54$ \\
\hline FFF & $-757,989.76$ & $-1,296,293.18$ & $-443,086.47$ & $168,665.33$ & $864,332.44$ & $2,630,868.41$ \\
\hline
\end{tabular}




\section{Anexo 12: Plano de planta}

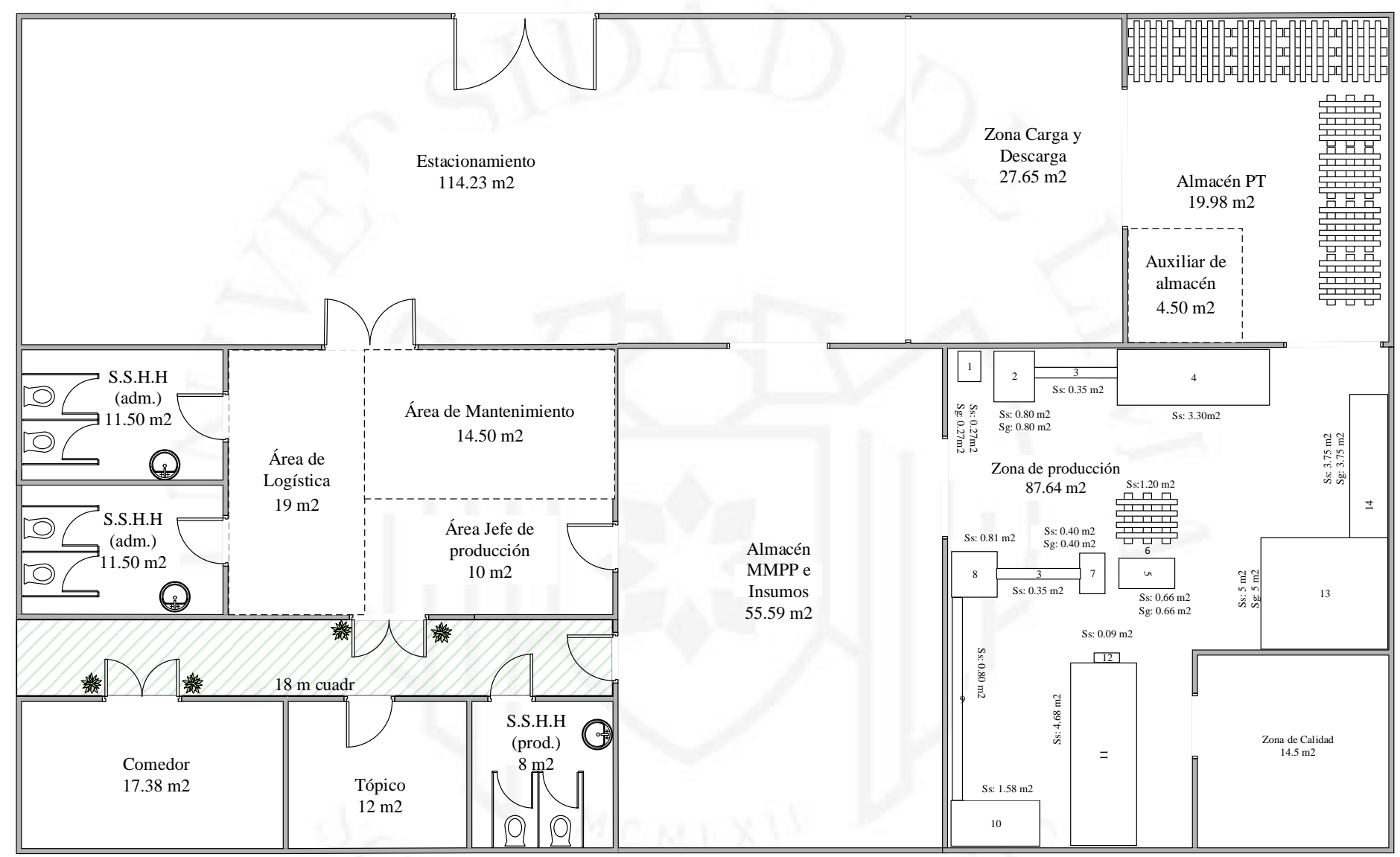

\begin{tabular}{|c|c|c|c|c|c|c|}
\hline \multirow{2}{*}{$\begin{array}{l}\text { Leyenc } \\
\text { 1. Báscula industrial } \\
\text { 2. Descascaradora } \\
\text { 3. Faja transportadora } \\
\text { 4. Lavadora } \\
\text { 5. Mesa de corte } \\
\text { 6. Pallet } \\
\text { 7. Deshidratador }\end{array}$} & \multirow{2}{*}{$\begin{array}{l}\text { 8. Molino } \\
\text { 9. Torillo sin fin } \\
\text { 10. Prensa } \\
\text { 11. Filtro prensa } \\
\text { 12. Bomba } \\
\text { 13. Envasadora tapadora } \\
\text { 14. Faja transportadora grande }\end{array}$} & \multicolumn{5}{|c|}{$\begin{array}{l}\text { Estudio De factibilidad para la instalación de una planta de producción de aceite de coco } \\
\text { Escuela de Ingeniería - Facultad de Ingeniería Industrial }\end{array}$} \\
\hline & & $\begin{array}{l}\text { Escala: } \\
\text { 1:100 }\end{array}$ & $\begin{array}{l}\text { Área: } \\
436 \mathrm{~m} 2\end{array}$ & $\begin{array}{l}\text { Fecha: } \\
\text { Diciembre } 2018\end{array}$ & $\begin{array}{l}\text { Dibujantes: } \\
\text { Chamorro Chávez Carmen Jesús } \\
\text { Noli Alva Adela Devly }\end{array}$ & $\begin{array}{l}20110300 \\
20112095\end{array}$ \\
\hline
\end{tabular}

